Portland State University

PDXScholar

Fall 12-20-2017

\title{
Living Between Worlds: Arrival and Adjustment Experiences of the Somali Community in Portland, Oregon
}

Neil A. Panchmatia

Portland State University

Follow this and additional works at: https://pdxscholar.library.pdx.edu/open_access_etds

Part of the African Studies Commons, Social and Cultural Anthropology Commons, and the Sociology Commons

Let us know how access to this document benefits you.

\section{Recommended Citation}

Panchmatia, Neil A., "Living Between Worlds: Arrival and Adjustment Experiences of the Somali Community in Portland, Oregon" (2017). Dissertations and Theses. Paper 4078.

https://doi.org/10.15760/etd.5962

This Thesis is brought to you for free and open access. It has been accepted for inclusion in Dissertations and Theses by an authorized administrator of PDXScholar. Please contact us if we can make this document more accessible: pdxscholar@pdx.edu. 
Living Between Worlds:

Arrival and Adjustment Experiences of the Somali Community in Portland, Oregon

by

Neil A. Panchmatia

A thesis submitted in partial fulfillment of the requirements for the degree of

\author{
Master of Science \\ in \\ Sociology
}

Thesis Committee:

Alex Stepick, Chair

Margaret Everett

Joseph Smith-Buani

Portland State University

2017 


\begin{abstract}
Since the early 1990s Oregon has witnessed an economic and politically based influx of immigrants and refugees. Most refugees resettled in Oregon initially settled in the greater Portland metro area, and Portland currently ranks eleventh among cities around the country that resettle international refugees. This research focuses on the reception and resettlement experiences of one sub-group of refugees and immigrants: those from Somalia. In the Portland area, Somalis are a largely marginalized social group. They live on the peripheries of society and are often segregated (physically as well as culturally) in what is historically a racially and culturally homogenous state. To date, limited research has focused on the reception experiences and adjustment challenges of the local Somali community.

The intent of this descriptive case study is to explore and record the arrival and adjustment experiences and perspectives of Somali refugees and immigrants, so as to understand their journey of displacement and resettlement holistically. It investigates the context of their acclimatization into US society via the Portland urban area.

It, more specifically, explores the nature of the arrival and adjustment experiences of the community, as well as the factors influencing them. It attempts to understand how these factors and the overall experience of adjustment influence the negotiation and construction of individual and collective identity of the local Somalis. In understanding the overall experience of resettlement within the community, the study also explores how well the needs of the community are met when it comes to support services and other resources for adaptation.
\end{abstract}


Seventeen participants were interviewed from the community, and they indicated that the journey of adjustment is an on-going one that needs to be understood holistically while incorporating all the stages of exile: from displacement to resettlement. Identity formation and negotiation is a key process that emerged within the narratives, through which the experience of resettlement is maneuvered. Within the local community, identity informs the participation of Somalis within social networks, as well as the myriad social roles they take on as individuals, family members, and community members. This study finds some important similarities and differences in the experiences of the local Somalis with other local and national immigrant and refugee groups. 
For my parents,

Anant and Chandrika Panchmatia

You gave me everything. You are my everything.

Thank you. 


\section{Acknowledgements}

I would like to express my most sincere gratitude to the Somali community of Portland. My goal, in writing this thesis, has been to objectively and respectfully share your narratives. I considered it a personal responsibility to accurately understand and share your journeys of arrival and adjustment in the United States through this work. I have attempted to understand, closely, what you shared with me through the lens of a fellow African, fellow immigrant, and fellow person of color. Your spirit of perseverance as a community inspired me deeply while I was growing up in Kenya, and continues to do so. You let me into your community, and showed me such kind respect and faith with your confidence in my ability to do this work adequately. Through your stories, you have also inspired me to go into mental health counseling as a profession - to help meet a need within the immigrant and refugee community you identified and stressed. There is currently a dire need of people-of-color mental health professionals who can practice culturally responsive care for populations that have experienced trauma. I intend to create awareness for these population-specific needs, and work hard at service provision and advocacy. I will always use and cherish my experience on working on this thesis, and the lessons I learned from you, as the foundation for my future work. From the bottom of my heart, thank you.

I would also like to express my gratitude to my thesis committee. Dr. Alex Stepick, as my chair and advisor, you have motivated and supported me since my first day in the program. I came to PSU to learn from you: one of the most eminent immigration scholars, and today I look back at that decision with pride. You have shown unwavering confidence in my ability as a scholar, and my drive as a social justice 
advocate to give back to the immigrant and refugee communities. You have spent countless hours advising me with this thesis, reviewing its contents, and guiding me as needed. Your support and encouragement will always be remembered and cherished with gratitude. You have been a true guru and like a parent to me. Thank you. Dr. Joseph Smith-Buani, so much of this thesis would be impossible without your guidance and support. Without you, I would not have been able to access participants for the study, and it is your vote of confidence in my ability to do this work that helped open the right doors. Your work in the local community, studying and advocating for the African diaspora, inspired my own work immensely. Thank you for everything you do, for African students like myself, and for the community. Dr. Margaret Everett, my respect and gratitude for you knows no bounds. You inspire me not only in our work together in the Office of International Affairs, but also in the humility and poise you project in working with different cultures and individuals. I am so grateful that you were a part of this committee, and I was able to share this journey with you. Thank you.

Lastly, I would like to thank my loved ones, for supporting me and standing beside me throughout the process of completing this program. To my parents: you were my first gurus, and taught me that in compassion lies our true essence and potential as human beings. You encouraged me to understand the trials and tribulations of individuals and communities less privileged than I was. It is from these roots of social justice awareness and advocacy, which you not only preached but also practiced, that I find my drive to do what I do today. In many ways, this thesis is also a product of your lifelong inspiration and guidance. Thank you for always believing in me, for loving me 
unconditionally, and for teaching me everything I needed to know to be the person I am today. To say I love you would be an understatement.

To my Anila Aunty: you have always been my role model and like a second mother. You would drag me along to volunteer in everything from blood donation drives to vision-loss clinics, to HIV testing camps in rural Kenya when I was just a little kid: nurturing a young social justice advocate within me. Your unwavering drive to give back to the community we lived in, the equity you always saw in all the people, and the strength and drive you projected inspired me more than you know. You taught me that barriers of gender, race, class, creed and so on were to be challenged and transcended. You were there for us all whenever we needed you. I love you so much. Thank you.

To my brother, Jay and my sister-in-law, Kinjal: Thank you for all the support you have shown me throughout my journey of being in school. You both inspire me in so many ways, and I consider myself lucky to have you in my life. Your compassion, humility, and love for everyone around you motivates me everyday. I love you both very much.

To Brandon: you have stood by me and supported me throughout this experience in so many ways: be it in appealing to my competitive side to get me to get writing, or in challenging my perfectionist side by telling me to pull back and not aim to write a perfect thesis. You always showed faith in my ability to get this done, and you have shown me so much love and understanding during this whole process. Thank you for this. You inspire me with your kindness and your drive, and you make me laugh with your zest for devious humor. You are my rock, and I love you with all my heart. 
To my dearest friends: you have always understood and encouraged me. My beloved Joyce: you have always encouraged me, and I have cherished the countless hours we have spent dreaming about all we will do in the future. You are my fellow Eagle and I am always grateful for your love and friendship. Mattie: you have been there throughout my long journey in graduate school. You have inspired and supported me in so many ways, and have always understood who I am at my core. Your presence in my life will always be cherished. Thank you. My sweetest friends Lwando and Kari, my fellow fighters and social justice activists, you are my family. My love for you knows no limits. You both keep inspiring me everyday with every barrier you overcome and every milestone you achieve. My dear friend, Monish, your passion for success and your youthful enthusiasm for life has always encouraged me, and made me laugh. You are my favorite Bollywood drama queen. I love all of you from the very bottom of my heart and am proud to call you my friends... my family.

Finally, to my Mamas, our ever-hungry dachshund: Thank you for your endless hours of company while I worked on this thesis, and for the cuddles when I needed them. I love you, my little monkey. 


\section{Table of Contents}

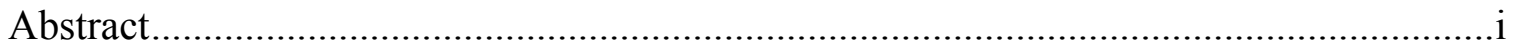

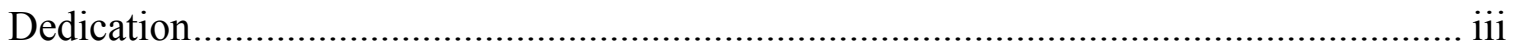

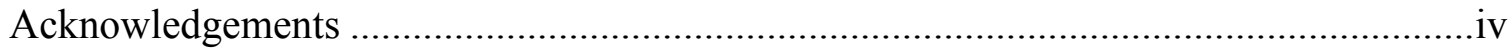

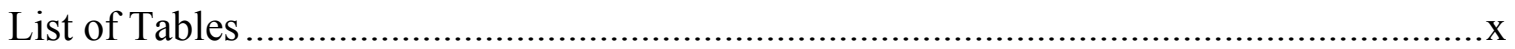

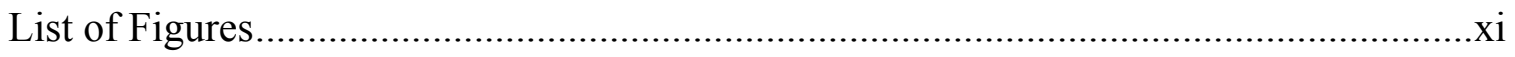

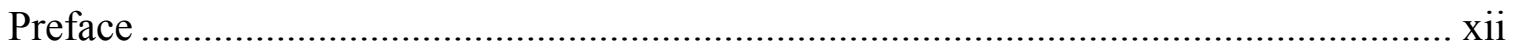

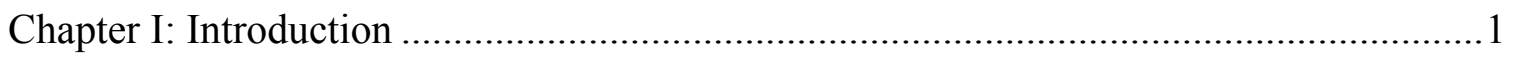

A. The US Refugee Resettlement System: A Background ..........................................5

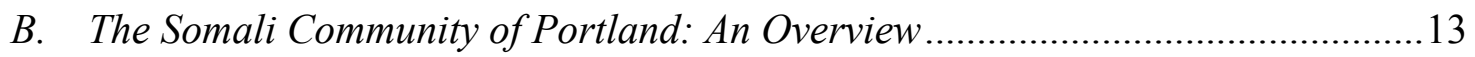

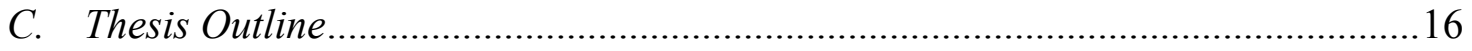

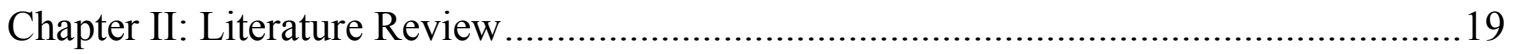

A. The Refugee Experience: An Overview .............................................................. 19

B. Refugee Resettlement: Between Displacement and Adjustment..........................23

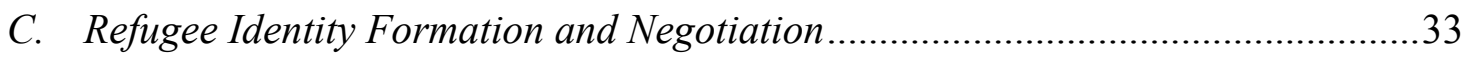

D. Somali Refugees and the Somali Diaspora ......................................................45

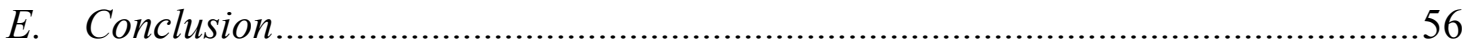

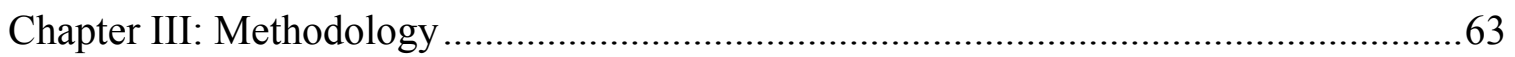

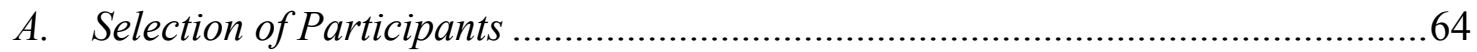

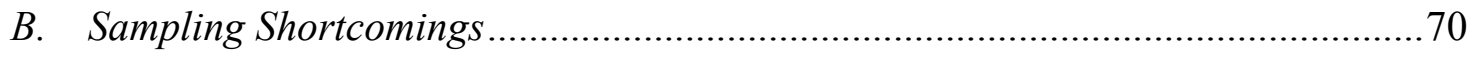

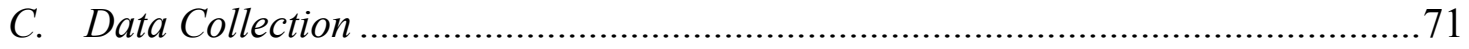




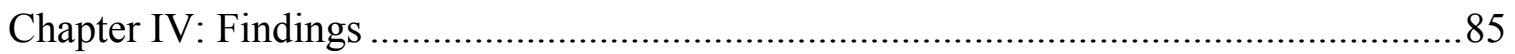

A. Overview of Findings: The Resettlement Journey...............................................85

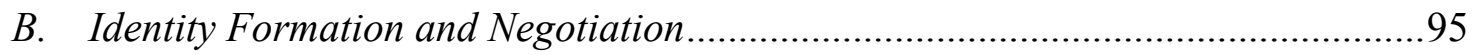

C. Social Roles as Informed by Identity ...........................................................139

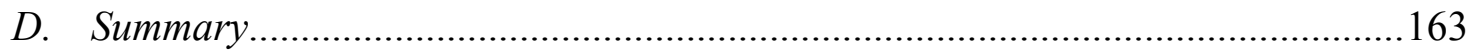

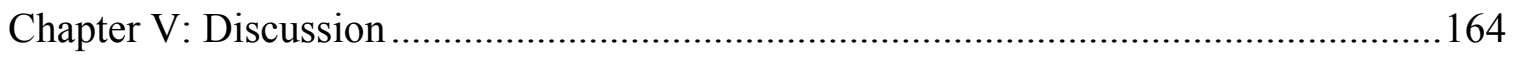

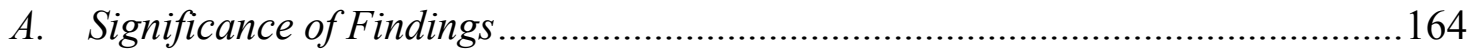

B. Community Needs and Recommendations for Service Agencies ........................182

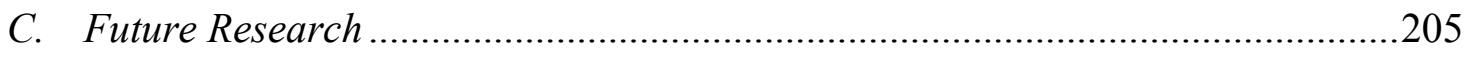

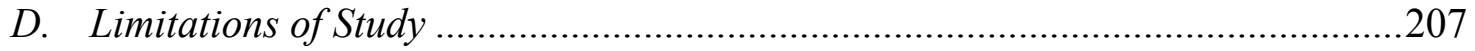

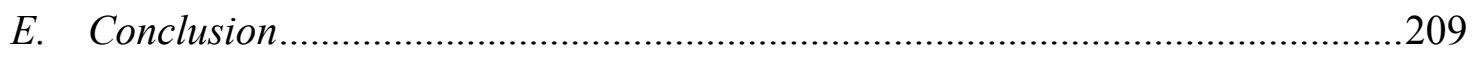

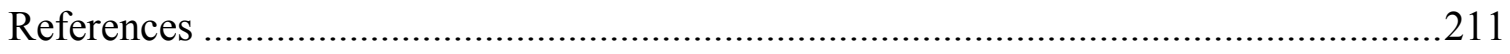

Appendix A: Research Announcement/ Participant Recruitment Poster ........................220

Appendix B: Informed Consent Form (English Version) ...............................................221

Appendix C: Informed Consent Form (Swahili Version) ..............................................224

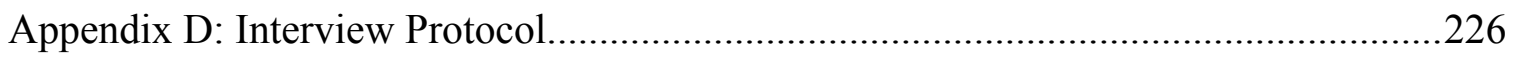

Appendix E: List of Community Organizations.........................................................22 


\section{List of Tables}

Table I: Sample Characteristics.........................................................................69 


\section{List of Figures}

Figure I: Refugee Resettlement Process in the US....................................................10

Figure II: Resettlement Process - Key Components, Agencies and Services...................11

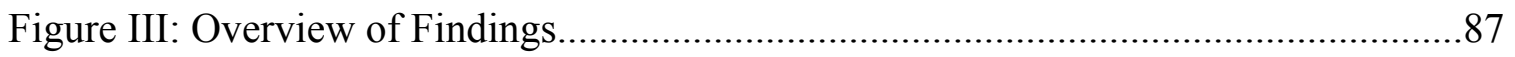

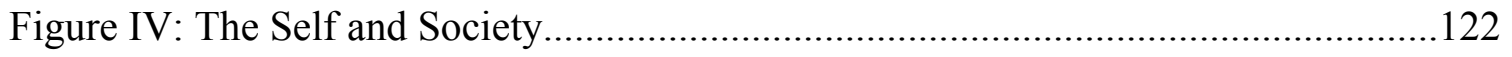

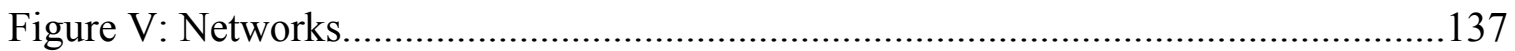

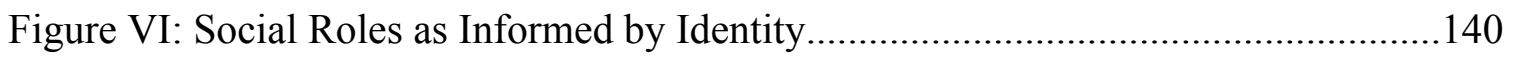




\section{PREFACE}

There is a place right here in my heart, Nourished within me everywhere I go.

The cool sands of Hamar tickling

My toes out of every cry or moan.

Sunshine replicated

In the mirrors of the river Shabelle.

The grand mountains of Sheikh and Bari...

What a feast for the hungry... but then...

What better panorama has Mother Earth on offer?

I nourish within me these scenes of my land

Children at play carefree in their land

I pray for the whole body:

Land, Sea, River, Lake, Mountain

Flora and fauna...

(Our Somalia by Safi Abdi)

\section{Somalia, Displacement and the Global Somali Diaspora}

While this study focuses on the arrival and adjustment experiences of the Somali community of Portland, it is imperative to review the history of conflict and displacement in Somalia. This context of pre-arrival experiences, expressed by the participants of this study as narratives of displacement, trauma and loss juxtaposed with fond reflections on the homeland, people and culture makes it necessary to provide a glimpse of Somalia, its rich history, its troubles, and its people: the current global Somali diaspora. Civil and 
political unrest uprooted hundreds of thousands of Somalis, scattering them through the far reaches of the world. The following is a brief overview of the nation's recent history.

Somalia remains a country with little political or civil stability. By most accounts, it is considered a failed nation-state. Ongoing violence following independence from Italian, British and French colonizers in 1960 (detailed briefly below) continues to divide the people and hinder economic growth. Natural disasters such as drought and famine add to the already difficult living conditions in the country. Human displacement from the region has resulted in individuals and families being separated from one another and residing as refugees abroad. A recent UNHCR report states that Somalia generates the fourth highest numbers of refugees, after Syria, Afghanistan and South Sudan. In the region surrounding the Somalia alone, relief and outreach efforts target an estimated 1.5 million internally displaced individuals (IDPs) and 900,000 refugees (2017). To date, over 2 million refugees have fled the country, and the UNHCR estimates that about 55\% of the total Somali global diaspora is currently living in a temporary refugee situation (Connor 2016). The number of Somali refugees, fleeing into neighboring host countries and awaiting permanent placement in receiving permanent resettlement nations continues to rise.

The land of the Somalis has had several names over the ages: Punt (Land of the Gods) to the Egyptians, Land of Barbaroi, Land of Milk and Myrrh, Terra Aromatia (Land of Aromatic Plants) and Regio Cinnemafore (Land of the Cinnamon) to the Romans (Harper 2012). Located on the east coast of Africa, modern day Somalia occupies the peninsula fondly referred to as the "Horn of Africa". It neighbors the nations 
of Djibouti, Ethiopia and Kenya and boasts the longest coastline of any other country in the continent (roughly 1,700 miles) along the Indian Ocean.

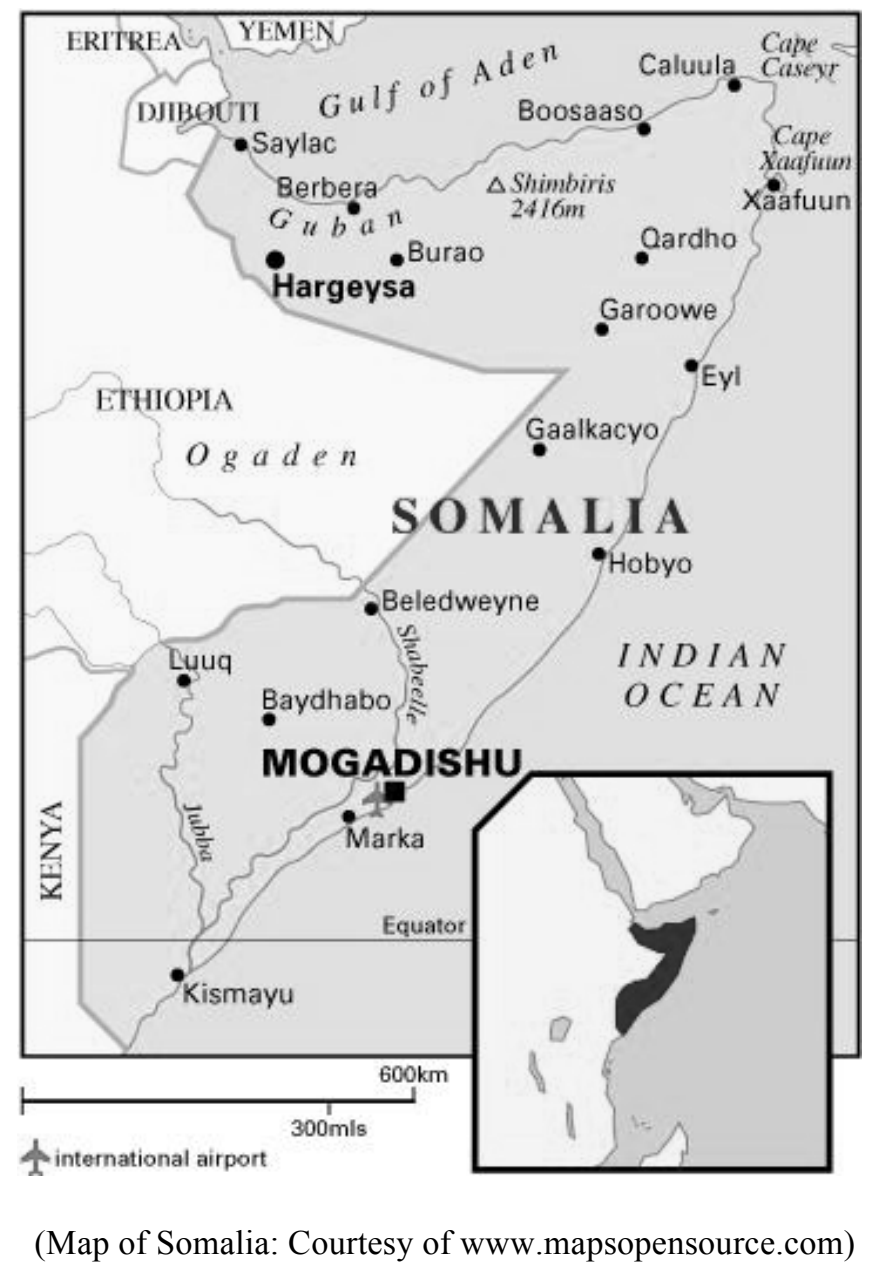

The traditional political and religious structure of Somalia involved rather strong hierarchies. The nation-state is a fairly new concept to the people of Somalia: one introduced by European colonizers. Prior to colonization, the land and people were governed by independent pastoral clans (with elders and religious leaders at the helm), sultanates and small city-states. There was no monetary class-based distinction between people but only a division along the lines of one's occupation: blacksmiths, farmers, 
religious men and so on. Leadership by the sultans or tribal leaders was expected to be consensual and not coercive. A popular leader was one who was skilled at negotiation, was a good orator and had strong persuasion skills. Usually this leader was purely ceremonial: with a majority of the important decision-making done by either appointed committees or representatives of the people (Harper 2012).

The Somali people are traditionally divided into pastoral "clans." Every individual belongs to a clan and holds strong loyalty to her or his clan while being extremely proud of this identity. Clans consist of the six major clans: the Darod, Dir, Hawiye, Isaaq, Rahanweyn, and the Meheri. These are further divided into sub-clans and extended family units. The clan adopts a unique and individual set of rules that govern the rules and norms of the group. The ties of an individual to the group were and remain immensely strong: when an individual or family faces difficulties, the rest of the clan unites immediately in assisting them (Huisman and Hough 2011). This identity-oriented norm continues in today's urban areas and Somali diasporas abroad: every individual identifies with a clan and is prepared to go out of her, his or their way for other members of the clan which plays the role of an extended family. It is critical to note that several important minority groups within Somalia, such as the Somali Bantu, traditionally do not conform to the Somali majority norms of clan belonging and identity. Their unique history and identity is discussed later within the study.

Scholars today believe that Somalia is the site of the ancient Kingdom of Punt which enjoyed a very lucrative trade past with Ancient Egypt and Mycenaean Greece. This ancient kingdom also had a written language that is not deciphered to this day, and current-day Somalia remains a popular study for ancient African burial customs due to 
the extensive ruins of tombs in the region. Archaeologists have also established that the Doian and Hergesian cultures flourished in the region during the Stone Age (Harper 2012).

During the Kingdom of Punt and beyond, the Somali peninsula was a supplier of ivory, spices, animal skins, gold and domestic animals to its trading partners. It was an especially attractive trading port for ships and merchants from Indian and China avoiding heavy Roman influence and regulations in other ports. This "free trade" policy on the Somali peninsula worked to their advantage. Ancient Somalis are also credited with first domesticating the camel, an invaluable desert animal, and spreading its popular use to Egypt and Northern Africa. Populous city states in ancient Somalia, such as Opone, Malao and Mossylon grew and benefited greatly from these profitable trade relations (Huisman and Hough 2011).

Pre-colonial Somalia became an influential Islamic center prior to the arrival of the colonists. Muslim migrants fleeing persecution from the Axumite Emperor in modern day Ethiopia and Arabic families fleeing persecution from the Arabic peninsula found a peaceful place to settle and practice their faith in Somaliland. The religion gained popularity and spread rapidly in the region and in Arabia, and pretty soon, wealthy Muslim Caliphs controlled the lucrative sea-trade. This trade influence remains a primary reason for the successful spread of Islam in Northern and Eastern Africa and for eventually making Mogadishu (Somalia's capital city) the influential center for Islam and trade in the region.

Prior to the arrival of European colonizers, powerful sultanates governed the land. These are referred to as the Adal and Ajuuraan empires that are marked by the Gerad 
Dynasty, the Bari dynasties, the Gobroon dynasty and the Sultanate of Hobyo. Influential sultans, backed by well-trained armies constantly declared war on each other to maintain political stability and dominate trade relationships in the region. Islam rapidly became more of a way of life than merely a religious faith. Islamic laws governed the people and the land. The governing sultanates were characterized by their affinity for having elaborate city-states with palaces, mosques and multiple-storied houses. They also focused on the growth and continuation of the sea trade that had served their predecessors so well (Harper 2012).

Pre-colonial Somalia had created and mastered a form of self-governance that worked efficiently for the population. A popular and successful trading port, it offered a high standard of living for its inhabitants and a safe environment to practice Islam. Although clan conflicts and political rivalries disrupted the peace occasionally, Somalis were a peace-loving people that were very communal in nature.

The Colonization of the African continent was brought forward by this very lure of trade and prosperity. Europe was undergoing an expansion effort: it needed new markets, raw materials and capital to facilitate its modernization. Initially, Europeans came to Africa to trade and remained confined to the shorelines where most of the trading took place. They came seeking gold, ivory and slaves, which were readily and best provided by African intermediaries (Wallerstein 2005).

In 1887, Britain established a protectorate in Somalia calling it British Somaliland. The motivation for this forced occupation was entirely trade related: it wanted to secure the trade route to India via the then-new Suez Canal. Following the successful foothold of Britain in this rather lucrative trade port, Italy took advantage of 
agreements and treaties it made with local sultanates, Ethiopia (which was never formally colonized) and Zanzibar and established its own protectorate calling it Italian Somaliland in 1936. Between 1899 and 1910, the British made repeated attempts to venture inland to establish colonial rule. Their efforts, however, were thwarted constantly by rebels who resisted not only the forced subjugation the colonists represented but also the Western ideals and rival religion of Christianity they brought with them. Finally, in about 1920, the British subdued the rebels, thereby allowing both itself and Italy to establish a full colonial administration in the region (Harper 2012).

In 1947, following the Second World War, the Big Four emerging powers (the USA, the UK, the USSR and France) demanded that Italy relinquish its authority and presence in Italian Somaliland. However, they failed to reach an agreement on disposition of the land and the UN General Assembly decided that after ten years as a UN trust territory under Italian administration, Italian Somaliland would be granted independence. It is through the establishment of this trust territory that the region (and new nation-state) received its name: Somalia.

In 1960, the year that Immanuel Wallerstein, an eminent Sociologist, refers to as "The Year of Africa" due to the spreading de-colonization attempts and granting of independence to most European colonies, Somalia became independent by unification of British and Italian Somaliland ${ }^{1}$. Almost right away, border disputes erupted with neighboring Western Ethiopia and Northern Kenya: traditionally Somali territories. This is a critical example of how the establishment, dissolution and further establishment of new artificial, haphazard, and culturally/historically insensitive borders and boundaries

\footnotetext{
${ }^{1}$ Somalia was also colonized by France (whose territory chose with a referendum during independence to form an independent Djibouti) and by Ethiopia (which continues to stir land conflicts in the region).
} 
by colonial administrators during their forced occupancy and departure from Africa sowed the seeds for regional disputes (Walls and Kibble 2011).

Prior to European arrival, the land was rarely divided rigidly and its occupancy was extremely fluid: it was everyone's land where nomadic clans freely roamed the open plains seeking pasture and water for their cattle. With the establishment of firm national boundaries, generations of Somalis (and Ethiopians and Kenyans), found themselves shut out from their ancestral lands, and the mobile livelihoods that formed such an intricate part of their self and cultural identities. In 1978, Somalia entered a war with Ethiopia over the disputed territories of the Ogaden region. The Ethiopian troops, assisted by the USSR and Cuba, defeated the Somalis: leading to a refugee crisis. Over 1.5 million individuals were displaced and moved into Somalia (Harper 2012).

The establishment of an alien form of governance: headed by an absolute leader was also ill suited to the traditional system of social control the Somali people were used to. This laid the foundation for decades of civil rife in the new nation. As mentioned earlier, the Somalis elected both representatives and committees to represent them in inter or intra-clan issues. The individual leader was purely ceremonial and was elected more for his charisma than his ability to govern. European powers left behind a legacy that insisted upon democracy, election of a single leader (hand-picked by the departing administration in most colonies) and a cabinet of subservient ministers: in essence, one group to represent the multitudes of clans (Walls 2014)

This artificial unity was certainly ideal - but far from practical or applicable given the geo-political history of the region. The reason behind this is simple: the elected leader (and his cabinet) primarily represented one or a handful of clans and usually were 
individuals that had sided with the Europeans to facilitate their rise to power: hence not very popular. Favoritism towards their clans of origin was predictable. Other clans felt a lack of loyalty towards this leadership and were agitated by the second-class status they were dealt with. Civil war was inevitable: and that is exactly what happened (Huisman and Hough 2011).

Somalia's first president was Aden Abdullah Osman who was succeeded by Abdirashid Ali Shermarke of the Somali Youth League. In 1969, Shermarke was assassinated in a military coup led by military leader General Muhammad Siad Barre who immediately dissolved the constitution, banned all rival political parties and formed a military government. He established the Somalia Revolutionary Socialist party and declared Somalia a socialist state. In the years to come, he showed blatant favoritism towards his clan, the Darod, increasing its political influence and suppressed the continuing (and often violent) efforts for equality from the northern clans: his rivals.

Barre's regime was a military dictatorship and led to the eventual establishment of the anti-government Somali Nationalist Movement (SNM) in 1982 by the rival northern clans. Barre was "re-elected" in 1987, but had lost a lot of political influence in the northern and eastern parts of the country to SNM. June 1989 brought about civil riots in which his government used force to suppress the uprising - thereby killing over 400 individuals. In 1991, Barre survived a coup but eventually fled approaching opposition forces by eventually going into exile in Kenya. A new president, Ali Mahdi Muhammad took over amidst growing political instability and inter-clan disputes (Walls 2014).

In the middle of riots, May 1991 saw the secession of the northwest region of the country, previously British Somaliland, from the rest of the country. Known as 
Somaliland Republic, it would be governed by SNM leader Abdel-Rahman Ahmed Ali. Although the four rival Somali sanctions signed a ceasefire agreement to prevent this division, it was too late. The seeds of disunity, hatred for rival clans and a clamor for presidency had become the ultimate goal for all parties and people involved. In 1991 and beyond, fierce violence erupted in the country - with over 20,000 people killed or injured and thousands more displaced as refugees into neighboring nations - creating a profound and ongoing global humanitarian crisis that has lasted over two decades. 
Chapter I

\section{INTRODUCTION}

\section{Barasho horteed ha i nicin.}

Get to know me, before you reject me.

- Somali proverb

The world today is experiencing an unprecedented displacement and movement of people. Social, political and economic traumas uproot individuals and families, and the United Nations High Commissioner for Refugees (UNHCR) estimates that there are currently about 67.8 million forcibly displaced people around the world in need of immediate protection and assistance (2017). Among these are 17.2 million refugees, 36.6 million internally displaced people (IDP), 3.2 million state-less people, and 2.8 million asylum seekers. The UNHCR defines refugees and asylees as individuals who are unable or unwilling to return to their country of origin or nationality due to persecution, war or violence or a well-rounded fear of persecution. IDPs are defined as individuals displaced internally within the country of origin due to conflict, and have not crossed international borders, while state-less people are those denied a nationality and its related rights and protections (UNHCR 2017).

It is estimated that less than $1 \%$ of people formally recognized as refugees or forced migrants are permanently resettled in receiving countries abroad (Zong and Batalova 2017) $)^{2}$. The UNHCR outlines three durable solutions for displaced populations:

\footnotetext{
${ }^{2}$ The UNHCR defines "resettlement" as "The careful selection by governments such as the U.S. - for purposes of lawful admission - of vulnerable refugees who can neither return to their home country nor live in safety in neighboring countries.” (2017)
} 
voluntary repatriation to the country of origin, local integration within the country of first asylum, or third country resettlement abroad. The latter is the least common option as it is the most costly and is said to place the most burden both on the refugees as well as host nations (2017). Most displaced individuals spend decades or lifetimes in a perilous and unstable state of constant movement, threat, persecution, trauma and loss. Temporary host and permanent resettlement nations around the world today are struggling to address this humanitarian crisis and find ways to accommodate the new waves of refugee movement within existing laws and policies.

Since the early 1990s Oregon has witnessed an economic and politically-based influx of immigrants and refugees drawn to the strong economy of the state, its natural beauty, family-friendly mid-sized cities, public amenities such as mass transit, affordable housing, and state-driven social support programs. In 2016, the state of Oregon admitted a total of 1,780 refugees (Oregon Department of Human Services 2017). Refugees from around the world, including the former Soviet Union, Ethiopia, Bosnia, Somalia, Vietnam, Iraq, Cambodia, Cuba, Burma, Bhutan, Iran, and Syria currently call Oregon home (Oregon Department of Human Services 2017; Hume and Hardwick 2005). Most refugees resettled in Oregon initially settled in the greater Portland metro area, and Portland currently ranks eleventh among cities around the country that resettle international refugees (City of Portland, Office of Neighborhood Development 2017).

In Portland, a small and collaborative network of faith-based and secular human service agencies provides aid and assistance to refugee populations. Local faith-based social service agencies such as the Ecumenical Ministries of Oregon (EMO), Catholic Charities and Lutheran Community Services Northwest play a crucial role, alongside 
secular organizations such as Immigrant and Refugee Community Organization (IRCO), in the provision of vital support services to the local refugee and immigrant communities.

This research focuses on the reception and resettlement experiences of one subgroup of refugees and immigrants: those from Somalia. In the Portland area, Somalis are a largely marginalized social group. They live on the peripheries of society and are often segregated (physically as well as culturally) in what is historically a racially and culturally homogenous state. To date, limited research has focused on the reception experiences and adjustment challenges of the local Somali community. It is important to differentiate between the terms "immigrant" and "refugee" as this study focuses on both as a part of the local Somali community. Immigrants move to another country, on their own volition, to seek a better life and opportunities, and enjoy free mobility to a setting of their choice. Refugees, on the other hand, are forced to move due to circumstances and are part of a controlled network of immigrants that are carefully selected, specifically settled and partially supported by the US government. Portland's Somali community consists of both immigrants and refugees depending on which "wave" of immigration they arrived with (discussed later), and the overall context of their arrival. Local immigrants and refugees experience some vital similarities and differences in their collective experience of settlement or resettlement in Portland.

The overall objective of this descriptive case study is to explore and record the arrival and adjustment experiences and perspectives of Somali refugees and immigrants, so as to understand their journey of displacement and resettlement holistically. It will investigate the context of their acclimatization into US society via the Portland urban area. 
The broad research question for this study, therefore, is: "What do the arrival and adjustment experiences of the Somali community of Portland look like?” Specifically, this study will address the following four research questions:

1. What are the factors influencing the arrival and adjustment experiences of the Somali community of Portland?

2. What does the process and experience of adjustment look like for the Somali community of Portland?

3. How do these factors and the overall experience of adjustment influence the negotiation and construction of individual and collective identity within the Somali community of Portland?

4. How well are the needs of the Somali community of Portland met when it comes to support services and other resources for adaptation?

It is hoped that this study, by highlighting the unique lived experiences of Somali refugees and immigrants in Portland, is able to not only "give voice" to this hidden and ignored population, but is also able to underline the similarities and differences in their arrival and adjustment experiences with other local immigrant communities. Immigrant communities, and the challenges they face are most often concealed from the rest of society. Immigrants often cluster in residential and community enclaves, fight their battles as a small collective, rely on each other, and forge on as they attempt to adjust to life in a new, alien country. What the rest of us know about them is what we learn in passing through a scattered media story, or what a politician tells us from a podium, or what we see in an odd movie or television show. Very infrequently, do we get to see the 
communities up close and through the first-hand accounts of its members: the trials and tribulations they maneuver, the large and small triumphs that fuel them onwards, and the pushes and pulls they brave as they negotiate multiple loyalties and shifting identities.

It is my firm belief that it is from the lack of knowledge of the other, a lack of close contact and familiarity, and a lack of crossing divides to learn about each other that hate and ignorance find their roots. Today, immigrants and refugees are blamed for everything from "stealing" jobs, to being overly reliant on social welfare, to threatening the racial and cultural composition of the country, and even the increased domestic and global terrorism. Hate and divisions truly find their genesis in ignorance and a lack of knowing, and in today socio-political climate it is even more important to challenge ignorance, hate and divisions with knowledge, love and unity. It is hoped that this study is able to bring forth the identical and varying experiences and narratives of the faceless individuals and communities hidden amongst us, giving the rest of us a glimpse into their worlds, and showing that at the very core, we are more alike than different. We are all human and we are all one.

\section{A. The US Refugee Resettlement System: A Background}

The United States is among the 10 countries worldwide that carries out refugee resettlement programs and has resettled approximately 3 million people since 1980 (Pew Research Center 2017). The federal Refugee Act of 1980 provides for necessary support services to newly arrived refugee immigrants. The United States has historically led other nations in resettling the most numbers of refugees. In the 2015/2016 fiscal years (President Barack Obama's administration), saw 84,994 refugees and 26, 124 asylees resettled (Migration Policy Institute 2017). The country, prior to 9/11, had even larger 
numbers of refugees resettled per annum, with numbers averaging around 112,000 between 1990 and 1995. This saw a sharp decline post-9/11 to about 75,000 individuals admitted per year (Pew Research Center 2017).

Currently, the Trump administration is targeting the refugee resettlement program and the overall immigration program of the country. Using rhetoric of hate and division towards Muslim and other immigrants and refugees, it has targeted refugees arriving from six Muslim majority nations including Somalia. Donald Trump signed an executive order on January $27^{\text {th }}$ of this year to "ban" refugees from Islamic nations due to "national security interests". The US Supreme Court eventually upheld some components of Trump's ban, suspending the resettlement program for 120 days, allowing for an ongoing atmosphere of uncertainty and exclusion for refugees currently approved for and awaiting resettlement abroad, as well as their loved ones in the country. Today's sociopolitical and cultural atmosphere of hate and division targeting people of color, immigrants/ refugees, Muslims, LGBT individuals and other non-dominant, marginalized groups in the country makes the timing of this research study like this one even more pertinent. It is estimated that a maximum of 50,000 refugees will be accepted and resettled in the country during the 2017 fiscal year, with a total of 42,000 admitted thus far (Migration Policy Institute 2017). This is a far cry from the pre-9/11 numbers of refugees resettled that were double the current amount. Before leaving office, the Obama administration had planned to resettle 110,000 refugees this year (Pew Research Center 2017).

Refugees in the country today are admitted through the federal Refugee Admissions Program (USRAP) overseen by the Office of Refugee Resettlement (ORR), 
which is housed within the Department of Health and Human Services. They comprise about $10 \%$ of the total annual immigration to the US (Pew Research Center 2017). Being selected as a candidate for resettlement in the US (or any other country for that matter) is a long and arduous process. UNHCR shares that the journey between application for resettlement consideration to arriving on US soil consists of maneuvering a dual vetting process: one conducted independently through UNHCR and the other through the US. Altogether, the process includes 5 different background checks, 4 biometric scans, 3 different in-person interviews and a separate 2 inter-agency security checks. Individuals also have to attend orientation trainings and undergo health screenings prior to arrival. This goes to show that that alongside other innumerable barriers to an individual or family's security and stability via permanent resettlement, the systemic barriers of the refugee resettlement system are but one part.

Refugees admitted to the country have historically been resettled in major metropolitan areas (called immigrant gateways) such as Los Angeles, New York, Chicago, Minneapolis-St. Paul, Detroit, Washington DC, Seattle and Atlanta. Smaller cities and communities, in the recent decades, have also opened their doors to refugees. Cities such as Fargo, ND, Binghamton, NY, Portland, ME and St. Cloud, MN have witnessed a considerable impact of the arrival of refugees to their previously insular and racially/ culturally homogenous communities. Portland, OR is considered one of the newer, mid-sized immigrant gateways that are accepting increasing numbers of refugees: making it a prime location for studying the arrival experiences of these populations, as well as their impact on the local communities (and vice versa). 
Individual states in the country qualify for a percentage of total annual federal funding for refugee resettlement programs from a variety of sources. The ORR works with a number of partners at the federal and state level. In communities across the nation, faith-based organizations are at the forefront of refugee reception and assistance efforts. They supplement and augment the work of state-sponsored and other private sector secular aid agencies serving refugees. Christian Voluntary Organizations (VOLAGs) such as the Church World Service (CWS) and their off-shoot affiliates such as the local Sponsors Organized to Assist Refugees (SOAR) use the Biblical mandate of "welcoming the stranger" to inspire their work. VOLAGs target newly arrived refugees and preliminary assistance including food, shelter, access to other social services and medical care during roughly the first year of their arrival.

In Oregon, the Department of Human Services (DHS) works with VOLAGs under the Refugee Case Services Project (RCSP). The RCSP is a public/private partnership which contracts government funds to local human service agencies to provide the necessary resettlement services to new refugees. It must be noted that state aid to refugees (in the form of Refugee Cash Assistance, RCA, administered by the VOLAGs) is limited to up to 8 months after arrival, upon which they are expected to have found employment, and become economically self-sufficient. Those qualifying for Refugee Social Services (RSS) receive up to 5 years of support services such as job training, job placement, English language instruction, case management, translation services and so on which are provided through IRCO locally. DHS oversees and administers the SNAP (Supplemental Nutrition Assistance Program) and medical coverage via the Oregon Health Plan (OHP) (ORR 2017, Oregon Department of Human Services 2017). Beyond 
the initial 8-9 months of resettlement, neither the DHS nor the ORR currently track the long-term experiences of resettled refugees - including their well-being, the "success" of their integration, or their economic self-reliance (Kerwin 2011). The latter is the underlying goal of the overall resettlement system: help refugees find jobs and become economically self-reliant as quickly as possible. It is important, also, to note that while social and cultural "integration" (also referred to as assimilation or incorporation in some contexts) is the central ideal within the imagery of the US as a large melting pot, critics of this thought process have mentioned that the alterative, distinct retention of individual and cultural identities should be celebrated and supported (Meer and Modood 2015). Embedded within the often inflexible expectations of arrived immigrants and refugees to quickly learn English, adopt American customs, and learn local ways of life lies a demand for them to shed large amounts of their former identities and conform to what is expected of them in appearance, behavior and speech. The following two diagrams (pages 10-12) highlight the key components of the current US refugee resettlement system: 
Figure I: Refugee Resettlement Process in the US

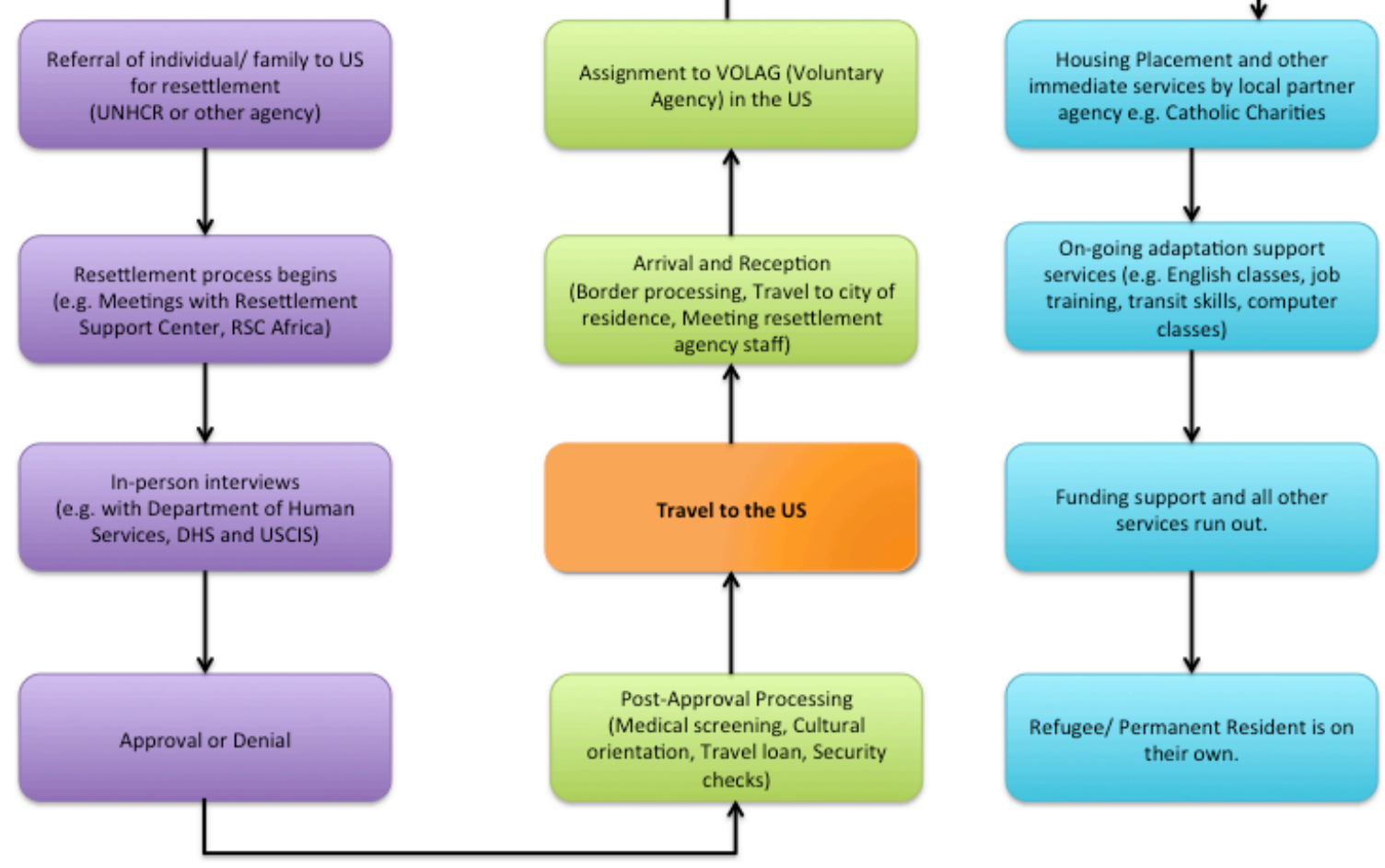


Figure II: Resettlement Process - Key Components, Agencies and Services

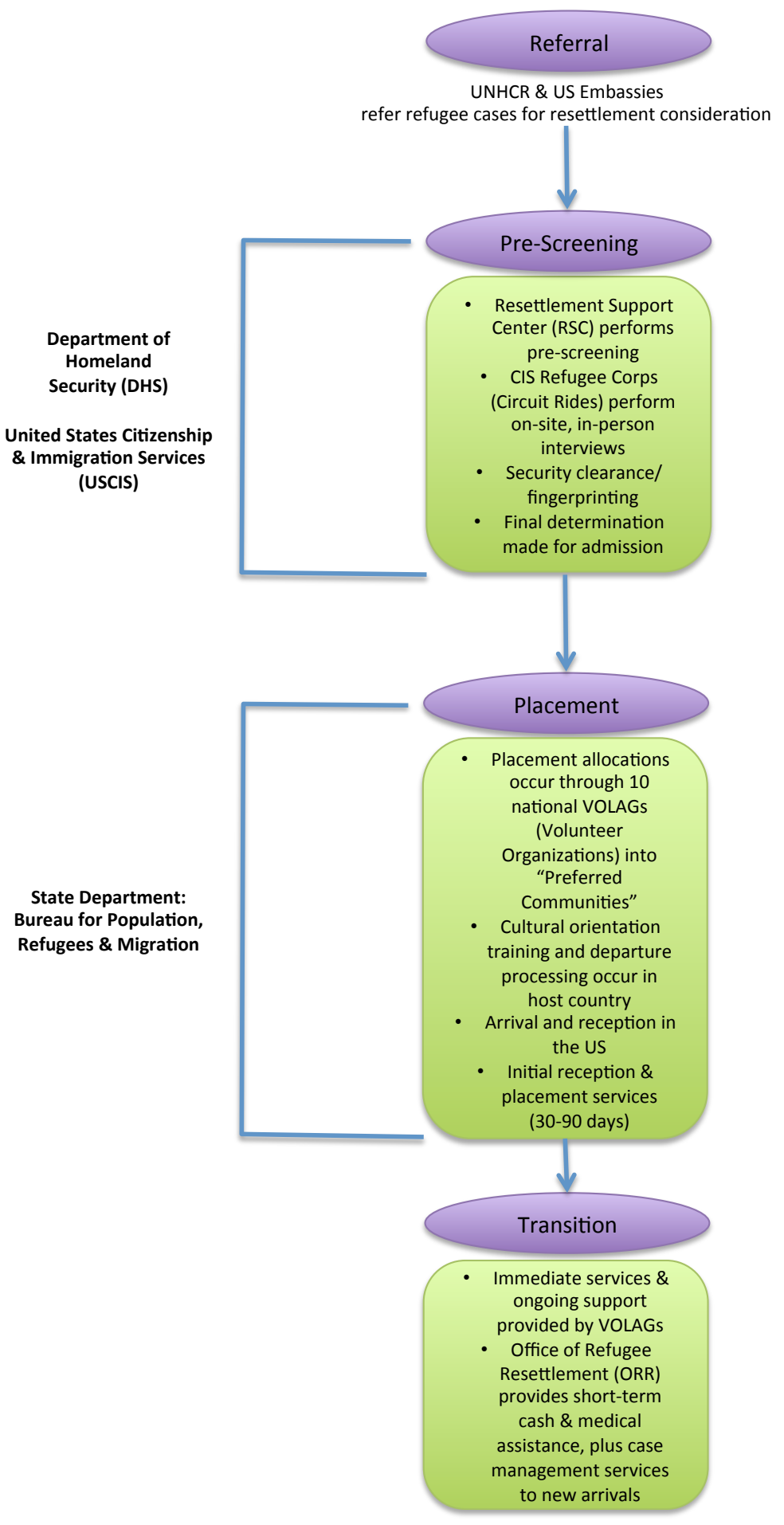




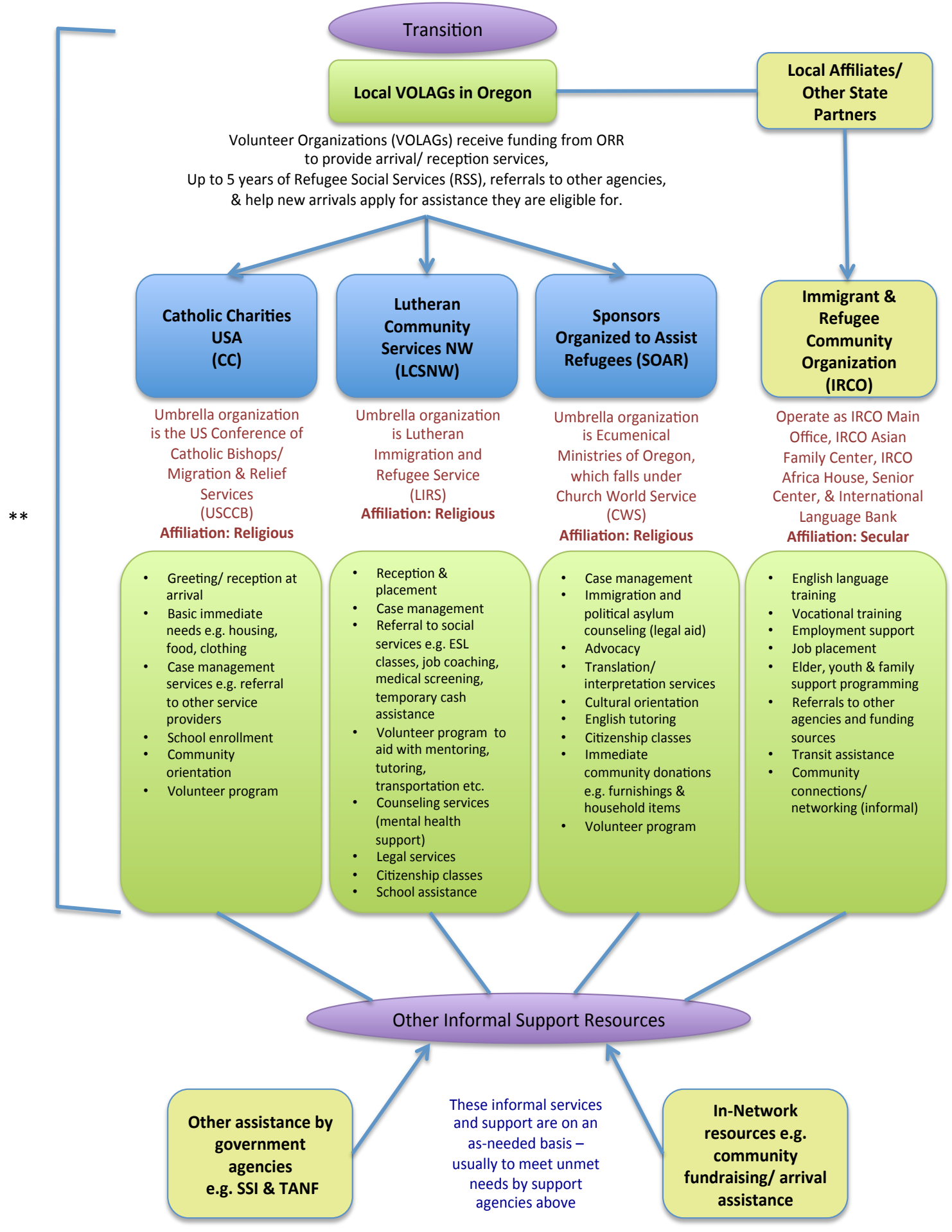

** Department of Health and Human Services (HHS): Office of Refugee Resettlement (ORR) 


\section{B. The Somali Community of Portland: An Overview}

The UNHCR estimates that around 1990, roughly 2,500 Somalis called the United States home. This number increased to between 140,000 and 150,000 by 2015 (2017). It is estimated that about 7\% of the world's Somali immigrant population is currently based in the US, and between 2001-2015, over 90,000 refugees from Somalia were resettled in the country (Office of Refugee Resettlement 2016). Somalis originally arrived in Oregon during the early 1990s, fleeing the political turmoil of their home country. Earlier estimates point to an earlier diaspora of Somali students arriving in the 1970s to study in US colleges and universities. Both these groups of early pioneers marked the first "wave" of Somali immigration to the US. Two more waves were to follow: one during the early 2000's where relatives and friends of the early migrants joined them (both as sponsored immigrants $^{3}$ and as refugees), and the third wave is the one consisting of current arrivals (Bashir et al. 2016). Today, it is estimated that between 12,000 and 15,000 Somalis call Oregon home. This is an informal local estimate from the community members and support organizations, as an official estimate is difficult to obtain due to the lumping of African immigrants under the "African American/ Black" category within most population databases, while leaving out the respondents' country of origin (Bashir et al. 2016).

Somalis have, in the past several decades, encountered numerous traumas of violence and persecution, resulting in displacement from their homes and separation from family members (as outlined in the preface). If fortunate enough to escape Somalia, they

\footnotetext{
${ }^{3}$ Sponsorship is a process within the US immigration program wherein currently settled relatives in the country can "nominate" a family member or friend to join them in the US as "immigrants". This process, while typically taking years to maneuver, is faster than applying and arriving as a refugee.
} 
often spend on average a decade or more in refugee camps in Kenya and other "host nations" awaiting permanent placement to countries such as the United States via the UNHCR. They often lack opportunities for formal education, and have few opportunities for economic mobility or personal stability while in the refugee camps. As they are primarily a nomadic people that have, over numerous generations, found their livelihoods in cattle rearing, they often find the culture shock and expectations for rapid adjustment and economic self-sufficiency in the United States an added challenge to their already precarious and troubled lives.

Somali culture is a patriarchal and collectivistic one, with clans identities being central, and individual affiliations at each stratum of the social structure strongly informing a person's identity and communal responsibilities. It is said that within Somali culture that one does not ask, "Where are you from?" but rather, "Who are you from?" as an individual's identity is linked inextricably to her, his or their ancestors. Somalis typically have three names: one of the grandparent, the second of the father, and the third of the paternal grandfather. Somali culture is a largely homogenous one, which includes their culture, ethnicity, heritage, language and religion (Bashir et al. 2016). They are all, for the most part, Sunni Muslims and speak in Somali. The role of Islam is central within the community: it informs most traditions, norms, social roles and expectations (for each stratum of the family/community). Everything from how Somalis dress, to the holidays they celebrate, to the principles they follow in intimate relationships follow Islamic code and teachings (Bashir et al. 2016).

Portland's Somalis today live on the fringes of Portland, out of sight to the rest of the city's communities. Their experiences are vastly unknown, be it the challenges and 
barriers they face as they adapt to the life in the United States as Somali Americans (or for the second generation as they negotiate their place between the currents of the parents' and grandparents' identities and their own), or the triumphs and successes they celebrate. The local Somalis are not a monolithic group, nor do they share a unified identity, as many would assume. There are many Somali communities locally, divided depending on the wave of immigration they arrived in, their clan affiliation, the part of the city they live in, the Mosque they choose to attend, or even along the lines of the linguistic, educational or economic advancement or success they have attained. Hidden within the dominant Somali community, furthermore, are the Somali Bantu: a minority with their own unique history and experiences.

The local Somalis were never really settled as part of a residential or immigrant community enclave in Portland. Most were scattered initially in the parts of town with the most affordable housing, by the resettlement agencies. Northeast and Southeast Portland, for instance, were a few of the initial areas of concentration. As time went on, many Somalis moved outwards into other neighborhoods, sought more suitable housing, bought homes, and also expanded to the neighboring cities of Beaverton, Clackamas and Eugene (to name a few).

The local Somali community was thrust into the limelight in 2010 when a Somali teenager was apprehended in a plot to bomb the area around Pioneer Square, in the city's core, during the annual Christmas tree lighting festivities. Suddenly, the rest of the city's attention was drawn to this previously hidden community: Who were they? Where did they come from? Are they safe? The Somalis, stunned by this action by one of their own youths, rallied together to try and understand what happened and where they went wrong: 
How did one of their children become so radicalized along the lines of religious identity that he chose the path of violence? How did the rest of the community miss the signs leading up the event? What were the youth of the community experiencing, in terms of their own isolation, difficulties, lack of supervision, and pulls towards gang activity/ radicalization? How can this be prevented in the future? ${ }^{4}$ Since then, a handful of research attempts have been made to learn about the local Somalis, and understand who they are. What is already known about the community (be in the context of the community at large, or as a subset of the local African immigrant community, or even in passing with the broader focus being on the Somali Bantus) is explored and summarized in the next chapter.

\section{Thesis Outline}

This thesis is organized into four sections. Chapter two reviews and presents the current literature on the displacement and resettlement experiences of refugees. By doing do, it aims to provide a foundation and context for this study to explore how these experiences look similar and vary across different populations. Current literature and studies general to the refugee experience are presented first, so as to assess what has already been explored and learned about the population. This is followed by a review of the literature and theories on the experience of identity formation and negotiation as a key component of the adjustment experience for refugee populations. In doing so, the relevant theories that provide a framework for understanding holistically this process are explored and presented. Lastly, key studies exploring the displacement and resettlement

\footnotetext{
${ }^{4}$ In 2014, Mohamed Osman Mohamud, then aged 23, was sentenced to 30 years in prison by a federal judge.
} 
experiences of the Somali diaspora within the US and around the world specifically are highlighted.

Chapter three provides an outline of the methodology adapted for the current study: highlighting the research design and revisiting the key research questions. As this study attempts to explore and understand the subjective experiences of the Somali community of Portland on their arrival and adjustment experiences, a qualitative method is adapted. It is hoped that this will elicit detailed narrative histories from the individuals participating in the study.

Chapter four presents the overall findings of the study, highlighting the analysis of the data as well as presenting selected quotations from the participants which underline the key themes that emerged through the data collection and analysis process. In this chapter, the narratives of the study's participants are explored at depth, and shared to highlight the narratives they considered important in understanding their arrival and adjustment experiences. This chapter also explores and presents how the findings of this study compare to the current literature on refugee adjustment experiences, including the theories discussed in the previous chapter.

Chapter five concludes the study by providing an overview of the key findings of the research process: situating these within the current literature and the framework of the theories presented within the review of the literature. The central findings of this study are elaborated upon, and the implications of these findings are presented in a section highlighting the current unmet needs of the local Somali community, as well as recommendations for service agencies working with them. Suggestions for future 
research studies, as well as the limitations of the current study are also presented within this final chapter. 


\section{Chapter II}

\section{LITERATURE REVIEW}

This study draws on sociological and interdisciplinary research regarding refugee resettlement experiences. The purpose of this review of the literature is to present a contextual background of the current research on the displacement (exile), resettlement, and post-resettlement experiences of forced migrant populations. Since this study focuses on exploring and understanding the arrival and adjustment experiences of the Somali community of Portland, this chapter highlights the existing literature on the Somali refugee diaspora around the world.

This literature review begins by exploring a cross-section of general studies on refugee resettlement, which explore everything from the motivations of resettlement abroad, to the psychosocial effects of the trauma of displacement, to post-resettlement experiences within host communities, to the stages or indicators of adjustment and integration. This review then highlights studies focused on identity formation and negotiation as experienced by refugee populations in exile. Lastly, it explores studies focused on the Somali community within the United States, and around the world: examining how their resettlement experiences compare and contrast with those of the Somalis of Portland. Within these three sections, key theories that help make sense of the refugee experience are underlined.

\section{A. The Refugee Experience: An Overview}

It is critical to begin by highlighting the uniqueness of the refugee experience within the broader literature on immigration and immigrant adaptation to the new 
homeland. While immigrants, in their bid to leave their countries of birth to seek greener pastures, display relative freedom and agency, refugees are more passive subjects to the "pushes" of displacement that include political unrest, civil war, genocide, identityoriented persecution, climate-change, famine or disease. E. F. Kunz presents a kinetic model of refugees in flight that underscores that, unlike a migrant, a refugee is not pulled out of her/his/their land by opportunities or the promise of a new life, but rather pushed out due to difficult circumstances. While the immigrant may seek a particular destination for resettlement, a refugee will generally go anywhere for safety (1973). Kunz also highlights two types of flight and resettlement patterns within refugee populations, which he presents as "kinetic types": anticipatory and acute. The anticipatory refugee is one who foresees an impending push, seeks out a more suitable place to move to, brings their family, resources, and is often more informed and educated. The acute refugee is the type we hear more about: the one that is displaced during times of war, famine and so on and are responding to an overwhelming push (1981). Acute refugees have not planned ahead for this displacement, rarely bring any resources with them, and have not planned ahead in any way. Their only aim is to get to safety.

Kunz also highlights some other critical elements of the refugee experience. Refugees, for instance, will upon arrival in a host country (the country they have fled to), then ponder their choices, which are often limited to three classic options: to go back to their homeland if and when the threat has passed, to remain within the host country and begin a life there, or to seek resettlement in another country abroad (1973). Kunz discusses another vital element in understanding refugee populations within a country: it is vital to not lump them into one monolithic group. He presents the idea of refugee 
"vintages," which are distinct groups within an individual community that have, for instance, arrived during different waves of migration, have had different "pushes", have distinct experiences of arrival and adjustment, or may hold distinct identities. Within a singular refugee community, the Somalis of Portland for example, there may be "majority-identified" and "events-alienated" groups. The former are defined by Kunz as those who identify with the nation of origin and its people but have had to flee an oppressive government for instance, while the latter are from marginal or minority groups that have historically been alienated or oppressed by and within the nation of origin. Kunz posits that resettlement and adjustment is an easier experience for the eventsalienated groups versus the majority-defined groups. The reason for this is that the former may actively seek opportunities to flee the nation of origin and also new identities, while the latter will often wait as long as possible before having to leave the nation of origin, and will long for the homeland, and dream of returning home (1973).

The refugee experience must be understood longitudinally as various stages of exile have distinct consequences from the initial displacement from the homeland, to arrival in the host country, to life in the host country (be it living in refugee camps or within the towns and cities), to the decision to go back, stay in the host country, or apply for resettlement abroad, to the journey to the secondary resettlement country, to arrival in the country, and finally to the ongoing adjustment within the new homeland (Stein 1981). Resettlement, defined and understood as adjustment, assimilation, acculturation, or integration, is a rather complex process. Stein explains that the adjustment experience can be broken down into four stages: the period of initial arrival (the first few months of living in the resettlement country), the first two years, after about four to five years, and 
then a decade or more. Each of these stages is characterized by its own unique elements, challenges and triumphs: from the acute drive to adjust and recover losses in the first year or two, to the more relaxed attitude of the better adjusted fourth or fifth years, to the general stability after the first decade or so. Another common way to summarize the adjustment experiences is: The first stage is an initial "honeymoon phase" where there is euphoria at arriving and making it. Refugees who flee to safety very commonly have this initial experience of having made it to safety. The second stage is that of rejection or post-decisional regret. This is when the differences in the culture of origin and the new homeland become most pronounced. The individual feels like an outsider and experiences a "culture shock". Adjusting feels like an immense challenge as the most minute of details are to be relearned. There is often anger, regret, acute homesickness and isolation experienced during this stage. This is followed by the third and fourth stages of gradual adjustment and adaptation. In these eventual stages, the daunting novelty of the culture wears off, and life seems to be manageable. The fourth stage is one where one finally feels at home. Reconciliations of identity usually happen at this stage. One begins to appreciate certain positive aspects of the new homeland, and adopts skills and resources that aid with further adjustment. The process of adjustment is an ongoing one, one without a particular ending point, and adjustment consists of many layers: be it economic adjustment (through occupational advancement for instance), or social/ cultural adjustment, or even adjustment based on a mental health level (Stein 1981).

Current studies on refugee adjustment tend to belong to two sizeable distinct groups: one that focuses on the refugees and the other on the support agencies and programs that aid their resettlement. Studies focusing on refugees explore everything 
from their mental health, to loss of socioeconomic status and labor market participation, to culture and identity, to interactions with the local native communities, to language, housing, identity and so on. Studies on the programs and agencies focus on the type of services provided, effectiveness of the services or representation, recommendations for improvement and so on (Stein 1981). Some of the key general studies on refugee resettlement are discussed below.

\section{B. Refugee Resettlement: Between Displacement and Adjustment}

By any account, life in host nations and especially within refugee camps is very difficult. Researchers such as Bram Jansen have attempted to understand the motivators of refugees for seeking secondary, permanent resettlement in nations such as the United States. These motivators are explored in addition to the otherwise understandable "pushes" of harsh circumstances. In his study based in the Kakuma refugee camp in Kenya, where many Somali refugees are initially settled, he learned that many camp occupants have a strong desire to be placed overseas (2008). The reason for this is an improved access to communication with the rest of the diaspora already resettled. Narratives of a better and easier life reach the camps through these transnational communication networks and encourage others to aspire to the same. Another reason for a strong focus on seeking resettlement is an increased knowledge of entitlements among camp occupants. Knowing what resources are available to aid their potential transition, usually through word of mouth within the camps, as well as actively seeking out these resources adds to the drive to benefit from them. A third reason Jansen shares is the high visibility of the resettlement process within the camps: everyone can see everyone else waiting in line for placement and going through the stages, and is thus encouraged to get 
in line. A vital finding of Jansen's study is that due to the harsh realities of life within the camps, alongside the motivators listed above, what results is an environment that encourages many refugees to "cheat" by exaggerating their insecurity or vulnerability to those vetting potential resettlement candidates (2008).

Within studies of the drivers of migration, there is some critical attention paid to the expectations versus eventual realities of immigration and resettlement abroad. Individuals, as they actively pursue the goal of moving to greener pastures, have high aspirations for their future life (Carling 2002, 2014). More often than not, however, the realities awaiting them are much harsher than anticipated (van Heelsum 2017).

Researchers such as De Haas (2011), Castles (2010), and Robeyns (2007) have discussed the concept of "aspirations" in immigrant drives to move to another country. These aspirations are best understood as components or ingredients sought elsewhere in creating or finding a more "satisfactory life" (van Heelsum 2017). Robeyns identifies some of these key basics sought: health (or healthcare access, clean water, good physical health and so on), food (access to a reliable supply of food), income (means to earn a living, and to have a comfortable life), education (opportunities for learning or earning credentials), justice (legal and social rights and protections), community activities (immersion and social support), and culture (living with one's traditions, norms and so on) (2007). Anja van Heelsum adds better access to information, the ability to speak in a language of one's choice, and freedom of religion to this list (2017). These aspirations are often at odds with the immediate expectations for assimilation in a host country, leading to frustration and disenchantment. 
At the core of any refugee resettlement effort by a host country such as the United States is an expectation of eventual successful "integration" (also known as assimilation in some contexts). Catherine Tyson discusses that these parameters or indicators of successful integration find their foundation within neoliberal notions surrounding productive citizenship: where an individual is economically independent and selfsufficient (2017). Within a capitalist nation such as the US, it is no surprise that the emphasis on a post-welfare citizenry shows itself within the country's refugee resettlement program. Current indicators of successful integration include English language acquisition and using this for successful job placement, both related irrefutably to economic self-sufficiency. Little to no emphasis, within the system, is placed upon any other indicators or signs of successful adjustment: such as an improvement in an individual's mental health, community relations, civic and political engagement and so on. Researchers such as Ager and Strang (2008), Garcés-Mascarñas and Penninx (2015) and Zetter et al. (2002) highlight other vital indicators such as educational attainment, housing, health, social connection, increased linguistic and cultural knowledge, safety and stability, and having more rights and citizenship, which are not emphasized within the US system. Tyson argues that current US refugee resettlement policy fails to address a more long-term success model in understanding and supporting the adjustment and integration of refugees. As such, when the official resettlement period is over, individuals and communities show signs of poverty, low-incomes, mental health issues, isolation and disenchantment that are largely ignored (2017).

Researchers such as Val Colic-Peisker add to this narrative of desirable integration through successful placement in the labor force versus the realities of poverty 
and difficulties for many resettled refugees (2005). He states that many recently arriving refugees are pulled into the secondary labor market that the locals avoid: such as driving taxicabs, low wage factory production and farming jobs. Refugees are often relegated to "undesirable jobs" due to the non-recognition of their prior qualifications, racial or ethnic discrimination in the workplace, a lack of support networks to assist in job placement, and also selective resettlement by the government in communities where there is a need for low-skilled labor (Colic-Peisker 2005). Phillip Connor shares the concept of the "refugee gap" in US society to highlight this economic discrepancy experienced by the refugee population. He shares that other disadvantages refugees have include linguistic difficulties, lesser educational experience, relatively poor mental or physical health, residence in disadvantaged neighborhoods, and differing forms of family support (2010). Clearly there are multiple barriers to meaningful economic self-sufficiency.

Prior to arrival in the United States, refugees selected for resettlement have to attend cultural orientation classes. Within these classes, the immediate things to expect upon arrival in the United States are taught. The orientation, however, focuses more on the practical aspects of arrival: such as working with the support agencies, how to get a driver's license, basic immigration laws, maneuvering public transit, opening bank accounts and so on. Cultural components of life in the US are not explored in much detail, and what results is individuals who arrive with little to no knowledge of what their communities and neighbors would be like (Crane and Fernandez 2017). While they know they would be expected to learn and speak in English, or follow other major US customs such as time keeping, they do not receive destination-specific orientation that is invaluable in ensuring a more successful integration into the respective communities of 
resettlement (Crane and Fernandez 2017). In their study of Iraqi refugees resettled in California, for instance, Crane and Fernandez highlight the fact that the Iraqi community were not told to expect having to become fluent in Spanish as well upon arrival to get by (due to the dominant Latino culture of the area they were settled in) (2017).

The role of faith-based organizations in refugee resettlement forms another critical portion of the existing literature on refugee and immigrant arrival and adjustment. Faith-based support organizations function at the community level (alongside secular ones) to form the middle-person between the state, or federal, government (that selects and brings over refugees for resettlement) and the receiving communities where the refugees are resettled (Nawyn 2006). It is the role of the resettlement organizations to provide the critical post-arrival services such as English language instruction, job training, job placement, cultural instruction and so on to aid in the smooth transition to life in the US. They receive funding from the federal government to ensure successful integration (Eby et al. 2011). The role of religion in immigrant adaptation has been covered vastly in the literature. Sociologists Oscar Handlin (1951), Will Herberg (1955) and Milton Gordon (1964) were among the first to study the role of religion in immigrant adjustment. They, however, limited its understanding to an agent emphasizing cultural continuity and as a psychological support mechanism aiding immigrants who had just experienced immigration, and failed to emphasize the socioeconomic role of religious organizations in American society (Hirchsman 2004, 1206). It is only recently that religion has been treated as and studied as an independent variable affecting immigrant experiences. 
Numerous other historical and contemporary scholars have written about the importance of the cultural and economic resources that faith-based organizations bring to their respective communities to aid immigrant adaptation (Ebaugh and Chafetz 2000; Min 1992; Menjivar 2001, 2003). The importance of religious participation in immigrant adjustment has been examined extensively in the literature (Dolan 1975; Gleason 1968; Herberg 1960; Tomasi 1970; Levitt 2001; Menjivar 1999; Mooney 2007). Stephanie Naywn argues that faith-based are very similar to secular ones in the work they do, but differ when it comes to the expression of religiosity within organizational rhetoric as well as within their networks (2006). This is an important fact to highlight as refugees and immigrants, as service-recipients encountering these organizations upon arrival, and simultaneously encounter the undercurrents of religious identity within them. It is critical to understand the impact of this on the service recipients. Research focusing on this element highlights the fact that many times, service recipients do not practice the same religion as the one forming the background of the support organization (such as Muslim refugees and immigrants seeking services from a Christian organization) (Nawyn 2006). This becomes of concern given the history of proselytizing by Churches sponsoring refugees from different faith backgrounds in the past (Ong 2003), the experiences service recipients may have, both positive or negative, with missionaries in their home countries (Holtzman 2000), as well as differences in religious practice in the case of the service recipients and the support organization sharing the same religion, which may restrict connections (Gold 1996).

Upon arrival in the new country, a vast array of barriers greet new refugees: be it an alien environment, new cultural norms, a new language, different looking and 
sounding people and so on. In his study on Bosnian refugees resettled in Australia, Val Colic-Peisker posits that the closer one is to the dominant group of the resettlement country, the easier it is for new refugees to blend in and be accepted as part of the community, and thereby face fewer barriers. Since the Bosnians are white-skinned, they have an advantageous closeness to the white-Australians. In turn, they experience less "otherness" and more interaction with the white-Australians. The result is an easier earlier acceptance and the ability to claim an "insider" status (2005). It is only when they reach the second stage of adjustment, which is past the initial "honeymoon stage" of arrival euphoria, that they experience barriers that simple outward appearances can no longer shield them from: their language barrier (as they come from a non-English speaking background) stands in the way of their success within the labor market. It is evident from Colic-Peisker's study that fluency in English as well as outwardly visible similarities to the dominant culture of the resettlement country as vital "resources" that aid in a smoother transition. Refugee groups establish and rely on other similar resources that are more community oriented: be it the establishment of informal community networks to support each other or the establishment of formal community organizations for services and representation (Koyama 2017). In her article, Odessa Gonzalez Benson refers to a fundamental drive within immigrant and refugee communities to come together to undertake the shared difficulties they are experiencing (2017). It is often informal leaders within the communities who form the locus of fledgling community organizations. These are individuals with a better grasp of the language, a higher education, more work experience, or simply a good reputation within the community. The close proximity, within neighborhoods, of resettled refugees has 
typically meant that word can travel fast among people of these grassroots support efforts and member of the community reach out to them for services such as mediation, translation, representation in formal settings, and so on. Even the support organizations, working in a service provision capacity to these communities, have over time recognized the vital role of community organizations, and have hired them as well as community leaders within the organizations. Resettlement organizations have also consulted with leaders within the communities to determine more culturally competent and effective modes of service delivery (Gonzalez Benson 2017).

Jill Koyama further discusses networks in her article and states that refugee networks, unlike immigrant ones frequently experience disruptions due to the fact that refugees experience little stability in their flight from their home countries (2017). She points out, however, that these networks extend globally: including connections in both the countries of origin and resettlement as well as within countries they transit in between. When they are eventually resettled in a country such as the US, the preliminary networks of refugees are informed by the support organizations aiding resettlement, other support agencies, as well as the local refugee population. These initial linkages give rise to the initial networks they turn to for support (Koyama 2017). It is also these networks that serve another critical function: aiding in the transition of newly arrived refugees into the workforce (which has previously been discussed as the central goal of the US resettlement system) (Ioannides and Loury 2004; Bayer et al. 2008; Morales 2016). Participation in networks not only increases the chances for securing employment (due to word of mouth on job openings, or informal referrals at worksites and so on), but being employed reciprocally results in an expansion of an individual's networks (Colic-Peisker 
and Tilbury 2006). Some researchers share that the importance of social networks in the economic advancement through job searching and placement for refugees precedes their arrival in the resettlement country. These networks play a crucial role even in exile, while living in the refugee camps (Porter et al. 2008).

In their article, Bloem and Loveridge (2017) state that today, it is becoming increasingly atypical for newly resettled refugees to have no pre-established network to turn to at arrival. Today, the chances that refugees will remain and establish themselves in the city of initial resettlement are also low. Many resettled individuals and families undertake a secondary migration to a city of their choice, which is usually determined by the refugees' social networks. According to Bloem and Loveridge, many factors influence this: be it increased knowledge about the geography of the country and the costs and benefits of living in one city over another, or simply lying low until the resettlement process is over (due to a distrust of the resettlement bureaucracy) and then moving to come together as a larger stronger group in one city, or even due to "shopping" for better resettlement services in specific states and cities (2017).

Other general literature on refugee resettlement is as varied as the global refugee diaspora itself. Some interesting studies that have potential parallels with the experiences of the Somali community of Portland are discussed briefly next.

Central within interdisciplinary research on refugee populations is a focus on their mental health challenges and needs. Researchers such as Dermot Ryan, Barbara Dooley and Ciaran Benson (2008) have explored the theoretical models upon which current research is based. Some models include the medical model, the psychological stress model, and the acculturation framework. They discuss both resources and constraints as 
factors affecting resettlement on a mental-health level, and also the impact of the host societies on the well being of refugees (2008). Other researchers have focused on more specific aspects of refugee mental-health needs in the diaspora (Marlowe 2010). In their study on Middle Eastern refugees based in Denmark, for instance, Katherine BekPedersen and Edith Montgomery note that children of refugees that personally witnessed violence during their displacement experience have more difficulties in creating new homes when compared to children who have merely heard of the violence or persecution through family narratives. Their very experience of being a refugee, on an identity level, is informed by these distinct experiences with trauma (2011).

Researchers have also addressed other specific aspects of the refugee experience such as the increase in domestic violence as a result of the displacement experience (Carlson 2005; Horn 2010; Ondeko and Purdin 2004; Payne 1998; Schrijvers 1997). Reasons that increase the experience of domestic violence in exile are tied to the structural conditions within the lives of the individuals. Factors such as cultural norms, gender roles, marriage practices, economic stressors, loss of family and support, psychological issues and so on are exacerbated in the context of the difficulties faced in exile (Horn 2010).

Lastly, researchers have focused on specific barriers faced by refugee populations while resettled. One of the most important barriers among these narratives is the access to adequate healthcare (McKeary and Newbold 2010). In their study based in Canada, they establish that there are many systemic barriers that impede refugee populations' access to healthcare. In a country with universal and accessible healthcare, it becomes even more interesting to understand the reasons why refugee populations do not access the care 
offered. Their study uncovered a variety of important issues that act as barriers: be it interpretation or language issues (that impedes proper conversation or care in health care settings) or the lack of culturally competent care (that takes into account cultural norms and values), or economic barriers, or social or cultural isolation, or even the lack of needed healthcare services that are geographically accessible to these populations.

\section{Refugee Identity Formation and Negotiation}

A critical component of the displacement-resettlement experience within the current literature is that of its impact on the individual and community identity. Identity refers to those salient aspects of an individual, community or culture within which individuals and communities seem themselves as holding a distinguishable character or personality: it is what defines them and outlines who or what "me" or "us" entails. More specifically, it is how we view ourselves, either as individuals or a community, in relation to others (Cerulo 1997; De Beauvoir 1983; Phinney et al. 2001). Identity, on a psychosocial level is embedded deeply within an individual or community (Berry 2005; Brubaker and Cooper 2000). La Barbera (2015) defines identity as, “...intended and best described as a relational and contextual process that refers to how individuals and groups consider, construct, and position themselves in relation to others according to social categories such as gender, sexuality, culture, race, nation, age, class and occupation. Identity encompasses the multiple roles endorsed by individuals in social life that are externalized through the use of markers, such as language, dress, and occupation of space."

Most of us take great pride in what we identify as, whether it is being from a certain place, or rooting for a certain sports team, or following a certain religious path (or 
choosing not to). Immigrants and refugees, within their uprooting from their native countries to new homelands find themselves in a position of having no choice but to revisit the core components of their identity, and negotiating these to incorporate the new values, norms, ways of life, and expectations they encounter. In other words, these negotiations/changes are made in an attempt to fit into the new culture, and the results of these changes promote further adaptation (Colic-Peisker 2005; Matsumoto et al. 2007; Phinney 1990, 1991). Identities, in the context of migration, go even further than mere descriptors or "cultural markers" of uniqueness and are embedded deep within the context of ideologies and power in the host country (Blackledge 2005; Gal 2006). Refugees, more specifically, experience a forced loss of components of their former identity embedded within their culture, and attempt to reconstruct their identity within the framework of the adjustment experience once resettled (Colic-Peisker 2005).

Asghari-Fard and Hossain (2017) argue that in the pre-globalization era of low cross-border mobility and relative cultural isolation, communities had "fixed identities". Within global mass movement came an era of a more fluid identity: one that is negotiated within the context of migration (Kellner 1992). The result is a "hyphenated hybridity" that constantly challenges what was long held or considered to be "native" or "original" to a place (Asghari-Fard and Hossain 2017). In the US, for instance, European colonizers had established a cultural "norm" of white Christians as what entailed an "American". The persevering presence of Native Americans as well as the arrival of Africans and later other cultural and ethnic groups has constantly challenged this status quo. Today, newly arriving immigrant groups continue this reconstruction of the "face" of the US. This has resulted in a persisted defining and assertion of "otherness", both by the host society and 
immigrant groups, by which those that do not belong (because they are dissimilar or different) are excluded or discriminated against. This exclusion, in turn, fuels identity negotiation and reconstruction within immigrant groups: what the internal perceptions of the group are (about themselves) and what the host society views them as being (external messages) are both incorporated to form a hyphenated hybrid identity as "African American” or “Asian American” for example (Asghari-Fard and Hossain 2017).

Salman Akhtar (1999) presents an eloquent explanation of how immigration (or forced displacement) is intertwined with the process of identity negotiation. Immigration, at its core as an experience, entails leaving all that is familiar and comforting to move to a new, alien environment where there is low predictability and an even low previouslyaccrued knowledge base about the culture, norms and so on. Psychologically, the process of immigration is one characterized by some profound losses and grieving for these losses (characterized by homesickness or culture shock). It is within the turmoil of this loss that an individual also experiences a novel advantage or opportunity: that of selfexploration and expression of self. Offered a blank slate of sorts, the individual or community can start afresh and redefine who or what they are in the context of their new homes. It is within this shake up of the individual psyche, Akhtar states, that the process of identity negotiation finds its genesis (1999). Many consequent factors determine what this process will look like for an individual/ family: the first being if the immigration is permanent or temporary (permanent for most resettled refugees), the second being the degree of choice one had in leaving her/his/their homeland (willingness and looking forward to the new home or not), third being the possibility of revisiting the homeland again for "emotional refueling" and the last being the age at which the migration occurs 
(the intensity of the identity negotiation being more acute for the older generations versus children who are considered more malleable). Akhtar maintains that for any identity negotiation to occur as a result of the inevitable and necessary adjustment process, the immigrant has to give up a part of her/his/their individuality. Identity negotiation is a process of losses and gains (Grinberg and Grinberg 1989).

Asghari-Fard and Hossain state that some critical factors help determine if cultural identity will be retained within a group, within the context of the pressures for acculturation within the host society. These are: connectedness within the family unit, language, ties within the community, ethnic pride, cultural beliefs, and a drive to engage in community events or traditions (2017). The "loss" of culture or identity is studied in great detail within the literature to understand its place within the context of overall identity negotiation (which is an adaptive process of growth and reconstruction). It is vital to note that even within immigrant groups, no two individuals experience identity and its formation and negotiation in the same way (Ho 1995). There are, however, reliable similarities within groups that help us understand how individual immigrant groups experience this process collectively (Berry et al. 2006; Bourhis et al. 1997; Sabatier 2008).

Some common theories researchers rely upon to make sense of the identity reconstruction, formation, and negotiation process within immigrant and refugee groups include constructivist identity theories that explore identity as more "fluid" and adapting than rigid or monolithic (Bucholtz and Hall 2005; De Fina et al. 2006). Other theories are post-structuralist ones where identity is understood as a product of membership within one or more social groups (Giddens 1991; Kroskrity 2000) as well as social constructivist 
theories within which identity is understood as a product of social interactions across historical, political and economic contexts De Fina 2007; Fishman 1989; Gal 2006; Rong and Brown 2002). Some researchers such as Colic-Peisker and Walker (2003) use more specific theoretical bases to make sense of the identity formation and negotiation experience, including the classical integration theory (known earlier as the theory of assimilation), or the socio-psychological perspectives of social identity theory (Tajfel 1981; Tajfel and Turner 1986) and acculturation theory (Berry 2001), as well as the sociological theory of the migration of human capital (which is more economically based on focused on how migrants' capital travels with them to give them an advantage in the adjustment experience) (Iredale 2001; Portes 1995).

In their study, Colic-Peisker and Walker (2003) outline two specific factors that interact to determine the outcome of the identity and adjustment processes: the characteristics of the immigrants themselves, and the responses of the host society (339). Characteristics of immigrants include its "visibility" in the new community, its "distance" from the host community, as well as the human capital within the group. The responses of the host society include the specific treatment of the immigrant community, the official policies it creates and enforces, as well as outcomes of formal and informal encounters between the groups. This, according to the researchers, creates a blueprint for the direction and nature of the overall adjustment process and the identity formation/ negotiation therein (Colic-Peisker and Walker 2003).

In her study of Sudanese refugees in Australia, Anikó Hatoss (2012) explored how the community viewed themselves, through identity self-labeling and selfcategorizations, in comparison to mainstream Australians. They focused on the group's 
encounter and responses to the common question: "Where are you from?" They found, similar to Bal and Arzubiaga's study (2014) discussed below, that the Sudanese community actively and purposefully negotiates an identity that willingly takes on more "Australian" aspects, while respecting and holding dear a strong ethnic concept. Irrespective of the in-group willingness to become more "Australian", mainstream Australia continued to categorize them as outsiders.

In their study on Ahiksa refugee youth in the Southwestern US, Bal and Arzubiaga (2014) focus on the effects of identity formation on their academic achievement, social adaptation and mental health. They found that three components define the largely tailored process of identity formation and negotiation within the Ahiksa youth and their families and community: glocal (a fusion of global and local) adaptation (where there is an emphasis by the families to worry about a loss of culture within their youth and an insistence to engage in community events, make friendships with other immigrant youth, and then take on identity markers from the local host population); multiple literacies (the learning, in many ways, of different community-specific languages alongside English language acquisition - be it by watching Ahiksa television shows, or learning Arabic, or emulating American hip hop artists and so on); and sticking together (this is an emphasized social cohesion that stresses that all Ahiksa must stick together and stand up for each other no matter what). Within this one specific community, and its second generation youths, Bal and Arzubiaga found unique ways in which the group negotiates identity upon resettlement in the US: both embracing the new inevitable identity markers that will add on to their current identity and also working hard to retain their traditions and cultural ethnic identities unique to their ancestors. The result 
is the formation and construction of a tailored hyphenated hybrid identity that the group negotiates actively.

In a similar study of the "hyphenated identities" of East Indian American youth based in New York City, Nina Asher (2008) found that immigrant youth actively define and redefine their identities based on the differences and often-contradictory messages they encounter at home and in school. Asher found that the youth find it difficult to express their American selves at home (more so) and their Indian selves in the school setting. The school setting, while perceived as more open and free to identity expression, had some strong contradictions of messages given to the youth: for instance while celebrating the diversity they bring, they would hear a message such stressing the importance of a singular, homogenous "American" identity over a hyphenated "Indian American" one. The youth in the study expressed that the Indian half of their identities was important to them to recognize and be recognized - and this was something that was stressed a lot at home especially (2008). Immigrant parents at home fear their children losing their identities and becoming too "Americanized" (Portes and Rumbaut 2006). Asher's study is a good example of the "in-between" cultural worlds that children of immigrants and refugees maneuver as they attempt to reconcile the identity of their parents' backgrounds with their own new identities as "Americans" - especially if they are born in the US.

In her study on African immigrant youth in the US, Shelly Habecker (2017) found that the youth find it difficult to maneuver their adjustment between the currents of two cultures. One of the participants in her study shared that while she was born in Africa and arrived in the US, she knew little to nothing about her country of birth - as she had no 
recollection of it. She felt that she could never really be fully "African" or fully "American" and was stuck somewhere in between. With her black friends, she is the lighter skinned one and with her white friends, she is the black girl. She does not fully belong as an "African American" and yet is classified as such by her white friends. Habecker explores the identity negotiation of youth like her within the context of "segmented assimilation" a concept developed by Portes and Zhou (1993). Segmented assimilation refers to the likelihood that non-white immigrants typically become a part of one of two or three main segments of American society at arrival, depending on the socio-economic resources they come with, and also what the context of their reception looks like. Class, in other words, is a strong driver in eventual social placement, and therefore identity formation. Those with fewer socio-economic resources within the family, for instance find themselves situated among and identifying more as African Americans within an inner-city context. Youth coming from a better socio-economic background have the luxury of being able to maintain a stronger, distinct ethnic identity or simply attempt to assimilate into the white, mainstream European immigrant group in the country (which is not really an option for African migrants due to their "blackness"). Segmented assimilation helps us see how initial placement within a community or stratum of society affects largely what the identity forming factors or drivers will be for newly arriving immigrants. Researchers have supported this concept as a strong and reliable one to understand how non-white immigrations are integrated into American society (Stepick and Stepick 2010).

Adding to the narrative on segmented assimilation and formation of a hyphenated identity (for instance African American), Asghari-Farda and Hossain found in their study 
that the second of the two identities (American in the case of "African American") is the weaker identity while the "African" part is the more dominant one. They found identity formation within their study sample of Iranian Americans, was greatly influenced by three primary contextual factors: the participant's place of birth (whether they were born in the US or not), their acculturation experience, as well as their overall attitudes towards the host (or mainstream America) (2017).

Doris Warriner (2004) takes the focus to the gender narrative within immigrant and refugee identity negotiation in her study on Sudanese women in the US. She found that the women she interviewed had an acute awareness of what they needed to do to become more desired as employees within the market place: learn English quickly, seek educational or vocational training and so on. The women showed an awareness that their own advancement, in turn, affected the prospects and comfort of their whole family. The women were also aware of the power structures and societal barriers they encounter due to their gender as well as immigrant status: be it a lack of access to much-needed English classes, adequate childcare, transportation barriers and other structural difficulties. The women also displayed an awareness of the dominant discourses that greet them upon arrival (viz., become self-sufficient) and the realities of the discrimination and barriers they encounter that keep them from reaching this goal. Warriner explores how the women construct, negotiate, and "deploy" their identities within the context of this initial adjustment phase. Gendered work identities, for instance, surfaced in the women's narratives where the women begin to express a need and motivation for a career for themselves (and resulting independence) and how this works with their other aspects of identity: such as being a wife, mother, daughter and so on (2004). This new recognition 
of the contextual and relational nature of gender within the space of the new homeland (with new gender expectations and behaviors from the country of origin) is also explored similarly by other researchers such as Donato et al. (2006).

Some researchers have focused on the schooling experiences of first and second generation immigrants to understand how the gendered experience of immigration affects the children of those who migrate. Studies have shown that men and women experience immigration differently: their new homelands receive them differently and therefore they experience different patterns of engagement and participation within social contexts (Itzigsohn and Giorguli-Saucedo 2005; Stritickus and Nguyen 2007). Some studies have found that women, through the experience of immigration, experience higher levels of emancipation and success in the new homeland. They, however, while liberated within social contexts such as the workplace, continue to be subordinated within the home or ethnic community due to patriarchal norms or other gendered expectations (Espiritu 2001; Kibria 1993; Lee 2005; Pessar 1999; Zhou and Bankston 2001). Men, on the other hand, while experiencing a loss of social or economic status upon arrival, continue to dominate the home frontier and the ethnic communities. To further "balance" the newly formed power differential in the home, men tend to emphasize cultural norms and traditional practices within the home or family (which are more often than not steeped in patriarchal norms) (Espiritu 2001; Lopez 2003; Kibria 1993; Lee 2005). These patriarchal norms and gendered experiences seep down to the daily experiences of immigrant children as well. Studies have shown that conflict arises in the family regularly as differential treatment between boys and girls is experienced and challenged. Boys are typically afforded more freedoms, encouraged to go to college and so on, while the girls 
are expected to be carriers of culture and controlled and confined vastly (Kibria 1993; Lee 2005; Louie 2004; Qin-Hillard 2003; Sarroub 2005). Some researchers have found that girls' socialization and sexuality are strictly governed within families so as to ward off the "evil effects" of Americanization (Espiritu 2001). Despite this, many studies have shown that immigrant girls and women are excelling more than boys do within higher education, pushing themselves for better opportunities and ways to give back to the family and community (Lopez 2002; Portes and Rumbaut 1996; Rodriguez 2003; Waters 1996; Zhou and Bankston 2001). This ties to individuals' identities level as well. Immigrant boys are more likely to adopt a hyphenated identity (such as African American), more likely to encounter negative experiences such as gang recruitment outside the home due to the greater freedom they are given, and have weaker social networks in school. Girls, closely guarded and protected from influences that would negatively impact their schooling, in comparison tend to soar academically (Qin-Hillard 2003; Stritickus and Nguyen 2007; Zhou and Bankston 2001).

In her study focusing on refugee resettlement in Scotland, Gina Netto (2011) stresses the importance of looking at identity as a multifaceted aspect of what defines an individual: that intersections of identity or "multiple identities" based on gender, race, age, disability and so on come together rather than identity being monolithic. Netto also discusses that identity negotiation is a fluid, life-long process and should be understood within the context of migration as multifaceted, situational and fragmented (2011). Other researchers have stressed the right of immigrants to thrive in their new homelands, and that identity construction is linked to the freedom they experience within the new homeland to enact and interpret their identities as they wish (Burdsey 2006; Hussain and 
Bagguley 2005; Song 2003). Netto finds in her study that "place" (or where one is spatially) is as critically linked to immigrant identity as is who one is. In seeking appropriate housing for themselves and their families, refugee and immigrant families often maneuver many barriers: affordability of housing in some cities, racism and discrimination in the rental sector in others, the inability to buy homes due the mortgage process and so on. Where they end up living is critical, be in in a more middle class suburb or in a low-income housing development, as this will determine the type of interactions they will have with the local communities, which will further shape their identities and overall adjustment experience (Netto 2011).

Lastly, in her study on first generation Indian immigrants, Elizabeth Chacko (2015) highlights the role of privilege and social positioning in the outcomes of the adjustment experience overall - and how hybrid identities are formed, negotiated and selectively expressed in different contexts as a result. Indian Americans, according to Chacko, are from a group considered partially assimilated. They arrive in the country equipped with critical resources such as English fluency, higher education degrees, and enjoy a generally higher level of economic success as compared to their white US citizen counterparts. Even prior to their arrival in the US, these immigrants considered themselves as "Westernized cosmopolitans". While in the country they formed deliberately ambiguous hybrid identities and acculturated more selectively in public and private settings. As a relatively privileged immigrant group, they maneuver their new homeland with more dexterity than the average immigrant or refugee, and encounter fewer barriers such as those of racism or exclusion. When they do confront barriers, the impact is significant: as it happens within spaces they thought they belonged in or could 
occupy just as freely, for instance, within work settings where they enjoy more capital or within the white middle-class neighborhoods they choose to integrate through (Chacko 2015). Chacko's study is vital to highlight as, at its very core, it points out that different immigrant and refugee groups experience adjustment and the process of identity formation and negotiation very differently. Some groups are privileged even prior to their arrival by the resources they bring along, blending in on an identity level, while others arrive disadvantaged and more readily "othered" and easily fall prey to social forces within the country that tend to keep them in their place and prevent upward mobility.

\section{Somali Refugees and the Somali Diaspora}

There has been sparse research on the Somali or collective African immigrant and refugee population in Oregon. This section begins by highlighting the handful of studies existing, and then presents the current research on the Somali diaspora within the US, usually focused on Somali immigration hubs such as Minneapolis or Portland, Maine, and throughout the world in the primary resettlement nations.

In their study on refugee resettlement in Portland, Oregon, Hume and Hardwick (2005) discuss the primary refugee groups that have historically and recently resettled in the Pacific Northwest: Russians and Ukrainians who arrived in large numbers before 1990. More recent refugee groups arriving to the state are from Cuba, Bosnia, Vietnam, Cambodia, Laos, Somalia, Iraq, Afghanistan, Syria and Ethiopia. Other immigrant groups that are helping diversify what has been referred to as "one of the last Caucasian bastions in the United States"' (Kaplan 1998) are groups from East Asia and Latin America such as East Indians, coming from states such as California, or Mexicans. Today, Latin Americans form the largest group of foreign-born individuals within the Portland- 
Vancouver, WA metropolitan area at 34.6\%, followed by Asians at 33.5\% (Hardwick and Meacham 2008). Due to the rapid gentrification of older neighborhoods, influx of migrants from neighboring states such as California, and the subsequent spike in housing costs, most refugee and immigrant groups are pushed to finding housing in the peripheral suburban cities such as Beaverton, Hillsboro and Gresham (Hardwick and Meacham 2008). Income and socioeconomic status at arrival in Portland determine what part of the city any immigrant or refugee group will resettle in (often pulled by already existent immigrant enclaves): higher income groups such as South Asians or second generation Vietnamese are able to live in suburbs such as the West Hills or Beaverton. Working class families from populations such as African Americans, Asian or Eastern Europeans can only afford housing in the northeast and southeast areas of the city, which are also presently experiencing a spike in housing costs (Hardwick and Meacham 2008).

The African refugee population in Portland began arriving in the early 1980s (Hardwick and Meacham 2008). Earliest arrivals were from Ethiopia, Somalia, Liberia, Sudan, Chad, Sierra Leone, Togo and the Democratic Republic of the Congo. A portion of recent immigrants from Africa live within the suburban city of Beaverton where a diverse Muslim community exists. Black Muslims from African countries such as Somalia, Ethiopia, Senegal and Eritrea come together for religious and cultural celebrations and services. Immigrants from Afghanistan and the Middle East are a part of this community that identifies primarily as "Muslim" over their respective national background (Hardwick and Meacham 2008).

Portland's Somali population has grown over and have thus been able to organize as a group to seek their needs and represent themselves as a community. They had 
established, a little after a decade of their initial arrival, the Somali Community Service Coalition of Oregon - which was a community center within a rented office space in a shopping center. This support center was established to help the rest of the Somali community with immigration issues, healthcare concerns, job seeking and placement, social services, education and so on. Although this center no longer exists, due to a variety of funding and unity problems within the community, the Somalis have recently come together to form another unified organization to represent them politically and socially: the Somali American Council of Oregon (SACOO).

Hume and Hardwick (2005) found that two important sets of social dynamics affect the lives of African migrants in Portland: their relationships and interactions with African Americans, and those with members of other African immigrant and refugee communities. The larger and more established a group, Hume and Hardwick learned, the less they are likely to engage in pan-African events and community efforts. The larger groups tend to stick with their own, turning to fellow community members in times of need. Cultural, linguistic and religious differences are believed to influence these interactions (or lack thereof), as Somalis tend to identify more with the Arab cultures than they do with West Africans, for instance. Somalis also tend to move to areas that are closer to Mosques and the larger Muslim community. Inner group tensions, such as clanism within the Somali community, further disrupt inter-community cohesion within the African community (Hume and Hardwick 2005).

Hardwick and Meacham (2008) also found that generational tensions within the African immigrant and refugee communities form a primary area of concern within the respective communities. First generation immigrants (parents and grandparents) are 
concerned with the gang affiliation and other criminal elements influencing their youth. This is especially true within the Somali community. The youth speak better English, are more exposed to American life, and have more Americanized ideas and identities compared to their parents, creating a generational rift. This, in turn, affects the ability of the diaspora to maintain critical ethnic networks (Hardwick and Meacham 2008).

In his study on the Somali community, Omar Eno (2008) focused upon the Somali Bantu, a minority group within the community. The Somali Bantu have been a historically subjugated and oppressed people from southern Somalia. They are ethnically and culturally distinct from the Somalis of the dominant-clans. Somali Bantus come from two groups of origin: one that were indigenous to the Shabelle river valley in Somalia and those that were brought into Somalia from the neighboring Tanzania and Zanzibar as slaves for the dominant clans. Somali Bantus have been outcast historically as inferior within the broader Somali community: while the dominant clans controlled the country politically and culturally, the Somali Bantu were never fully integrated into society and were offered very few educational, political or economic opportunities (Eno 2008). The Somali Bantu, therefore, have distinct experiences as refugees fleeing violence in Somalia, and seeking permanent resettlement abroad. There is some important research that draws this distinction between the dominant-clan Somalis and the Somali Bantu when it comes to understanding their experiences of forced displacement, exile and resettlement, such as Hill (2010) and Van Lehman and Eno (2003). The Somali Bantu began arriving in the United States in mid-2003 and have since been lumped together with the rest of the Somali community when it comes to support service provision as well as housing placement. Their experiences of being viewed and treated as outsiders or as 
inferior, however, persist within the local community, and they have lead a largely isolated and independent existence from the dominant-clans (Eno 2008).

In her study on the intersection of gender and identity within the Somali diaspora in the US, Cawo Mohamed Abdi (2014) points out that Somali culture is a largely patriarchal one. The idealized image of men as heads of the household persist within the diaspora, and finds its roots within Islamic gender prescriptions. Post-Colonial Somalia saw women venturing into the labor market to supplement their low-income households. The role of women as economic contributors, however, has largely been ignored in the literature on Somalis (Mohamed Abdi 2014). This has been the case, especially, as the community has experienced an increase in religiosity since the civil war conflict where the religion-inspired images of the man as the breadwinner and the woman as the one running the household have been propagated (Mohamed Abdi 2014). Mohamed Abdi discusses in her study that arrival in the US sees the Somali family unit increasingly dependent on aid and support services as they come with low human capital. This directly challenges the male breadwinner ideal, and diminishes the economic position of the "man of the house" - leading to conflict within the family. Women, on the other hand, understand the new gender economic dynamics within the household distinctly: older generations think more like men and think that economic independence (and related opportunities) for women are a menace as they disrupt cultural practices and the ideal household. Younger women, according to Mohamed Abdi, celebrate the newfound independence and opportunities while acknowledging the impact it is having on the men, and in increasing conflicts within the home and community. Men, in Mohamed Abdi's 
study joked that in the US, there is a hierarch of rights offered to people: women come first, then children, then pets, and men last (2014).

In her study on the immigration experiences of Somali women, Hillarie Kelly (1989) found that there are two groups of immigrant women: one that are part of the displaced refugee "enclaves" and the other a part of the "Republic" who have historically been of means and have travelled as immigrants seeking pleasure and better lives. Kelly found that women from refugee enclaves tend to interact more with women of other cultures and countries while in exile (experiencing greater benefits of expanded support networks as a result) in comparison to those from the "Republic" who tend to stick with other Somalis only. Kelly also draws attention to an often ignored segment of the population: women left behind when their spouses emigrate or are resettled before them abroad. These women rely primarily on the established support networks as well as the extended families to get by as they await joining their spouses. Many find economic independence as a result of this need to survive in the interim: they seek opportunities such as education or jobs to support those left behind with them (Kelly 1989).

In their study of Somali youth in the UK and Denmark, Valentine et al. (2009) explore the identity intersections as Somali, Muslim and English or Danish. They found that since many of the young Somalis they interviewed fled Somalia with their families when they were very young, they had a very abstract recollection of Somalia or what life was like there. Many had no memories of Somalia. They also found that the younger generations often encounter negative representations of Somalia in the media and through other communication circles. This is balanced with positive recollections of life in Somalia at home by their parents and grandparents. The parents' experiences of 
dislocation and homesickness, the researchers argue, make a significant impact upon the children's' identities. The identity of being "Somali" by the youth, in other words, is often formed through "knowing" (or learning indirectly at home) versus "remembering". Somali youth who visited Somalia recounted how they were made to feel out of place or not belonging by the locals who stressed that they had lost their identities. As such, the youth describe having a "confused attachment" to Somalia: belonging because they are told that is where they are from, and yet feeling little to no real attachment to it. Valentine et al. also found that in the diaspora, the presence or absence of a large and wellestablished Somali community affected how the youth identified with their Muslim faith or practiced it. Immigration afforded them and their families a less rigid "supervision" by the rest of the community in how they were doing as "good Muslims". They were able to, thus, create an individualized faith: revising the expectations that worked for them or did not. Some youth, for instance, admitted not doing prayers five times a day as is required of Muslims. Others, overseen by a more established community presence (felt through Somali community organizations, Somali Mosques and so on) feel more pressure to engage in "performative" religion and tend to be more visibly religious: dressing in appropriate attire, attending Mosque regularly, fasting, and so on (Valentine et al. 2009).

Ramón Spaaij (2015) studies the role of community soccer clubs and teams in Melbourne, Australia in his study on Somali youth. He found that male Somali youth find a critical place of belonging within these sports clubs within which they maneuver aspects of their identity as younger members of the diaspora. Spaaia found that intergroup boundaries of identity based upon clan, team and locality tend to be more porous as the youth navigate identity in these settings, while boundaries of gender, religion and 
ethnicity tend to be more rigid. Sports allow newly arrived refugees and immigrants to navigate the integration experience in a unique way: its offers a productive, leisurely and affirming space to make connections, rebuild broken networks, and gradually adapt to the new society. Some studies have linked the role of sports, and youth engagement in them, as a way in which refugees and immigrants try and find their own success story as they arrive in a new country. Other studies and narratives equate sports as a space in which they find exclusion, segregation, and racism. Refugee youth, in other words, might find a space to be productive, find community and mentorship, and "stay out of trouble" within soccer teams, and yet be segregated with each other if it is a "Somali boys only" team (Spaaij 2015).

In her study of Somalis in Minnesota, Kebba Darboe (2003) stresses that immigrants from East Africa often find the concept of racial differences and stratification in the US to be an alien one: they are more accustomed to differences based on other identity based divisions, such as those of nationality or clan. They also encounter an automatic classification in and within the experiences of the African American community, thereby having to negotiate prescribed elements of identity, expectations and prejudice while trying to form their own space and identity in their new homeland. Darboe also found that the arrival status of Somali immigrants and refugees affects their housing experiences and residential segregation. Newly arrived Somalis, who have lower English language fluency, lower levels of education, and different cultural backgrounds tend to prefer to live close to others like them. With time and socioeconomic advancement, these groups tend to move away from each other resulting in decreased segregation. Darboe found additionally that within the community, the parents and elders 
tend to stress the importance of pursuing a higher education and staying out of gangs and trouble to the youth (2003).

Meritt Buyer (2008) found in his study of Somali refugees living in Cape Town, South Africa that clan identity is a deeply persistent element of individual and community identity. Experiencing displacement, poverty, xenophobia, and unemployment, the local Somalis have to often negotiate between the identities of nationality, clan and refugee status as they navigate different spaces and contexts. In other words, there are spaces and times in which the clan identity of an individual takes precedence (usually in interactions within the community) over that of nationality (when experiencing xenophobia and forced to collectively identify as "Somali"). Then there are times when the refugee status takes precedence over the identities of clan and nationality (for instance, when maneuvering permanent resettlement and its barriers). Buyer found that alongside these three dominant identities were vital sub-identities that further took precedence when appropriate. These identities include gender, class, education level, and how they were raised. Two distinct groups existed overall within the sample studied: those who were not interested in going back to Somalia and were seeking permanent resettlement elsewhere (such as those from the minority clans or those targeted in the violence that erupted in Somalia) and those who placed their national identity at the forefront and talked about little less other than one day moving back (usually hailing from the dominant clans or having experienced higher social capital, economic success or opportunities back home) (Buyer 2008).

Understanding cohesion and strength within the family unit is critical to understanding how Somali identity is informed at the individual and community level. 
The family unit is a critical component within the predominantly collectivistic culture. In her study on Somali families of Minnesota, Dianne Lynn Heitritter (1999) found that three elements critically informed the family unit: culture, religion and tradition. Somalis equated religion to culture, and this is expressed in the common Arabic word for both: diin. Religion was seen as a protector of the family within which members found peace and stability and were able to ward off outside influences that weakened the family unit. Within the family unit, the established hierarchy was always to be respected as it brought stability and drew a parallel with spiritual unity. Appropriate role following and cooperation among family members was seen to support broader unity. These beliefs of unity, solidarity and support were extended further to the community level: bringing forth narratives of unity in the name of religion and serving, in turn, a greater purpose of increasing social cohesion amongst the Somalis (Lynn Heitritter 1999).

Shimantini Shome (2011) conducted a similar study to this research project in attempting to understand the adjustment experiences of Somalis in the Kansas City. She found that the traumas and losses Somalis experienced prior to arrival in the US made them tentative and distrustful as a whole. She also found that the age of arrival, for any individual, greatly impacted their overall experience of adjustment: making it easier for those who arrived when younger. Shome also found that the short-term emphasis of the US refugee resettlement program, which emphasizes quick economic self-sufficiency, was an impediment to the long-term economic success of the individuals she interviewed. She also found that arriving with low English language competence impeded the overall economic success of Somalis greatly: those employed in low-wage jobs were not receiving any or appropriate English language training. They were required to take up 
any job they found upon arrival, and the longitudinal focus on their success (by taking up English classes, for instance) was largely ignored. Shome stressed that while English classes are offered to arriving immigrants and refugees, there are many factors that make individuals drop out of classes or not attend them at all: be it financial stressors and the need to be at work, or finding the classes inadequately created and run to match their educational levels, cultural needs, age and disability requirements. Shome also found that employment was largely touted as a primary indicator of successful initial adjustment and something to be proud of, most participants in her study did not have a positive association with working: those working did so in low-end jobs where they could barely afford to pay their bills, and those unemployed were endlessly frustrated at how helpless this made them (2011).

Lastly, in her study on the perceptions and experiences of disability as a social concept within the Somali community, Tiece M. Ruffin (2004) learned that Somalis understand disability through a lens of particular cultural attitudes that find their roots in their religion, history and cultural background. Somalis showed a deep concern for addressing the needs of individuals with disabilities within the community, and acknowledged that the diagnosis and treatment of disability (or support services for disability) were impeded by a lack of access to knowledge and resources. Ruffin advocates for more research and social implementation on the understanding of disability from a Somali-specific context and encourages its exploration in academic and social service settings (2004). 


\section{E. Conclusion}

This chapter reviewed previous literature related to the displacement, resettlement and post-resettlement experiences of refugee populations: with a special focus on the Somali diaspora settled within and outside the US. First, general studies on the refugee displacement and resettlement experience were reviewed. These explored everything from the traumatic experience of displacement to the arduous journey of resettlement, the on-going experience of adjustment after resettlement, the reception of the host countries, expectations of rapid assimilation and independence, the indicators of "successful" integration, the resources and barriers affecting the adjustment experience, the role of resettlement agencies such as faith-based support organizations, the role of religion and social networks in the transition to life in a new country, the mental health needs of newly arrived immigrants and refugees, and the family and relational dynamics they experience as a result of the overall journey.

Second, studies focusing specifically on identity construction and formation and negotiation were reviewed, which explored everything from the meaning of identity and its transformation and negotiation as a result of the resettlement experience to the losses and gains experienced at the identity level in the diaspora. Studies exploring the formation of hyphenated or hybrid identities, the differences emphasized between group or cultural insiders and "others", and the factors affecting identity retention within communities were also reviewed. Lastly within this section of the literature review, studies that explored the unique experiences of refugee and immigrant youth in maneuvering identity formation and negotiation, the gender and class element in identity 
negotiation as an aspect of overall adjustment, and the overall understanding of identity as multifaceted and consisting of many intersections were reviewed.

Third, literature focused on the resettlement and adjustment experiences unique to the Somali diaspora was reviewed: from studies focused on the primary refugee and immigrant groups in Oregon, to the local African refugee population and Somalis specifically. Experiences of the local African immigrant and refugee population, as well as the unique experiences of the Somali Bantu were also reviewed. Then, studies focused on specific elements of the displacement and resettlement experiences of Somalis were reviewed: from the intersection of gender and identity in adjustment, to the economic participation and social emancipation of women; the identity negotiation of youth; the impact of US racial tensions on arriving African immigrants and refugees; the importance of religion and the family unit within the Somali community; intergenerational differences and conflict in experiencing the adjustment experience; the labor force participation and economic woes of the Somalis, and lastly the understanding of disability by the community.

While, as this section shows, there is a rich plethora of existing literature exploring the longitudinal experience of displacement and resettlement of refugee populations (as well as the adjustment experiences of immigrants), there continues to be a need to understanding local refugee and immigrant groups from within the context of their current communities. While the experiences of no two immigrants or refugees are identical, current studies show that some reliable generalizations can be made about populations that share some common characteristics. What gets lost in the narratives is the unique experiences of immigrant and refugee groups when explored and understood 
from within the even more unique context of their arrival and adjustment in a specific community or location. The narratives of the Somali community of Portland remain vastly unrepresented in the current literature, resulting in a primarily silent presence of an otherwise vibrant and driven people. What we know of Somalis locally is what the local news media tells us every now and then when a sensational story is deemed worthwhile to represent one element of the community: assumed to represent anyone. Researchers have rarely ventured into the community and attempted to understand its unique experiences of displacement, exile, pre-resettlement challenges, arrival, and postresettlement experiences. It is vital to know more about how similar and different the arrival and adjustment experiences of the Somalis of Portland are from the rest of the Somali diaspora. It is vital to understand their needs and challenges, and to explore their subjective understandings of belonging and exclusion in the Portland community.

Given these previous studies, I expect that Somalis in Portland will potentially share some important similarities with other refugee groups/members of the Somali diaspora studied elsewhere. They will likely also express some unique differences in their experiences of displacement, arrival and adjustment. I anticipate that as Kunz (1973) recommends, Somalis in Portland will have experienced very different barriers, resources and overall experiences of reception in Portland depending on which "vintage" they come from, or which wave of immigration to the city they were a part of. I have a strong feeling that although I am approaching this study in trying to understand the community's narrative as a monolithic one, their experiences will be very richly diverse.

Knowing more about Somali Bantus, and their experience as marginalized within the broader Somali community, I also anticipate that participants that identify as Somali 
Bantu will have some interesting narratives to share about their outlooks on being perceived as "inferior" and how this impacts them on an identity level. I anticipate some rich reflections based on the intersection of clan identity and minority status.

I also expect participants to share some important narratives on what life was life in the camps, and what the pushes and pulls for resettlement in the US were like. I anticipate that the US was viewed at the best possible place for resettlement (given its earlier international reputation as a land of opportunities). I anticipate that these narratives of anticipation and expectations will be countered with reflections on what actually greeted individuals (in terms of difficulties or disappointments) upon arrival. Central among these narratives of disappointment in the land of opportunities, I have a feeling I will encounter narratives of what it was like to experience the "refugee gap" within the community. Within Portland, I have seen a lot of Somali taxi drivers, and have a feeling that like other cities of resettlement, local Somalis have also experienced a placement within the secondary labor force in Portland. I anticipate narratives of economic difficulties as a result of this.

I also think the local Somalis will potentially share what it was like to be greeted by the predominantly white cultural landscape of Portland as a city and Oregon as a state. Historically, Oregon has not been a diverse place to live, with exclusionary laws in its past, and current experiences of neighborhood gentrification as well as the dominant presence of white supremacist hate groups within the state. I anticipate that the local cultural context of Oregon was not shared with the community prior to their arrival here, within the orientation within the camps. 
I also anticipate reflections on what it is like to work with and receive services from Christian support organizations like Catholic Charities and Lutheran Social Services locally. Being predominantly Muslim, I feel the Somalis will have some rich narratives to share about what it is like to rely on these organizations for assistance. I feel that they may be some experiences of ambivalence towards religious differences, while other strong experiences of discomfort in dealing with Christian groups. I also anticipate some rich narratives on what it is like to set up Somali community organizations in a bid to seek more community-driven representation and service provision. I have a feeling, given the historical clan-based divisions within the community, there might be some interesting reflections on how community "elders" are selected; if minority or minor-clan groups are included at the administration level; or if all the clans' needs and priorities are represented equally. I anticipate that, at some level, there is bound to be some exclusion and underrepresentation which would impact the community's unity as a whole - and therefore their ability to unite as and under a singular organization. I also anticipate learning about individuals from the community who currently work within the local faithbased and secular support agencies.

It is also possible that narratives of networks within the community will be just as rich: that there were some preexisting networks they could rely upon during their early arrival to the state (other African groups already here, for instance), and how these networks have evolved over time. I anticipate that the Somali networks today are much more transnational and organized than they were in the past. I also anticipate that within these broad networks will be some well-defined or informal sub-sections of networks: those specific to the women of the community or the elders, for instance. 
It is also possible that because of their difficult experiences of displacement, and the continued barriers within current adjustment, local Somalis also experience some unmet needs when it comes to mental health. I anticipate that mental health concerns are vastly undiagnosed and not prioritized within the resettlement services system. It is likely that there are perceptions of mental health needs as secondary on a cultural level, and that the community has not experienced much education or culturally competent care when it comes to mental health.

It is also possible that like other Somalis studied in the literature, and other refugee/ immigrant groups discussed, local Somalis also maneuver an innate fear of loss of culture: especially when it comes to the different experiences among the generations. It is possible that parents and grandparents worry quite a bit about their children not following their cultural ways or becoming too Americanized. I also anticipate that there are some challenges to the evolving identities of women and youth who end up challenging the traditional religious or cultural confines. I feel that gender based narratives of individual emancipation will find great representation within this study, and that local Somali women will likely experience a lot of freedom within spaces such as school or work, while being exposed to traditional patriarchal norms and gender confines within the home.

It is also possible that local Somalis maneuver the incredibly difficult and unaffordable local housing market via some critical identity negotiation: they likely cannot afford rentals or buying homes and this in turn segregates them residentially. I anticipate that this residential segregation further impacts their overall experience of adjustment within the communities they are surrounded with. 
Lastly, I also anticipate that local Somali youth may have some important reflections on what it is like to being a Somali-American, Muslim-American or AfricanAmerican. It is possible that they experience exclusion and a lack of belonging within the African American community locally. It is possible that local Somalis experience the concept of race in a very distinct way: being minorities on many levels and being relatively new arrivals to the state.

The next chapter will describe the methods employed in order to explore and understand the arrival and adjustment experiences of the local Somalis. 


\section{Chapter IV}

\section{METHODOLOGY}

The methodology employed to examine the experiences unique to the Somalis of Portland, Oregon is presented in this chapter. It is divided into four sections: selection of participants, sampling shortcomings, data collection, and data analysis.

A qualitative approach was adopted for this study for many reasons, the core being intentionally giving a voice to a marginalized population that lives in the peripheries of society within their new country (Ragin 1994). As black, Muslim immigrants, experiences of barriers and triumphs within the Somali community are seldom sought or heard about unless they are within the context of newsworthy topics such as crime, violence or terrorism. There is currently, within the country, a biased onesided portrayal of immigrants and refugees that focuses on the negative aspects almost entirely, and when this is done, the narratives and opinions of the communities spoken about are rarely sought and included (Ernst 2013). As such, it was deemed extremely vital for this study to focus on seeking narratives and opinions directly from the crosssection of the population it intends to understand and speak about. In doing so, this study aims to empower Portland's Somali community by giving them a voice to express their individual subjective experiences, and by providing them with a culturally responsive research participation experience.

As this research, a descriptive cross-sectional case study, seeks to understand the arrival and adjustment experiences particular to the Somalis of Portland, Oregon, it utilized in-depth semi-structured interviews as a data collection approach. The use of in- 
depth interviews relies upon the establishment of an authentic relationship of trust between the researcher and participant, and is aimed towards attaining a mutual understanding of a unique experience (Karnieli-Miller et al. 2009). The data collection method chosen also acknowledged the social location of both the researcher and the study participant. Although the researcher shares some important common experiences with the study's participants: being an immigrant, a person of color, a non-Christian within a predominantly Christian nation, and a fellow African from Kenya, there are other vital aspects of cultural identity that are not shared. As such, the adoption of the data collection method was done with the intention that it would, hopefully, assist in bridging a cultural divide.

The primary research questions that are addressed by this study are: what factors influence(d) the arrival and adjustment experiences of the Somali community of Portland; what does the process and experience of adjustment look like for the community; and how do these factors and the overall experience of adjustment influence the formation and negotiation of individual and collective identity within the community. Additionally, this study also seeks to understand how the needs of the community are met when it comes to support services and other resources for adaptation.

\section{A. Selection of Participants}

Upon receiving IRB approval for the study, it became clear that the next step would be to access the Somali community and seek participants. Although the community, a numerical and cultural minority in Oregon, is somewhat visible, it is also largely insular and hidden. As such, the immediate dilemma was to access the 
community, establish rapport, and recruit participants: all within the constraints of the study's timeline.

My initial approach was to identify and contact support and advocacy agencies such as IRCO (Immigrant and Refugee Community Organization), SOAR (Sponsors Organized to Assist Refugees), CIO (Center for Intercultural Organizing) Catholic Charities and Lutheran Community Services Northwest (LCSNW). I made the assumption that the best way to connect to the community would be to focus on sites they would likely frequent as service recipients. I explored the websites for these organizations, and sought out five individuals I identified as cultural brokers or "inbetweeners" who were African immigrants themselves, but worked within a service provider capacity in immigrant and refugee support organizations locally. In my e-mail and phone messages to them, which I followed up on diligently over the course of three weeks, I would introduce myself, and state my intentions, and request their assistance in connecting me to their clients who were Somali.

I also created and included a flyer titled "Our Story in Our Voices: A Study of the Somali Community of Oregon" (See Appendix A), which used very basic language so as to be accessible to non-native English speakers. The flyer outlined, briefly, a description of me, the study, and why I thought it would benefit the community. It also outlined the criteria individuals had to meet in order to participate in the study: be a member of the Somali community and be 18 years of age or older. I did not hear back from most individuals from the agencies and the one individual who set up a meeting with me, ended up having to reschedule it indefinitely. 
In the meantime, I also reached out to groups catering to African international students and students of African-descent both at Portland State University (PSU) and Portland Community College (PCC). I assumed that I would receive better consideration within these academic settings, as individuals are probably more likely to support a research effort. At Portland Community College, I contacted and was supported by an individual within the Multicultural Academic Program (MAP), an academic transition program that provides English language training and other support services for students to aid with high school completion, and application to PCC. The individual at MAP offered to share my flyer and e-mail message with the handful of Somali students enrolled in their program. I also contacted the Association of African Students (AAS), a student group at PSU, asking them if they would be willing to share my recruitment information with their members. I did not hear from any individual willing to participate, either through MAP or AAS.

Changing strategies, I then tried to identify common meeting and gathering spaces, both within the city and online in the virtual world, that I could get the word out on the study in, directly to the community. I found out from doing some research online that a local coffee shop in Northeast Portland, Caffe D'Arte, was a popular meeting space for Somali men. I printed out about 50 copies of the study's flyer, and left them at cashier's counter. I also researched community pages and organizations for the Somali community online and on social media, and found three local groups on Facebook. I posted comments on their main pages, and private-messaged their members directly requesting their participation, and attaching a copy of my flyer. Noticing the online presence of the Somali community, I also created a Facebook page advertising the 
research study (so as to encourage easy sharing online with any potential participants through "invites" to the page by the groups already on Facebook, or by other Somalis or Africans locally). I did not hear back from anyone from either the coffee shop or via Facebook.

At this point, I had to completely re-evaluate my participant recruitment strategy, as nothing seemed to be working to grant me access to the community. People were, seemingly, aware of the study but choosing not to participate. As a fellow-African, I had the benefit of having a cultural understanding of what it might take to gain access to the Somali community. I knew I very likely had to identify "elders" within the community who would vouch for me. Being an “elder” does not refer to a person's chronological age, but is a culture-specific way to refer to individuals the community knows well, respects and trusts.

Using this gut feeling, I began by looking for "elders" close to home: on the Portland State University campus. It turned out that the person I was seeking was much closer at hand than I had anticipated: one of the members of my thesis committee, Dr. Joseph Smith-Buani. I had approached Dr. Smith-Buani to be a part of my committee because I saw, on the university's website, that he was a fellow-African immigrant, an esteemed professor of Black Studies at the University, and someone who was both dedicated to, and had extensive experience in local research focused on the African diaspora. I requested Dr. Smith-Buani to think about any potential connections he might have with other "elders" within the community. Within a matter of days, I was sitting across Mr. Djimet (Jimmy) Dogo, the Director of Africa House, a program and support center within IRCO. Dr. Smith-Buani was also at this informal meeting, which took place 
at a local African restaurant, and told Mr. Dogo that his help was needed in supporting this student (me) to complete his Master's thesis. Mr. Dogo, a longtime friend of Dr. Smith-Buani, asked me how many Somali individuals I was hoping to interview, to which I replied, “As many as I can!” He then told me to expect a phone call from him connecting me to people he knew.

Within a matter of two weeks, three individuals contacted me, telling me that $\mathrm{Mr}$. Dogo had recommended they participate in the study; that he had vetted and vouched for me; and that they wanted to learn more. Thus, due to necessity and sheer luck, a snowball sampling method of participant selection was adopted for this study. Word spread fast, and I ended up interviewing 17 individuals in a matter of 3 weeks: 9 identifying as female and 8 as male. Mr. Dogo had referred a total of 7 participants, while the rest were recommended by each other.

Table I, on the next page, outlines the primary characteristics of the participants. Some important identifying details are intentionally omitted from the diagram because individuals were assured of complete confidentiality if they participated in the study. Many mentioned concerns on being identified within the numerically small, collectivistic community. Most were wary of participating in the study due to a variety of possible repercussions as an outcome of being identified by other Somalis. These concerns are also omitted out of respect for the participants and the community. Confidentiality was a special concern for those working in leadership and employee capacities within community and support organizations. As such, to protect the identity of all participants, the diagram outlines only basic characteristics. 
Table I: Sample Characteristics

\begin{tabular}{|c|c|c|l|c|c|c|c|}
\hline Alias & Gender & Age & Education & $\begin{array}{c}\text { Arrival } \\
\text { Year }\end{array}$ & $\begin{array}{c}\text { Age at } \\
\text { Arrival }\end{array}$ & Arrived With & Generation \\
\hline Haweeyo & F & 25 & Bachelors & 1997 & 5 & With Family & 1 st \\
\hline Ayaan & F & 27 & Bachelors & 1995 & 5 & With Family & 1 st \\
\hline Beydan & F & 26 & Bachelors & 2000 & 9 & With Family & 1 st \\
\hline Abdalle & M & 32 & Graduate & 2001 & 16 & With Family & 1 st \\
\hline Hibaaq & F & 29 & Bachelors & 2004 & 16 & With Family & 1 st \\
\hline Fadumo & F & 30 & Graduate & 2004 & 17 & With Family & 1 st \\
\hline Abshir & M & 36 & Bachelors & 1998 & 17 & Alone & 1 st \\
\hline Cabdi & M & 28 & Associates & 2001 & 12 & With Family & 1 st \\
\hline Daahor & M & 32 & Graduate & 2004 & 19 & With Family & 1 st \\
\hline Yasmiin & F & 30 & Associates & 2009 & 22 & With Family & 1 st \\
\hline Aamina & F & 31 & Bachelors & 1996 & 10 & With Family & 1 st \\
\hline Amiir & M & 42 & Associates & 1996 & 21 & With Family & 1 st \\
\hline Leylo & F & 38 & Graduate & 1993 & 14 & With Family & 1 st \\
\hline Khaalid & M & 48 & Graduate & 2003 & 34 & Alone & 1 st \\
\hline Mahad & M & 44 & Graduate & 1996 & 23 & Alone & 1 st \\
\hline Guuleed & M & 55 & Graduate & 1981 & 19 & Alone & 1 st \\
\hline
\end{tabular}




\section{B. Sampling Shortcomings}

It is important to note some important shortcomings in the sample I was able to recruit for this study. The group of participants represents a narrow cross-section of the current Somali community of Portland, i.e. individuals between 25-55 years of age. Most the participants either arrived to the United States as children/teenagers or as young adults (thereby as part of the first generation of migrants within their families). All of them had received some level of higher education. They also represent a section of the population fluent in English, and were thereby able to fairly and accurately reflect on their own and their parents' experiences without any linguistic barriers impeding the interview process. The sample, however, lacked any participants from the older generation of Somalis, i.e. the parents and grandparents who navigated the resettlement experience and arrived alongside their children and grandchildren. The experiences of this older Somalis were shared indirectly by the participants, i.e. their children and grandchildren, and are included within this study's findings.

It must also be noted that the participants recruited for the study represent another distinct cross-section of the community: individuals who are willing and able, and also motivated to be heard and be representatives and cultural ambassadors for the Somali community. This trait became prominent within the interviews as many shared that it was important for them to speak about and share the experiences of the community. Accordingly, the narratives unique to those segments of the Somali community hidden to the media and to academic researchers like myself, were potentially missed once again. Many of the participants also declined to share their clan identity, for various reasons, 
and it is therefore impossible to draw any conclusions based directly on unique clan identity as it relates to arrival and adjustment experiences.

\section{Data Collection}

\section{i. $\quad$ Collection Method}

All participants initially contacted me via e-mail, and I was able to share my flyer with them, along with a standard message outlining what the study was about, what the time requirement for an interview would be, and that I could meet them at a location, date and time of their choice.

When scheduling a time to meet, I would also attach two copies of the Informed Consent Form (see Appendices B and C): one of the copies would be in English, the other translated to Swahili. It was assumed, at the time of contacting participants that those with difficulties understanding English would have better familiarity with Swahili, a language spoken and shared commonly throughout East Africa (where both Somalia and Kenya, where I am from, are geographical neighbors). I later learned that not too many Somalis retain much usable knowledge of Swahili, especially those who lived in Kenya for a handful of years, and within refugee camps full of Somalis, where they did not have to learn or rely upon another language). I learned that it might have been better to seek someone online, or within the community, to translate the English version of the Informed Consent Form directly to Somali for the access and clarity.

I met each of the 17 participants in various locations throughout the city for the interviews, depending on their choice and convenience: I met some on campus at Portland State University, others at coffee shops, and others within service agencies. Interviews lasted between 45 minutes and 1 hour, were semi-structured and were kept 
conversational so as to facilitate the formation of rapport between me and the participant, and also encourage free sharing of information they felt was most pertinent. At the start of each interview, I would review the Informed Consent Form with participants, and ask them if they had any questions. I would then ask them to sign it or mark with an X if they decided not to sign their name. I would use this to reiterate the participant's right to confidentiality within the study, and their right to decline to answer any question or end the interview at any time. Additionally, I would stress that I am approaching this study from an objective and respectful perspective, wanting primarily to share the experiences and narratives of the Somali community with the rest of Portland and beyond. To further assure participant confidentiality, I would ask participants to choose a pseudonym they wanted me to use when referring to them in my thesis. Many declined to do so, while others were excited by the prospect of an "alter ego" that could speak their mind. All but one of the interviews were audio taped using a digital voice recorder: one participant expressed concern at the recording of the interview, and I offered to take notes instead, as she spoke, so as to assure her confidentiality.

\section{ii. Interview Guide}

The interview guide (see Appendix D) focused on gaining information from participants based on five primary topics (Sections A-E), each focused on addressing a unique component of the Somali community's arrival and adjustment experiences: A. demographic characteristics of the participant, B. their own and their family's experience of moving to the US and to Portland, C. the local Somali community and what made it and its interactions with the rest of the community unique, D. local service agencies and 
experiences of receiving support services from them, and E. recommendations for improvement of services within these. A separate topic would focus, loosely, on any other things a participant would want to add, clarify or ask me questions about.

Data were gathered within the interviews using loosely structured, open-ended questions that allowed for longer narratives from the participants. This allowed me to listen closely to which themes or topics each participant found most salient about their identity, arrival and adjustment experiences and probing more deeply about those for more data. I found that this style of interviewing allowed for a more conversational flow to the process, which made it more approachable and relaxing to all participants. It also allowed me to show a genuine interest in the participant's narratives, and allowed me to take pauses to empathize, reflect and check in on narratives that were difficult to talk about (such as experiences of displacement trauma) or those participants were not sure they could share safely (such as opinions on clan divisions within the community). Maneuvering the more "difficult" aspects of the interviews became easier with each interview, and allowed me to respectfully and tactfully probe for more information, while triangulating for data received from other participants, thereby cross-checking important facts.

Section A of the interview guide consisted of several closed-ended questions intended to elicit basic demographic information from participants: their date of arrival in the US, for instance or their religious background. I would also ask participants to rate their level of religiosity on a scale of 1 to 10: 1 indicating being least religions, and 10 being the most. This question elicited some exciting information, very early in the interviews, on religious identity and dynamics. This section also consisted of a question 
asking about clan affiliation, which I quickly realized put people on the edge, and made them suspicious of my intentions. I, after the first interview, made this one of the last questions to ask. Within this section, I also asked about level and types of participation within religious and other community organizations. This elicited critical information on other aspects of a participant's life: such as their other social obligations and barriers towards volunteering or giving back in some settings.

Sections B and C began the open-ended and chronological and biographical side of the interview guide. Within Section B, questions focused entirely on the experience of moving to the United States. It is within this section, during the initial 2-3 interviews, that I learned that all participants wanted to share experiences related to their life prior to arrival in the US: their displacement narratives, life in refugee camps, and also the application process that is tied to resettlement consideration for the thousands of refugees living in camps around the world. In subsequent interviews, I made a deliberate space for including these narratives by saying: "Please feel free to include anything about what it was life for you and your family to make it to the United States, and what life was like back home." The mention of the word "home", I learned, elicited a very strong emotional reaction that led to some deep reflection, and sharing of how the meaning of "home" had shifted.

As a continuation of Section $\mathrm{B}$, Section $\mathrm{C}$ focused on learning more about what the local Somali community looked like, what made it unique. It also sought to learn how the participant, as an individual, related to the community. I also included questions on initial barriers and discrimination participants experienced upon arrival in the US, and in Portland. Again, this led to some rich narratives. Within this section, I noticed that 
mentions of remittances to family members and other loved ones back in Somalia and Kenya came up organically. It was my first indication that the Somali community was a part of a larger, global network of communities. Accordingly, I adjusted my interview protocol make sure to ask questions to probe about this "global network".

Section D was initially designed to be the "meat and bones" section of the interview guide. I assumed that the most important information I would gather would be regarding interactions with support agencies as well as reflections on unmet community needs as tied to resettlement experiences. I quickly realized that due to the intrinsic nature of the sample I was working with, most of the questions I had initially gone in with did not really apply to the participants. All participants were individuals who had either arrived with their families when they were very young or those who had arrived as immigrants (not as designated refugees) or under alternative visas such as student visas, or even those who had been removed from the support resource-acquisition process for a variety of reasons (for instance, it was the duty of the older sibling to seek out the local English language classes for one participant).

I attempted to revise this section to elicit information on what they knew or remembered about their parents and their families' or friends' experiences on dealing with support agencies or the other actors within the resettlement system. I found that the narratives, while very helpful, were not as detailed as I had anticipated. I was able to learn, however, about what some current unmet needs of the local Somali community are, and also had most participants share their thoughts on what support agencies could do to work with the community better. These suggestions were based on their own experiences 
as community members, as well as what they had heard about difficulties in working with support agencies from people they knew.

The interview guide, as a result, had become a rapidly evolving document, one that I tailored to each participant and conversation, depending on what I learned from them as well as the role they played within the community (for instance, if they were a cultural broker within a support agency, or a single young mother, or a young male aspiring to lead the local Mosque one day). One question that elicited a lot of rich information was "If I were somebody who had all this grant money, and wanted to set up a support program for local Somalis, how would I spend the money?"

Section E flowed as a natural continuation of the previous section, with me probing about more recommendations for various social actors in the community that impact life for the Somali community: barriers such as discrimination, racism, Islamophobia and gender-based discrimination were probed greatly in this section. I would also ask participants to reflect upon if they had a chance, whether they would move to Portland again. This would elicit some very interesting information: from fondness for the city in some cases, to outright disappointment in others.

I would wind up the section by asking participants about any advice they might have for Somalis who have not arrived in the US and Portland yet. This prompted them to reflect upon what the primary difficulties as well as resources available to them were during their own arrival. I would probe any interesting information that arose within this section; for instance one participant mentioned that people should not expect that machine in the wall that spits money out at you. Upon probing, I learned an in-culture 
joke about Somalis back home thinking that the US was full of these machines (which, I learned were ATMs) that just spewed cash out, and everyone was so rich!

The final section, Section F, consisted of closing components. I would wind up the interview with very open-ended questions such as asking participants if they wanted to add anything else they thought I should know. I learned, towards the third interview, that this was the point of the interview most people were tired and ready to be done, so I revised the question a little bit: "Say I am a news reporter and am putting together a story about the Somalis of Portland. What do you think I should share with the rest of the community?" This would elicit some deep and thoughtful narratives on collective identity within the Somali community, and also highlight some critical needs the community had: such as the need to be understood and included by others.

\section{iii. $\quad$ Concluding Interviews}

Towards the end of each interview, I would ask all participants a standard question: What else would you like the rest of the world to know about the Somali community of Portland? This facilitated a nice way to end the conversation that allowed for exploration of community or individual identity that were most important, personally, to the participants. It also allowed for some follow-up questions on my end.

Each interview was ended with turning the recorder off, putting away notes, and thanking the participant for their time. I would also ask participants if they have any questions for me. Most declined to ask any questions, but two participants asked me what I intended to do with my findings, beyond my Master's thesis. Three participants also thanked me for engaging this study. One told me how they were happy that a non-Somali 
was doing the study, so they would be more objective, while the other (very encouragingly) told me that they could tell I would do justice to the narratives, because they could tell I had respectable intentions at heart. One participant acknowledged that they felt included in a study exploring their community, that typically people have the tendency to write and speak about the community without approaching it for context or clarification.

This brief and informal time spent with participants after interviews would sometimes yield other critical information. One participant, for instance, went into great detail about the history and chronology of the establishment of the Somali American Council of Oregon (SACOO), which is the singular organization aiming to represent all Somali clans under one umbrella. The participant shared their own experience as a formative member, and the barriers and limitations the founders faced as a result of disunity and distrust within the community. Another participant shared how difficult it was for them, as a cultural broker within a support agency, to meet the sometimesunrealistic demands for service by fellow community members. Another participant shared how torn they were between cultural demands for supporting their retired parents versus dealing, individualistically, with their responsibilities towards their own nuclear family.

I would conclude each interview with offering each participant a resource guide (see Appendix E) that I had created for the study. This list was loosely based around support services available to the community within the city, and included a link to a more comprehensive resource directory (for immigrants and refugees) created by Lutheran Community Services. I would also ask each participant if they would like to stay in touch 
and receive a copy of my Master's thesis when it was written. All participants agreed to this and encouraged me to share the findings with them when I could. All participants showed a genuine excitement in learning more about what I learn from the data.

It was towards the $15^{\text {th }}$ interview that I felt that the data had reached saturation, that narratives were beginning to sound repetitive, and that very little new information was being acquired from the interview process. I decided to interview the last two individuals who had already set up a time to meet, and use these interviews primarily for triangulation of data, as well as clarifying any specific information I had realized as pertinent. One question, for instance, I would ask in the last two interviews would be focused upon the 3 waves of Somali immigration to Portland - and what the participants knew about the distinct experiences of people that arrived within these waves.

\section{Data Analysis}

The qualitative analysis of data, for this study, consisted of evaluation for similarities and differences, coding and thematic categorizing and triangulation, as well as continual comparison. This section outlines the process of analysis in its entirety.

All digital audio files for the interviews were stored on a password-protected device only accessible to me. The interviews were all transcribed by me, as well, and to protect participant confidentiality, I removed any mentions of names and other identifying information from the transcripts. I also assigned aliases to each participant (if they had not already chosen one themselves). Upon completing transcription, I printed out three hard copies of each transcript for initial review and preliminary coding. I began by reviewing each transcript line by line, coding anything that stood out to me as 
important. This initial phase of coding was very loosely oriented towards anything I felt the participant was trying to highlight.

Issue-focused analysis became the method of conducting a secondary review and coding of the data (Weiss 1994). Within this phase, the focus was upon identifying similarities and differences within the similar experiences of the participants. I uploaded the transcripts to Dedoose, a web-based qualitative data analysis software, and conducted a secondary coding using the initial codes identified, as well as other codes found within the literature reviewed. This secondary coding involved refining the initial codes into broad conceptual categories that found their root within the interview guide. The following categories were derived from the secondary coding:

\section{Basic Descriptors}

This category contains data on basic demographic information on participants, such as their age, martial status, religious background, number of children, city of residence, total household number, year of arrival, occupation and so on.

\section{Pre-Arrival}

This category focused on all information provided on experiences prior to arrival in the United States. It was important to consolidate the information in this way so as to form a chronological foundation from which to assess the data. Experiences within refugee camps, for instance, and mentions of difficulties in maneuvering the resettlement application process were categorized here.

\section{Adjustment Resources}

This category contains participant's self-reported resources that aided them and/or continue to aid them with the adjustment process. It was important to separate this 
category from that of barriers due to the sheer number and types of resources and barriers mentioned. Resources included things such as social capital, presence of early immigrants, monetary aid from support agencies, and linguistic ability and education.

\section{Adjustment Barriers}

This category is similar to the one on resources but focuses on barriers such as family separation, poverty, housing, racism, and SES loss.

\section{Support Agencies}

This category includes all mentions of support agencies as a critical component of the resettlement experience: participants' mentions of how the agencies and their work helps or impedes the adjustment experience were categorized as such. Also included were any mentions of how support agencies could improve their work.

\section{Community/Networks}

This category was created as a separate one (as networks can also be understood as an adjustment resource or barrier) because there were some specific mentions of how the Somali community needs to be viewed as multiple communities rather than a singular one, and also as a global entity comprised of many intersections. This category helped consolidate any identity oriented mentions of the community.

\section{Needs}

This category outlined any specific current community needs mentioned by participants. It was important to differentiate these early as they were often mentioned with passion, and sometimes as an afterthought. Participants made it clear that the needs should be highlighted, as a whole, within my findings, so I created a separate category for them. 
8. Identity: Clan, Gender, Family, Youth Elders, Religious Participation, Parenting

This category became a way to consolidate mentions of issues such as parenting, individualism versus collectivism, religious identity, gender dynamics, youth versus elder experiences, clanism and so on. This was the first point in which I realized that a broad category of "identity" nicely consolidates many of these issues.

\section{Case Worker Narratives}

Some of the participants interviewed were, as mentioned above, cultural brokers working within support agencies. They shared some very candid opinions on what it was like to work with fellow Somalis who came in as service recipients. Some also made recommendations on how fellow Somalis could better service recipients. These narratives were categorized separately as they stood out as distinct from the rest of the data.

\section{Post-Arrival}

This category included all experiences related to the Somali community as it is seen and perceived today. Mentions of hopes for future generations, as well as worries for how the current youth and elders were navigating their own adjustment were categorized as such.

All of these categories were then triangulated within Dedoose by use of colorcoding that represented the various themes emerging from the data. For each of the questions asked within the interviews, a theme was determined. These themes were then cross-compared further for analysis. Lastly, emergent themes from the data were also compared to the existing literature on refugee resettlement experiences, as outlined in the Literature Review section. 
As a result, the following final themes were determined to be succinct representatives of all categories previously identified:

1. Arrival

This broad theme included all categories related to arrival pre-arrival and arrival narratives.

\section{Adjustment: Barriers and Resources}

Focusing upon adjustment as a distinct experience, this theme focused upon which barriers and resources affected adjustment, and how.

\section{Adjustment: Identity and Social Roles}

Further focusing upon adjustment, this theme isolated both identity as expressed within different categories, and related social roles identified across categories.

\section{Community Needs}

This theme was carried forward from the previous category and included both recommendations for improvements for support agencies and actors, as well as current unmet needs of the community.

\section{About Us}

This broad theme was used specifically to highlight reflections, as tied to collective and individual cultural identity that were specifically mentioned by participants, and did not fit into any other themes.

In addition to coding and thematic categorization, I also created several schematic diagrams to help me understand the data using a more visual method. These helped, profoundly, in two ways: first, they helped me view the narratives from a chronological perspective: highlighting elements that were important to participants and relating events 
to one another. Second, they also helped me recognize that an overarching way to understand and consolidate what was being shared in all the narratives was using a lens of identity. How identity best informs an accurate understanding of the data, as well as the final diagram created to represent the overall findings from the data are discussed in the next chapter on Findings.

This chapter restated the underlying goal of this study, and outlined the details of its research design and methodology. After explaining why a qualitative study was essential to adequately meet the overall goal, it discussed the selection of the participants. The 17-participant sample was acquired using snowball sampling, initiated by a community "elder" who worked in a support agency. Limitations of this sample were also discussed. Lastly, this chapter also outlined the process of data collection and analysis: highlighting how the formation and refining of categories and themes helped build connections between the primary findings and relevant literature. 


\section{Chapter IV}

\section{FINDINGS}

This study investigates the arrival and adjustment experiences of the Somali community of Portland, Oregon. It aims to understand holistically the longitudinal process of refugee resettlement as it applies uniquely to Somalis living in and around Portland. This includes the barriers and triumphs that guide and result from the initial experience of displacement from the home country, Somalia, to eventual "successful" adjustment to life in the United States. In the introductory chapter, three research questions are introduced: the first asks what factors influence the arrival and adjustment experiences of Portland's Somali community; the second asks what the process and experience of adjustment looks like for the community; and the third question asks how these factors, and the overall experience of adjustment, influence the formation and negotiation of individual and collective identity within the community.

The participants in this study responded to these questions in a variety of ways, however some common themes emerged that indicate that their experiences share vital common attributes. This chapter presents these attributes, addressing the three stated research questions, as explained by emergent themes from the data. These themes are highlighted using quotations from the research interviews conducted with study participants.

\section{A. Overview of Findings: The Resettlement Journey}

America is not really what you picture it to be. There's a lot of responsibilities and there's a lot of consequences. America is 
whatever you make yourself to be. If you want to be someone that is dedicated and focused, you can be that. If you want to be someone who's careless, it will make you that - and will break you in the process of it. You have to be determined, you have to be on point and focused, you have to be a go-getter. You have to be careful not to lose your identity here. Don't think America is heaven. For everybody, being in their own homeland, that's real paradise.

- Aamina

In discussing their narratives of leaving Somalia amidst civil and political unrest, narratives of forced and necessary adjustment and adaptation were a common, central theme among all participants. Adjustment was discussed both as an outcome of the difficult resettlement journey, and an important driving force guiding it. For each participant, the journey was influenced by certain factors, some common among all participants, some unique to the individual. An overarching theme of "perseverance" or "survival" was used to explain the difficult journey, which typically constituted of: the trauma of displacement and loss of home and/or family; moving to a host country like Kenya; living in refugee camps or with relatives and friends; maneuvering the lengthy and arduous process of applying for refugee placement through the UNHCR;

experiencing the surreal journey of traveling to the United States, and then navigating the sea of services and support providers while learning the ropes and starting to build a life for oneself and one's family. As Ayaan shares:

I feel like us Somalis, we don't fall. Whenever I meet another Somali person, we just have that hope. They're not willing to give up that easily. They're always trying to find a way to make it work, you know?... When we come here, we face many challenges, people don't treat us like the way we are used to, there are more bad days than good days, and we don't always get what we need. We just learn to work with what we have... We never give up. 
Beydan added her own impression of the Somali diaspora:

I think we are very resourceful and hardworking people, you know... Somalis are scattered all around the world, and they've just somehow managed to adapt and get settled and to just thrive, and I think that's amazing, you know? We are devastated as a country, the government is not functioning, and all these terrible things are happening. At the same time, you know, the people that are lucky enough to leave, somehow have just managed to make a strange land their home. And they're helping the economy, they're starting businesses, they're doing all these great things in a land that's not familiar to them, to their ancestors, you know? Where they have no roots at all. So I think that is pretty amazing.

The journey of resettlement, represented by the central themes of arrival, barriers, resources, adjustment and unmet needs, is summarized in the diagram below.

Figure III: Overview of Findings

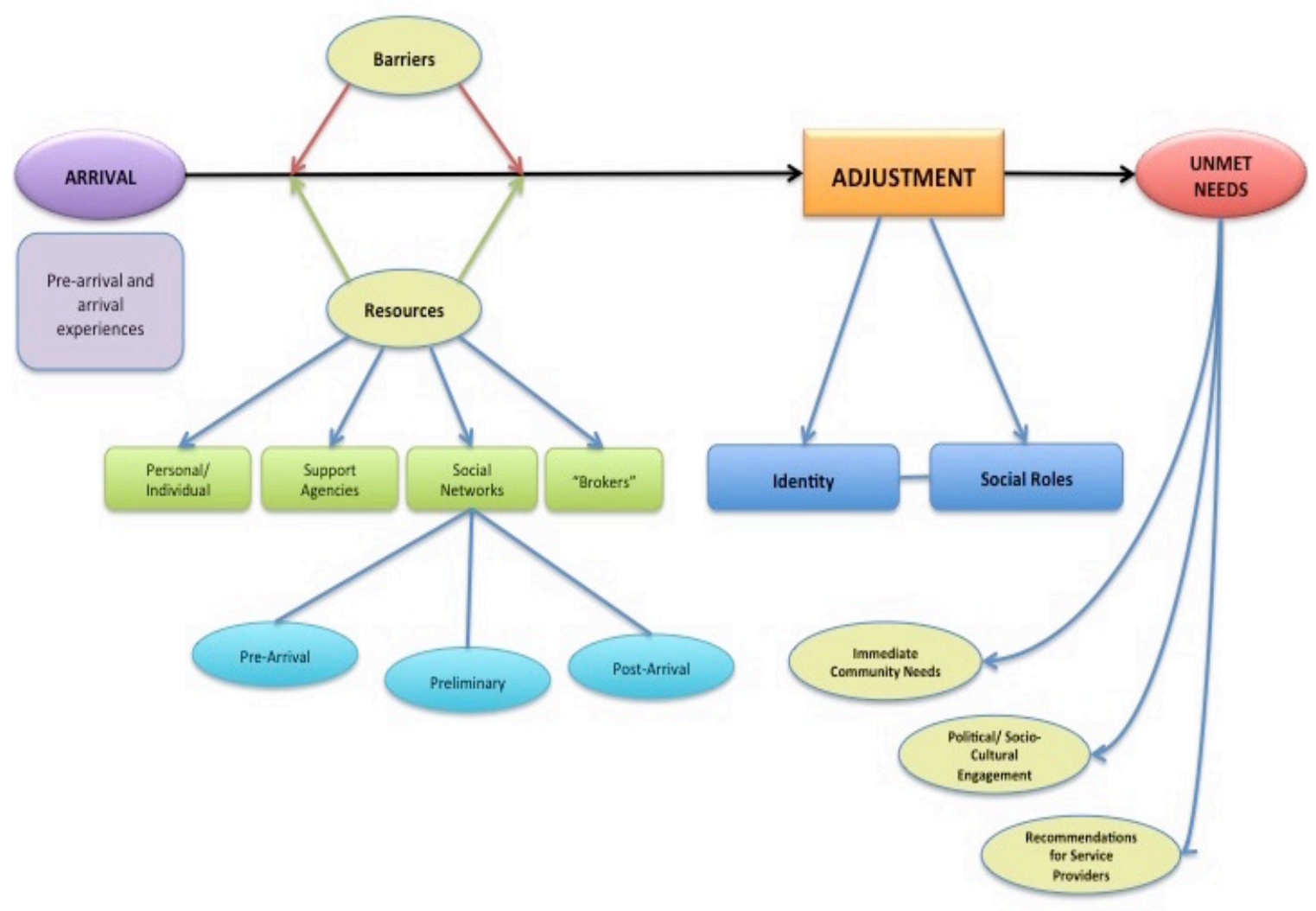


Narratives shared by participants indicate that the adjustment process begins much earlier than one's arrival in the United States when they are labeled as a "landed refugee." Adjustment begins at the moment of displacement and is affected by various important resources and barriers that are experienced by the displaced individual and their family. Personal resources such as a positive outlook (alluding to an underlying spirit of perseverance), an inner drive to seek out resources and support services (such as maneuvering the murky waters of refugee selection), as well as other resources including collective social capital (one's family name or standing in the Somali community of origin) play important roles in pushing an individual towards successful placement overseas or to a better quality of life in the in-between world of refugee camps.

The variable ability to find and mobilize resources is reflected in the lack of a typical time between being displaced and resettled. While the resettlement process took some participants upwards of 10 years, it took others merely 2-3 years, for a few, even less. How well one was equipped to navigate the process, the resources one had accrued (such as connections within the United Nations), as well as sheer luck seemed to guide how quickly one would be placed overseas. Hibaaq shared her own family's experience with placement:

Well if you are not coming as a refugee, if say like I have a cousin or someone who lives there [in the US] and is sponsoring them, but if you are a refugee and like the government does everything, it takes longer. It took [our family] more than 12 years just to get the process approved and to move to here.

Aamina's narrative, by contrast, highlights how having family already in the US can make a tremendous difference: 
When you are coming here, being sponsored and coming here as refugees are two different things. Because we are sponsored by our aunt so she was the one that was given the check for the resettlement and everything so we didn't have to worry about for shopping or anything or how much this house the rent is or how long, because she has been here already. She used to take us to school, drive, come back, grocery shopping. For many people that are coming now, they don't really have that kind of a support.

The United States, with its reputation as a land of opportunity, holds a very prominent place as a potential country for resettlement. Before resettlement, many refugees viewed placement in the United States as an end to their predicament and an assurance of a comfortable and affluent life for themselves and their families. Hibaaq joked about her own family's impression of the US prior to arrival:

Well back home people believe that the money it is growing from the trees in America, or the money is just, this is what people used to tell us, "You just walk outside and you can grab money!" [Laughs]

This keenness for resettlement in the United States, and its impression as the land of opportunities, milk and honey are also reflected in the studies by Jansen (2008) and Horst (2006). Horst discussed the Somali concept of "Buufis" in her study, which is the strong drive, need and effort to find permanent resettlement abroad: especially in the United States. Buufis was named a very real phenomenon by another participant in this study, Mahad, who reflected that there is constant comparison in the refugee camps of life there versus the life that could be overseas. He equated buufis with an irrational obsession that overtakes people: that they do little else but work relentlessly towards coming to the US - viewing this as an end to their predicaments.

Narratives of pre-arrival expectations and the surprisingly different realities that greeted all participants form an important foundation to understanding the overall 
resettlement journey, and are explored within the context of identity formation and negotiation in the section that follows.

Upon arrival in the United States, barriers and resources immediately began to shape both the individual and collective journeys of the participants. Those who arrived by themselves maneuvered a country with a language and alien culture they had difficulty understanding. Others arriving as a family experienced barriers such as lack of adequate housing, difficulties in schooling, finding a job, and lack of a community to call one's own. Necessitated by their resettlement and following guidance from the support agencies assisting with their transition to life in the United States, participants reported turning to the personal resources available at hand. These include the ability to speak English, for instance, or an inner drive to succeed.

Hibaaq reported that she experienced racial and ethnic discrimination in school, and that her own resilience and the insight of her mother allowed her to find a much more supportive school environment:

In the third grade, I had a teacher who actually bullied me. I had just come here, I didn't know the language, I didn't know anything and then she, she [stammers]. Oh, I still get emotional to this day. She was very, I don't know how to describe her but I would try to do the class work that was assigned to me, even though I was still getting extra help, and I would still be unable to do as well as other students. Obviously because I didn't go to school here. And what she would do? She would tear up the paper, the work that I did, in front of me. She was white. I was just a child and I was like, "Should I say something? Should I not? What will happen? Will I get in trouble?" You know, because a teacher is such an authority, I was taught to respect my teachers like they were my own parents, you know?... And um, I would come home and wouldn't tell my mom anything but my mom could read that off me and would ask me, "What is going on?" And I told her and then we went to the school and we went through a process and I was actually placed in another classroom and after that I was just thriving. Like, within a year, I was speaking English and I was much better than any other students. 
Leylo shared her own experience learning of the centrality of racism and Islamophobia in the U.S.:

In the United States, it is very unfortunate but you are made to recognize your skin color and all the limits that go with it. They leave you no choice. You are required to "check a box". Even one of my African American friends told me once, "You are not black!" And yet I know I am looked at and experience the same things a black person does here. They don't see me and go "Oh, Somali" first, they see a black woman, and then they see my hijab, which for both my mum and me has resulted in the other person automatically drawing dismissive and racist conclusions about us in a matter of seconds after meeting us. I recognize that our exterior, in this country, determines our experiences. They see us, put us in a box and treat us depending on how we look, what the color of our skin is.

This element of surprise towards the American concept of racial hierarchy and racism is discussed by researchers such as Darboe (2003), who pointed out that immigrants and refugees from East Africa are more familiar with divisions based on nationality and tribal/ clan affiliation.

Support agencies responsible for resettling refugees form a second, critical source of resources for all arriving refugees. They provide guidance on how to access services they are eligible for to providing vital services such as school placement, job training and placement, and English language training. Mahad shared his experiences with local resettlement agencies:

They help a lot. They give us the resources we need when we get here, and we really appreciate it. There are some nice people working in the agencies. Really good.

Leylo, in contrast, shared her outlook on newcomers to Portland city, and their lack of "voice" in their interactions with the resettlement agencies:

Newcomers have it especially difficult. They cannot read or write. They feel empty and helpless. They are completely and fully reliant on their caseworkers and agencies to help them. They literally have no voice and are 
made to feel, because of their circumstances, that they have to wait around and be helped. Many of them comment how they would go back happily to the refugee camps as those were familiar. There they knew how to get the little they needed to survive and be happy. They feel they were better off there and not knowing English and be able to ask for help and express their frustrations makes it even more difficult. It affects everything from understanding forms they have [to] sign, to putting together a resume, to something as a simple as taking the bus. They go to Africa House every single month, on the first, and ask for help with their rent, electricity. Back home, they may have made $\$ 50$ a month, but felt that it covered all their expenses. They cannot understand why it is so hard to survive and provide here.

An individual's and family's social networks form the third important source of resources. These networks include a pre-existing Muslim community as well as Somalis who are already established in the city of arrival; helping new arrivals with basics such as household items, showing them where to shop for halal meat, and guiding them through their own experiences of maneuvering the resettlement system. Abdaale shared his impression of what makes the Somali community a reliable support network:

So, um, one of the things I think that works for the, especially for the Somali community, is they share information. Like, you know, people share information on Facebook or YouTube or whatever. Anything that any person that is Somali knows, go viral within the community. So, if there is any new program that would help people to build houses, like Habitat for Humanity, or if there was a landlord that mistreats tenants, anything good or bad, one person knows is everyone else knows. That is kind of the information sharing. Also a job is open somewhere? A new company in town? They always know it and they will tell you and they will volunteer and they don't have to know you. That is one thing. The other thing is, people give each other a hand up. We had no trouble with people giving us rides, we didn't have cars to get anywhere. There are a lot of support networks that help us, not just our family but the whole community at large.

Beydan discusses the coming together of the community to assist others in times

of need as a core defining value and identity:

Tragedy is what kind of unites us, brings us together. You know, if there's a funeral, if there's wedding, if there's holidays, that's when you see everyone. 
That's so amazing to me. Like, you'll just see people helping you out when you need help, you know and the community is just the type of community where even if you haven't heard from this person, if something bad ever happens, word just gets out and people just come to you to help. So that's one thing, we're very helpful as people...

Researchers such as Gonzalez-Benson (2005) have also discussed this drive within immigrant communities to come together to form support networks, and to organize in times of need. Koyama (2017) also discussed the formation of formal and informal networks. While these networks are represented, predominantly, as a source of resources and support within the data, there are also mentions of how the community network sometimes acts a barrier towards resettlement. Aamina's narrative highlights one example in which the community does not always have the best interests of others in mind:

My dad, you know at the beginning when he came in, he got a good job and was working, but as people, Somali people, they start putting ideas into his head that why are you working? Your kids are here, why do you need to work? You used to be this, you used to be that back home, why do this menial work? The kids should take care of you. So then he quit working. When we came here, for him, it was a time, where he felt he needed to step in and provide for the family, as he wasn't working in the camps. Before he quit, he was a very hard worker. He never complained, you know, and was going to school, also, you know. He wanted to learn English on his own, although he spoke a little, his English wasn't that great... But then it all stopped. I think the community influences a lot of us, like really takes over, you know?

Within these community networks are cultural brokers. These are critical "inbetweeners" who are both a part of the existing Somali community and serve as employees, advisors, and volunteers who link refugees with the broader non-Somali community. Researches like Gonzalez-Benson (2017) have also found that resettlement agencies tend to look within the communities they serve to seek out qualified individuals 
or "elders" who can act as sources of knowledge or bridges. Beydan discusses the

voluntary role her own mother played within a support organization between 2005-2007, aiding with new arrivals in the Somali community:

My mom had a friend who worked with a church service that was working to help them [refugees] relocate and you know there a language barrier so, my mom was kind of like the middle person and she would speak and kind of tell them things like how to settle, how things would be and she'd translate for them, take them grocery shopping and so my mom volunteered with them to help them get accustomed to the new country. So, um, that's one way that people help out each other. Where they teach you how to drive, or things like helping you enroll your kids in school, stuff like that.

Social networks are best understood within the context of a participant's arrival, changing and meet differing needs depending on which stage of the resettlement and adjustment process refugees are in— be it prior to their arrival in the United States, in the first few months of arrival, or years into their adjustment experience. Which of the three waves of Somali immigration to the United States an individual was a part of also vastly influence their needs as well as services and support available to them. These distinct waves of immigrant were discussed within the introduction section.

An individual's self and collective identity formed the most important overarching theme within the data from which to explore and understand the whole resettlement journey. It is the locus of the refugee experience unique to the Somali community of Portland; explaining everything from the drive for perseverance to the eventual social roles taken on by individuals or the community at large. The section below outlines these findings. ${ }^{5}$

\footnotetext{
${ }^{5}$ While the diagram highlights "Unmet Needs" as a component of the resettlement process, these shall be explored in detail later within the discussion section.
} 


\section{B. Identity Formation and Negotiation}

"There is not one Somali community in Portland. There are many communities. They are still attached to their culture, their religion, and their way of life. And they are adopting the US way of life, so they are having a two way of life balance now." - Saalima

Identity emerged as a prominent theme when many participants highlighted it specifically within their narratives: guiding the overall analysis and understanding of the data. All participants indicated that they were attempting to understand and negotiate their place between currents of culture. Identity, in its various forms, strongly dictated everything from how the arrival process was viewed or experienced, to how current barriers and resources were viewed or maneuvered to how they were currently living their lives. Values, beliefs, and goals were continually created and adjusted by this construction and negotiation of self and community identity. Studies by Asghari-Fard and Hossain (2017), Bal and Arzubiaga (2014), and Colic-Peisker (2005) have all found that identity negotiation is a central experience within immigration or displacement.

The data presented four important themes within the context of identity formation and negotiation: i) identity as informed by the displacement experience; ii) identity as informed by arrival in the United States; iii) identity as informed by the adjustment experience; and, iv) identity as shaping the vision for future generations of Somalis.

\section{i. Displacement Experience}

At the core of the refugee resettlement journey is that of the displacement narrative itself. To most participants, this displacement represented a significant loss, especially at an identity level. Colic-Peisker (2005) also found that refugees experience identity loss as a result of their displacement, and attempt to reconstruct identity in exile. 
The understanding of "home" as a place of belonging, safety, continuity and culture also changed almost overnight for the participants in this study. The forced uprooting and loss of loved ones, ancestral homes and lands, belongings, lifestyles and other comforts and privileges deeply impacted participants on both a personal and community-level. Leylo shared:

I wish people would try and understand fully who we are, the trauma so many of us faced with the violence we saw, the displacement from our homes, the separation from our loved ones and culture. I wish they knew how our parents still yearn for their homeland and people and dream about going back one day.

Migration to a host country, usually a neighboring country with shared borders, such as Kenya, also significantly affected identity. The process was rarely a smooth one, with border police frequently conducting raids on makeshift refugee settlements along the semi-porous Kenya-Somali border, for instance. The uncertainty of a life across the border added to the trauma of displacement, as there was no telling what came next. Some participants indicated that the geographical proximity to Somalia, from countries such as Kenya, was comforting. It represented a hope that the homeland was not yet lost, it was a stone's throw away — this displacement was a temporary one. Life in the host countries, as such, was lived with a self-ascribed identity of "temporary visitors." Aamina shared her own family's experience with this:

In Kenya, in some way, there was not that feeling of, "Oh, I'm a refugee," although we're begging for food, standing in line and living in tents. That reality wasn't clear. Because in a way, you're still in the continent of Africa, so you still have hope of going back. You had the whole camp was filled with thousands and thousands of Somalis and my mother was also, she used to sell small stuff. She would go to Nairobi, it was close to us [to buy goods to sell in the camp] when we were in Tika and Hururu camps. When we were in Kakuma camp, forget it, life was isolated. 
Life in host countries was experienced between two extremes. Those with relatives, connections, and means were able to avoid a life in the refugee camps. For instance, they were able to live among Kenyans in the main cities such as Nairobi or Mombasa. Those living in the camps were greeted by a reality and culture that was unique, embedded with special difficulties, and vastly removed from the eyes and minds of the rest of the world. Within these camps, struggles for basics such as food and clothing, or opportunities such as schooling or a living wage typified each day. Leylo recollects her family's life in the camps:

So we came to the refugee camp in Kakuma. It's a desert area in Northern Kenya, no trees, nothing. In the refugee camp where we were before, in Dadaab [another refugee camp in Kenya], there is trees, there is animals, all this. You have access to goat milk and all this, but then we come to Kakuma, we have no access. Like we completely rely on what they give you to eat. And that's what forced me to look for a job first, the rest of my siblings, to find a basic job because in Dadaab, my dad would go and build houses for the people who have money and that was the way you survive. But when we came to Kakuma it was really hard, he couldn't support us, there is no job. There is no house to build. They build all the houses with mud and stuff and there is no, like, people with good income that one could go work for.

Aamina shared her family's difficulties in the camps as well:

Life in a camp is really difficult. And you know, someone who really lived there is the only one that can testify and say that it is very, very challenging. You're talking about, not today, but life is meal to meal. So now people are given food for a month. Back then, every meal was one at a time; you got breakfast and then you got lunch. You don't get dinner or anything like that, and if your child is younger than three, then they give the mother - you can take extra food to her. But is the child is five or older, they expect him to be in line [for food]. Little kids to be in line with older people and you get one slice of bread, two slices of bread. So it's very, very harsh. It's very difficult. So a lot of times, people are escaping out of the camps because they understand that it can't get worse than this - and never really fully understanding what that really means because we are coming from that. And so anything else is better. 
Identities were shattered and reshaped by the harsh realities of life in the camps. Confined to the camps with few alternatives, individuals and families established vital preliminary networks, assisting each other when called upon. This tendency to come together in refugee camps has also been found by researchers such as Porter et al. (2008). Be it helping another family build a makeshift home, providing much-needed translation or peer-counseling services within the agencies working in the camps, or even acquiring and sharing news of the homeland. These networks helped form a collective identity of “camp community." Fadumo shared her experience:

I was a mental health assistant in the camp-in the refugee camp. It was a very challenging thing to do. I was the only female there. It was a challenge for me when I went for the interview they said, "Why would we hire you, a female, you can't work with all these sick men or sick women?" They're very rough and aggressive. And I said, "If the men can do it then what makes me unable to do it? If they can do it, I can do it." And I so impressed them during the interview, that's how I was hired. I was first female that was hired to be a mental health assistant, you know. When they send us to training in Nairobi, for like a month and then, after that, I came back and I was doing all the jobs that men do and now, you know, they were surprised that I helped most of the women that were always, you know, quiet and didn't wanna open up. Most of them have post-traumatic stress disorder, some of them have psychosis, anxiety, all this, and I say, if they see a female in the work area, you know, they might open up. And which they did and most of them came to take medication. Before they wouldn't come for help and they felt shy as the men might think they're crazy and all that stuff, so I changed a lot of women's lives.

With narratives that swayed between loss and hope, most participants indicated the presence of a deeply embedded common experience of trauma. The trauma of loss, separation of family members, experiencing violence, experiencing symptoms of PTSD within the camps and beyond, and struggling to meet basic daily needs made their marks deep within the psyches of most participants and their families. An overarching identity of pride at their perseverance, with a solemn remembrance of "what we went through to 
be here" marked most narratives. The presence and role of trauma within the Somali resettlement journey affected and continues to affect their overall adjustment to life in the United States. Yasmiin shared her reflections on how the stressors of life in the United States add on to already existing worries and challenges refugees face upon arrival:

Like a family of four will come and their agents, the resettlement agents, will find them an apartment of $\$ 800$ or $\$ 900$. But what they're gonna get [aid] is only $\$ 600$ per month from DHS [Department of Human Services]. Which couldn't pay their rent or leave any extra for their electricity. They say, "My light is off, my kids need something to eat, I need help." And then the case manager will not be able to pay the money out of his pocket, he is using this grant to help and if the monies are already over... so there is really stress. So they develop mental issue. And this is the problem, they try to look for a [cheaper] house, and each landlord will say, oh their income is low, we cannot rent to them, there's no way they can pay their rent later on. So that's the challenge. They talk to themselves and they develop these mental issues also. Yes, they are worried about the rent money, the light and also money for family use. Maybe they have left 4-5 kids back home, or their mum, or their parent, their brothers who are in really bad condition and they need to support them. But they cannot... Yet, how will you think of your mental health and your family if you don't have the basic services?

A participant's age at displacement also emerged as an important theme when discussing how individual identity was shaped. Researchers such as Bek-Pedersen and Montgomery (2011) have also found that the experience of trauma at a very young age by refugee youth further complicates their overall resettlement experience: making it more difficult. Some participants were too young to remember leaving Somalia, while others were born in the camps, yet others were teenagers when they left. Depending on their age at displacement, their understanding of their overall identity varies. Those born in the camps, for instance, indicated they have no reference point for Somalia. They cannot say they miss the "homeland" because they never experienced it. Others, arriving as teenagers indicated a greater yearning to go back to "rebuild the homeland" or "return 
home" because they remember it vividly. This finding is also reflected in the work of Valentine et al. (2009) and Shome (2011). Some participants speak of family members back in Somalia whom they grew up with while others speak of family members they have never met, separated by borders. Leylo shared her experience of coming to Portland: My experience of coming to Portland was that the streets were so empty! Back home there were people, cars and activity everywhere! This, because of the trauma I had experienced in Somalia as a little girl, added to my worry. I kept on thinking something was wrong, that something had happened to everyone and they had disappeared. Where is everybody? When I was a girl, I remember very little of what trauma I had experienced, but I had definitely seen bullet wounds, hurt people, gunshots and so on. I had severe PTSD for years, including in Nairobi and for a long time here in the U.S. I would have nightmares for many years and wake up scared every night.

Leylo's experience dealing with mental health issues, as a result of the trauma of displacement is not unique to her. Other researchers such as Marlowe (2010) have found this to be true, and written advocating for more mental health attention to refugee communities.

Within the refugee camps, important resources such as food or clothing often came with many strings attached. With resources sparse, refugees were quick to accept much needed supplies, even with provisions attached to them. . It is within these narratives of resource availability and accruement that the religious, cultural, and linguistic identities of participants showed up. Some participants, for instance, indicated being fluent in Arabic or Italian. This was a direct result of which schools within the camps they were able to attend: be it the Arabic Islamic schools, those set up by the Italian aid agencies, or English-language ones. For those able to speak, write, and 
understand English, this skill would ultimately be one of the most critical factors shaping a successful adjustment to life in the United States.

Religious identity, likewise, was greatly and gradually shaped within the refugee camps as refugees sought to access and accrue necessary resources through religious aid organizations and preliminary networks. Participants share narratives of asking the Islamic leaders (Imams) to pray for them to guarantee a fast and safe passage to resettlement in countries like America. Facing the immense trauma of displacement and an uncertain future, religion became a reliable source of comfort and hope. Within prayer, many found a will to keep pushing forward. Researchers such as Nawyn (2006) have written about the role of religion in refugee resettlement, supporting these findings. Other researchers have also written about the exposure of refugees to different religions prior to arrival (the support work they do as well as the proselytizing some engage in as an exchange), and how this impacts their overall view of faith-based support agencies (Gold 1996; Holtzman 2000).

Aamina reflected on the change of Somali cultural identity to a Muslim identity vastly informed by Arabic Islamic culture:

You know, the funny thing, which I'm not sure is sad or funny, I look back on pictures of my mum back in Somalia, this in early 80s, 70s and 60s, my mum is not covered in there. Wearing pants, some wearing shorts and it's like, and you're coming from a country that is $99.9 \%$ Muslim!... I think after the war happened, something like, people felt like they had to escape to something, or hold on to something so religion became this thing that was like a new trend for us and we became so obsessed. We became way too conservative... When you look at Somalia, which is a country that was introduced to Islam in like the 11th century-so to us, it's not that old, the religion-before that, it was the land of Punt, which is Somalia, is that they had their own religion, whatever it was. So whatever that religion was, it definitely got destroyed. And we became, even if you look at our language, our food, everything became very Arabic. There is nothing original left and 
I think after the civil war happened, then you know, people felt like religion is something that can save them. So, we became so obsessed to a point where, you know, covering our faces, and so on, things that were really new to us... In the camps, which are the camps we lived in-I lived in Kakuma, Tika, Hururu - the beginning of the camps, there was actually an Arab agency that would come and give us like a hijab. Like the loooong covered ones and they would give you money. Not to buy food, but to buy that. Not any other clothes, but to buy that. So in a way, it was almost like you had to. You needed the money and everyone else was wearing it so you don't want to be the only one that is not wearing it. It became a trend. The UN was there, but there was a lot of religious organizations which were also providing. Yes, they were providing food, I don't want to take that away from it, but they also provide, if you wanted to cover yourself, like hijab. And that really encouraged a lot of youth to become religious and that's pretty much. What can you do when you're in a refugee camp? You eat, sleep, read, that's pretty much it, and there was no other education. By the way, it was only religion, the Quran, and religious organizations that was something that was available. Other education was not available in all the camps we lived in.

Cabdi confirmed this with his own reflection, "We are trying too hard to be Arabic, and forgetting to be Somali."

It is within the host country that for some the first reflections of changes within their Somali identity began to surface. Traditionally identifying as a nomadic culture, reliant upon pastoral land and livestock for survival, displaced Somalis in Kenya now had to accept a new reality: that of earning money to pay for basics. This was already the case for those who originated from the capital city of Mogadishu, but for those displaced from the rural areas, this reflection on the changes in their cultural, individual and family identity was most prominent. This is also the point at which the importance of education and learning as a guarantor of future opportunities, such as reliable employment, for their children found its genesis. Faced with a new reality, new modes of survival and success began to be adopted. 
For many, the promise of a positive future came from the possibility of placement in a country abroad, such as the United States, where life could begin anew. The resettlement process, discussed at length in the introduction chapter, is filled with its own challenges and loopholes. It is a long and arduous process that further shapes the individual and community identity of Somalis as people who persevere. Keeping their eyes on the goal of going overseas, many participants shared that their families approached every resource possible, fought a hundred small battles, and did not give up until they received final confirmation of their placement. Although selection and placement overseas is affected by many factors, many outside the control of applicants, participant narratives show that a relentless drive to "get there" forms an important common theme among those resettled.

Lastly, within the displacement narratives surfaced the prominent theme of clanism within the refugee camps. Clanism, as discussed earlier, refers to a traditional system of division based off Somali clan identity and through which benefits are derived or otherwise deprived depending on one's clan identity. Participants indicated that clan divisions, the cause of divisive identity politics and violence in Somalia, carried over to life outside the homeland. Participants shared narratives of how certain refugee camps consisted largely of members of one clan over another, or how members of a minority clan (i.e. the Somali Bantu) would not receive the same consideration and services from support agencies, or how those considered to be from an inferior or lesser clan were excluded from the preliminary networks. Clan identity, as such, continued to form a core component of individual and community identity within the camps. Ayaan shared her reflection of clanism in the camps: 
It is kind of broken up in that way. Yeah. Clan A is with Clan A, Clan B is with Clan $B$ and so on... The Somalilanders do not look at the minorities favorably. Like, we are Somaliland, you guys are not, no.

\section{ii. Arrival in the United States}

Narratives of arrival in the United States share a common theme of bittersweet recollection: on the one hand, there is a relief at finally being here, while on the other hand, there is an almost immediate disappointment in what greets a person or family, as life in the United States is not what refugees had expected. Participants shared that as part of the pre-arrival orientation within the camps, they watched videos that showed them what life is like in America: high rises, beautiful people, food and money everywhere. For many the America that greets them is far from this post-card image. Many researchers have also found this discrepancy between expectations and realities of arrival in their work, such as Carling (2002) and van Heelsum (2017). As such, confronting the realities on the ground makes an immediate impact on the excitement of living in the United States and the life they look forward to. Beydan shared her own family's experience with this:

Back home, we think America is just a land of wealth and land of gold. Some people think that there's a machine in the wall that just spits out money [ATM]. That's what they say! There's so many things that we don't know. I mean you first need money to go in to come out. There's a disconnection, we didn't really understand what life really is like here. You have to work hard. Life here is not as easy as what we were told. Even though we had an idea of what it would be like here, it wasn't what they, we expected. Until you live it, you don't really know. You know?

One participant, Leylo, shared that her mother upon arrival in the United States remarked that this was the very first time, since leaving Somalia and living in refugee 
camps for about a decade, that she felt like a refugee - truly displaced. Individuals greeted by the VOLAGs and their subsidiary organizations at airports are immediately placed within the resettlement process and calendar. Some recall that their initial arrival in the United States was one of the first times that someone had referred to them as refugees so many times. This identity, of being a refugee and a displaced individual, the data shows, is solidified upon arrival in the United States. Fadumo shared her family's difficulties at arrival:

The dream we had was shattered at the beginning. We had a dream that we are going to America, we will be in a big house, you know, fridge full of food, all this luxury things that they show you on the orientation. Which is like, they show you New York, all these tall buildings, and when we were brought to picked from the airport and we were taken to a small village in Chicago, very old model apartments, and you have this dream, you are going to America. What they show you on the TV was a big difference from what we see and so... what we expected was never true. And it breaks us, most of our hearts and I was like, well, let's start over and see... After the second night, my dad said I want to go back; I don't want to stay here. And he kept calling the case manager, he said I don't want to stay here, this is not life, I want to go back... So we had to go through counseling with my dad. I told him, "If you leave us here and you go back, what are you going to benefit?" You know? It's not going to work... When families come to America, they neighbors look strangely to them, they don't have family members that were here before them, which we didn't have, it gives them a lot of depression. They feel like they were abandoned, put somewhere and forgotten about. Feel alone and it's really hard.

Participants also shared that coming to the United States felt like a second displacement after being uprooted from Somalia to the refugee camps and secondly, to the United States; a reliving of the experience of leaving the familiarity of home to go to an alien land, not knowing what the future held. This double-displacement, to many, added to the trauma that the initial displacement and forced and necessary adjustment created. To many, the culture shock was a difficult experience. One participant shared 
how strikingly thoughtless and cold she felt the resettlement process was: by taking a desert people and placing them in the middle of Chicago in the dead of winter, as was the case with her family. She felt there was little humanity behind the process of refugee resettlement when one assesses how decisions for placement are made and that there is this overarching attitude within the system that, "We let you into the country, we already did you a huge favor. You should not complain about the little things." For individuals who are survivors of trauma, experiencing such sudden, random, and unanticipated changes and challenges is deeply impactful on an identity level. Many shared that this was the first time they felt like "outsiders," no longer among "those that look and sound like us." Fadumo shared her 2004 arrival experience:

Within 2 weeks of arriving in the country, they put me and my brother into a warehouse production job. I wanted to go to high school but they say, "You're 17, you'll be 18 and you don't have time to go to high school here." So we worked 16 hours. We did full time and overtime and all that stuff.

Participants also shared a wide array of narratives regarding their interactions with support agencies. Many of these narratives were about the difficulties they experienced in receiving the necessary support and services from these agencies. At the same time, many were about appreciating the help they received from the agencies and a sincere appreciation for the work they do and support they provide. One participant, Saalima, reflected on how interacting with the agencies and other individuals receiving services from them helped shape her own identity as an immigrant:

When we came to Portland, we went to IRCO [Immigrant and Refugee Community Organization]. That's where I found it's not only me who is suffering because I saw IRCO is serving a lot of people, different colored, diversity. Then I thought like only refugees are coming from Africa or only civil war countries, but that's not true. I found, like, someone coming from Mexico, Iraq, Kenya, Somalia, Egypt. Some of them are coming from even 
like all over the world and everybody says, "I'm immigrant, I'm immigrant," and I said ok, the problem isn't not only mine. I have a bunch of people to share with my problems.

Some participants shared they had some reluctance asking for help upon their arrival in the U.S. given that Somalis identify themselves as a proud people who only ask for help when they are able to offer something in return. Others, however, shared that for them asking for and receiving help had become a common and necessary experience for them. Abshir shared:

I think there is some negotiation there [accepting help from Christian organizations]... When you are here, you can appreciate whatever [help] you can get. And whoever gives it to you. You don't have a choice. You go wherever you get help.

Some shared that as Muslims, they felt hesitant asking for and receiving help from a Christian organization such as Catholic Charities. They viewed the work the agencies do with suspicion: What do you want from me? Do you expect me to learn about your religion and convert? Prior research has affirmed this hesitancy in seeking and receiving assistance from religion-affiliated organizations by refugees and immigrants. Ong (2003) found, for instance, that the effects of religious difference between service provider and recipient make a large impact on the overall experience for both. Other researchers such as Gold (1996) and Holtzman (2000) have credited these "effects" on the prior experiences service recipients have with religious organizations prior to arrival (being suspicious of their true intentions). Ayaan shares her own family's experience:

A lot of Somalis don't feel comfortable [receiving help from Christian organizations]. Like they will do it, but they don't feel very comfortable, you know? I think it's just like, oh they're Christians. They feel like they might be pressured into their religion. Because a lot of missionary work happened back in Kenya. My mom was like, for her, one of the reasons she hated Kenya was because of that. Because there would always be people coming 
around, like, "Just come to our Church and come to our thing and we will give you food or give you this or that." You know?... There wasn't a fear of having to convert, but I think we all give things expecting something back. And so, when Somalis take something from the Christian community, they are thinking, what am I giving back? That's something I learned from my parents: if someone does something for me - I want to give back. I think that's why a lot of Somalis don't like to take from the Christian community they ask, what am I giving back to them?

Others shared a disconnect from a completely alien American system they could not grasp: One filled with forms they could not understand; money they had to budget and account for; strict meeting times they had to adhere to, which went against their traditional culture; to knowing ahead of time what their needs were, and who to ask for what. Many relied on old patterns of seeking and acquiring help, formed as a necessary survival mechanism for life as displaced individuals. Fadumo shared how these old patterns affect their interactions with staff at the agencies:

A lot of people carry that mentality that you have to be aggressive to get what you need. But in the USA, that won't work. You have to push but you have to ask in a nice way. Back home, you don't get something, you use your aggressiveness otherwise no one will help you. But here, people are here to help you, you just need to be patient and ask nicely.

Most participants shared an important aspect tied to receiving support services from the agencies: the hiring and presence of cultural brokers within these organizations. Some shared that the presence of a Somali caseworker, interpreter or member of staff within a support agency made life much easier. This role and effect has been reflected in prior studies by researchers like Gonzalez-Benson (2017). Participants in this study could communicate their needs more easily, have their specific individual or community needs anticipated and expected, and also have a community insider advocating for them on a system-level. Aamina stressed the importance of brokers: 
They [support agencies] should maybe hire people from the same cultural background. That will give them less stress. If someone came to the office and I'm Somali, they won't give a hard time to the other person, you know. I know the culture, I know what are their roles and all that stuff and I know my job and you know, it's easier to explain to them and make them understand. But when they see a white person in the office, they have to put someone to interpret over the phone, most of the people don't feel confident sharing their information... Because you don't know where I come from, so it's not easy.

Narratives of cultural brokers working within the organizations showed first-hand what it was like to work for and represent the community "on the inside" and what the triumphs and challenges are. This provided critical data for this study, further explored within the discussion chapter. Fadumo shared using her own knowledge of the difficulties new arrivals experience in the United States, and how she uses this to advocate for specific community needs from within the system:

The agency where I work, I told them, "It happens that people don't receive all the money they are entitled to from their caseworkers so you need to be careful." So now, they created a form that the client has to sign that they received the money. But we didn't have that form. Sometimes, people can sign a form they don't understand, that's why I told my managers that if the client does not know English, someone gives them a blank paper saying sign here, they should say no, and I always tell the client, "Always ask the interpreter," let them tell you what you are signing for. When my family came, we spoke the language but we didn't know the system, you know? We didn't know all this, and we never got a form from any of the case managers to read and to sign and so it was really hard.

Saalima, who works for a Christian-affiliated support agency shared extensively

about the pressures she experienced, from the community, who while benefiting from having a fellow Somali on the inside, also critiqued her for letting them down:

There was a relative of mine who visited Portland once. He saw what I was doing in the community and by the time, a week before he was supposed to leave, he calls me and said, "Saalima, you so good person, you do good things, everybody likes you but you make one mistake." I say, "What is that?" He was like, "You know what, and your business card has Christian 
sign. It says the name of that Christian organization. Every Muslim person, like 911, they have your number here. They go to the mosque with that cross sign. All of that goes to you. You made a sin." I say, this is not sin. This agency has cross sign. They have been so good to me. They hired me, they paid my bills, is that a sin or not? I work hard. He says, "But think about it, you can change another job." So I told the agency this and they said, "No, don't go, because we can change your business card logo." Then I went to visit this family when I was still working with the agency. They welcomed me nice and appreciating all the stuff, by the time I was supposed to leave, I gave my business card and told them I worked for this agency and call me if they need any help. "Allahamdillulah, aren't you Muslim?" I said, yeah.

"Then why are you giving me this? This is Christian!"

Other participants shared how gender played an influential role when it came to approaching agencies for assistance. Men felt ashamed asking for help as the "men of the household" and would ask their wives or daughters to approach the agencies instead. One participant, Saalima, shared that her father sincerely believed that if a woman went to ask for help, the agencies were more likely to feel sorry for her and offer more assistance than if a man would. He felt that men are judged for being unable to provide basics for their families upon arrival. She stated:

Some men, because of pride they are like, "I will not go there. I will not go to IRCO. You go and ask them, we need this." And then the system, the way I have seen. If a woman takes the bill is in her name, they help more than if it is in the man's name. Men, sometimes they are strong and this [receiving aid] is like charity. Coming into line, waiting in line for charity. The way the [the agency staff] see you, they don't know. They wonder why they don't have a job and so they say they don't have any more money. They just say, "Go home, we don't have enough money." But when a woman goes, they say like, "Yeah!"

This gender dynamic informs identity construction and negotiation among other important lines, previous research shows (Donato et al. 2006; Espiritu 2001; Kibria 1993; Pessar 1999; Warriner 2004). Women in newly arrived household show a prominence as the problem-solvers and resource-acquirers for the whole family. Be it from the agencies, 
as mentioned above, or simply by walking from door to door to ask someone for help in learning how to use the stove for cooking, or asking for a ride to the grocery store. Many participants who arrived as youth with their families shared witnessing the gender dynamic in their family shifting, with mothers becoming the unofficial head of the household. Beydan reflects on her own mother's drive and perseverance in supporting her family and empowering her daughters:

My mom from a young age told me that you should never depend on a man. Like, if you ever want to do something, you should always do it. And like, when she says that, she followed it with her actions. Because I saw her in action, not relying on anybody but herself. She would take care of the house, she would go to work and she would do all these things as my dad was ill and not rely on anybody, and set a good example for me. Even when it came to teaching me about getting married, though that's a part of life, my mom told me to never have that limit me. Or that should never just be the end for me.

Haweeyo reflects on her own gender identity negotiation, and finding her voice:

I feel like as a Muslim woman, a lot of the time we are inhibited from speaking up. We don't want to hurt people's feelings or speak up. But I am slowly learning as I get older that, you know, I need to voice my voice. A lot of the time as a Muslim woman, people will treat you differently because of your skin or the way you dress. I have to stop with that thinking and I have to grow. If I have a problem I have to speak up. I have to be very confident when I talk...

The process of arrival, the narratives show, is experienced very differently by youth and elders - and this has been discussed previously in other studies (Bal and Arzubiaga 2014). For instance, parents, coming with young children often differed on how they viewed their new home. One participant shared that her mother immediately disliked America and fell into a deep depression, speaking of nothing else but going back. Her father, on the other hand, loved everything he saw and decided to make the most of every opportunity he was afforded. 
Initial impressions have a deep impact on the construction of an arriving refugee's identity as either an "outsider" or a "new American." One participant reflected that some people viewed the moving process as an opportunity, and were more likely to fare better in their lives in the United States, while others viewed it as a necessity, something they did to improve things for themselves and their families. These impressions continue almost throughout an individual's time in the United States. Some participants share that their parents speak of nothing more than "going back home." They reflect that now that their children are adults, they should return to their roots. Others share that their parents never sold their homes back in Somalia and find fuel in the knowledge that one day they shall be able to go back. Ayaan shares:

My dad is planning on going back... I would want them [my parents] not to leave for a while but I feel like there's this hype going on right now, all these Somalis are going back. They're like, "Oh it's getting better." But then you hear about this new thing that happened, this attack or something and it's like, why would you want to go back?

Participants also shared narratives of initial barriers they faced that impacted their identities as "outsiders" in a profound way. One participant, Haweeyo, shared how she was informed that she needed to get to work immediately to become financially independent and self-sustaining (so as to stop receiving aid money to support her). This led her to a minimum-wage job in a production plant as a 17-year-old. She shared her deep disappointment in the fact that it was never mentioned to her that she could, instead, decide to go to school and finish her high school education first. Another participant shared that her family was resettled in an area where there were no other Somalis. No one spoke their language making it harder for them to get help — and to fit into the community. She mentioned that other families, living nearby, viewed her family with 
suspicion, because they looked and sounded different, and would pretend not to understand her, even though she spoke in near-perfect English. Previous studies have found similar difficulties in adjustment experienced as a result of no prior orientation or information on community-specific realities prior to resettlement (Crane and Fernandez 2017). Other participants in this study shared narratives of kind and supportive neighbors who helped their family with everything from taking them shopping, to showing them how the light switches worked.

Many participants also shared experiences of an additional loss upon arriving in the United States: that of their academic credentials and prior job experience. Some lacked documentation to show their prior training while others had credentials that were simply not recognized or honored within the United States' education and employment systems. There was a general expectation that resettled refugees would have to start over from zero: a reality that made an immense impact on the arriving community. Beydan reflected, "When you come here, you have to start from the very bottom - yeah, because your degree is not recognized." Some individuals went from holding positions as politicians, nurses or college professors to working in a manufacturing plant overnight, losing their career and vocational identities upon arrival in the United States. Previous researchers have also explored and found similar narratives of loss of economic standing, experiences of poverty, and the limitations of the "refugee gap" as a result of the resettlement experience (Colic-Peisker 2005; Connor 2010). Beydan reflected on this loss:

It's like your economic status kind of like changes, you know? Because like my mom came from a family that was pretty well off back home. Like the village that we lived in, my, our family's home was the only home that was 
actually like not a hut. It was actually like a home-home, you know? Like a building. So when you're used to living like that and having a "name," like, when you have a well-known family name and then all of a sudden then you come here and you're just like nobody...

Many participants shared how an underlying expectation of a speedy resettlement experience, as expected and anticipated by the resettlement agencies and system, reaffirmed their self-identity as "outsiders" or "discards of the system." They felt that the only thing the system cared about was that they become financially independent as soon as possible, even at the cost of opportunities that would help them succeed in the long term. Previous studies have also criticized this short-term-priorities nature of the current resettlement system, which largely ignores more long-term success that is not limited purely to economic self-sufficiency as the gold standard (Tyson 2017). Yasmiin shared:

Everything is fast, fast, fast, to make people not rely on help anymore. Things that are more important, like bringing family here to join is not made important. This is where it fails. They want to make people stop needing money as soon as they can. But then they never really become really independent, you know? They are set up like to keep struggling, stay poor, and like, not really meeting basic needs. So they continue to rely on help, so who really wins? The system? The person? None.

Some shared that the system of resettlement was a rigidly structured one that predetermined needs for all arriving refugees rather than giving attention to specific family and individual needs, goals, or experiences. This lumping together experience meant there was little room for deviance or pursuit of individual goals right away. Researchers such as Kunz (1973) have long emphasized the need to view and understand the diverse experiences of refugee and immigrant groups separately, rather than lumping them as one. Other participants in this study mentioned that during their initial months they were reliant on any information, guidance, and support that the agencies provided. 
With no alternative sources of knowledge on what opportunities were available to them many participants share narratives that open with the phrase, "If I knew what I know now back then...” Alluding to not receiving the right information or guidance upon their arrival in the United States and learning through mistakes and lost opportunities about the breadth of opportunities and services available. Fadumo reflected on her family's lack of knowledge of the myriad of support agencies in Portland or the services they provided, which could have further assisted their resettlement upon arrival, "No we didn't know all those... we didn't know they existed, and we were lost."

Some shared that how they dressed and sounded also attracted unwanted attention, further solidifying their identities as outsiders. Many of the participant narratives share a similar thread of how their outward appearances led to direct discrimination in everything from a mere shopping excursion (where a participant was followed around the store) to applying for jobs (where an interviewer took one look at the participant and decided that the position had already been filled). Haweeyo shares her experience of discrimination:

I don't think I felt welcomed... People always just kind of questioning you and your validity of being in America. I don't see it in my face, obviously, people don't say it to you, they say it behind closed doors. I know that at work people always ask me where I am from and they always expect something. When I say I am from here, they always ask, "Where are you really from?"... But I just, honestly just don't pay attention to it. I kind of ignore it. I don't, it's all, yeah, I know for a fact that people treat me differently and in different social circumstances but I just kind of go on about my life... I feel like it is the only thing I can do.

Previous researchers, such as Colic-Peisker (2005) have also found that the "closer to whiteness" a refugee or immigrant group experiences at arrival, the more 
comfortable their reception and transition are. They are not "othered" as much as groups that are visibly different (as Somalis generally are, being black, Muslim and typically not being very fluent in English at arrival).

Participants in this study perceived identity is also an important factor in why they chose Portland as their eventual city of residence. Some were seeking a smaller-sized city that was more family-friendly to raise their children in. Others shared that Portland's exceptional transit system served as a major pull for them, making it easier for them to commute to work or school, for instance. While others felt that the testament of Somalis already living in Portland - who would speak of the resources available for resettlement, the then-affordable housing and the presence of other Somalis within support agencieswas all the assurance they needed to move to the city. For Somalis seeking a home that would provide safety, security, and opportunity, Portland was a no-brainer. Previous studies have explored this "second resettlement" that refugee communities eventually take on, once their initial resettlement is over. The second resettlement is an experience of free agency on their part: they learn about what cities have better social services, for example, from within the diaspora and move there (Bloom and Loveridge 2017). Fadumo shared what attracted her family to the city:

Portland is a very nice city, um, you know very open, nice, public transport is nice. I can't compare Portland public transit with any other city. Other places you will not find that. So Portland isn't a big city, it's a small city, but it's a city that you can raise your family and feel safe here. It's also cheaper, cleaner... When we moved to Portland, a lot of the Somali community was moving here, it was in 2000, and so we all moved to the same place and everything, and then we all branched out. I mean, we're all still are friends. We still see each other. 
Participants also shared that religious identity played a vital role in the arrival experience. In most communities they were resettled in, the mosque was often the first place they would go to introduce themselves as new arrivals in the community. The mosque community was able to provide assistance with everything from recommendations for grocery shops to giving them used bedding and kitchen appliances to fundraising for any initial needs the support agencies were unable to help pay for. Khaalid shared:

The Masjid [Mosque] plays a kind of central role where people get together, where if you need something, that is where you go to look first. Even if you are not religious, the Masjid is open to you.

For new arrivals, religion in the United States looked different from the makeshift mosques in the refugee camps. In Portland, many participants share the congregation "looks and sounds different." One participant, Haweeyo, shared that for the very first time in her life, she realized that not all Muslims were Somali. That there were Arab Muslims, Indo-Pakistani Muslims, American Muslims and others.

My first time in Toronto, I went to a huge Muslim convention and I saw Asian Muslims wearing hijab, that was so new to me. I saw Muslims who were different skin tones, different languages, and different looks. They weren't all Somalis. I was very curious. I was just very shocked because up until then the only Muslims that I had come into contact with were Somali. So going out and seeing such diverse Muslims for the first time was very shocking to me.

This recognition from the local Muslim community, as well as its ability to offer assistance to new arrivals was a reaffirming process for most participants. It is within these mosques that they found their preliminary local networks. Previous researchers have also found that in the Somali community, religious is seen as the same as culture. It plays a central role in everything from how the family unit functions to social 
engagement (Lynn Heitritter 1999). Researchers studying the local East African refugee and immigrant population have also found a tendency within the community to come together as Muslim first, giving secondary priority to national origin as an identity (Hardwick and Meacham 2008). Saalima, who works for a support agency, shared how the mosque connects new arrivals to resources within the community:

Six months ago, this guy came he is from Senegal. He is not even Somali but he went there as Muslim and then he was crying over there at the Mosque saying, "My wife and children came and I don't have where to go, I cannot support, I don't have a job." This and that. So, the mosque says like, "I think you qualify for refugee services, I know Saalima, let me call her." See! So the man calls me and says that this guy, his wife and child just joined and he has been here for a while, is there any support from your organization?

Yasmiin shared her understanding of the roles the mosque plays within the community:

The mosque plays three different roles. The first one is domestic violence. When domestic violence is there, the mosque interferes and makes things in a religious way and they follow up. They take action with whoever is at fault. They shame them for doing this, before the locals. The second role they play is when people move in and they don't have a place to stay, the mosque lets them live there for a while. Or if they have no electricity and they have children, the mosque collects on Friday some money to help those poor people. The third role is, like when weddings come or you know, somebody dies. Like hotels and stuff, they want you to buy their food and some of us, we cannot afford and it is not halal so the mosque opens the door and does not charge the people to do the niqaab [wedding] over there.

Participants also shared narratives of "old" versus "new" Somalis. Alluding to the earlier waves of Somalis who settled in Portland and whose experiences differ vastly from their own. Kunz (1973) refers to these waves as "vintages of arrival" in his study. The early pioneers to Portland arrived in a city where there were almost no other Somalis, which made encountering other Somali immigrants a welcome and fond experience. Somalis who arrived in earlier waves also had the disadvantage of fewer agencies and 
services available to aid in their resettlement. Newer arrivals, in contrast, share benefiting vastly from groundwork and resources formed by the established Somali community they found in Portland. While this is viewed favorably by new arrivals, there is also notable discontent from the established community as the resettlement experience, to them, appears much easier for new arrivals due to the increase in services and networks available to them. For some, there is a need for new arrivals to experience the same difficulties they did when they first arrived in the United States. Aamina reflected on this:

Once, at mosque, we were having a conversation on how we should unite as Somalis and come together and help if there's a new refugee arrival. We're not saying that we want us to be the responsible one in getting them the apartment and so on, but at least meeting them at the airport, greet them, instead of having a Caucasian or another person that is the first face that they see. And follow up with them, see how they are doing. And then this girl, she goes, "No one did that for us... why should we? We also struggled, that's the only way you can learn. This is America... Let them struggle." And for me to hear someone say: this is America, it's just so... Yes, it's a land of individuals, but you're a community, you're a collective, where do you lean? So that's the part I'm thinking, people really change, you know?

New arrivals to Portland city also find a hierarchy formed between alreadyestablished Somalis and the newer arrivals. For members of the established community, there is also a need to differentiate oneself from the new arrivals based entirely on their newly adopted identities: "I am more Americanized, therefore we do not have the same outlook." Researchers such as Hume and Hardwick (2005) have also found that in the local African refugee and immigrant community, there is a tendency for groups that are large numerically to stick with their own when it comes to events, organizing, or forming support networks. Smaller groups tend to engage in more pan-African networks. Daahir shared his experience as a member of the "established community" of Portland: 
You know we have something called established community and new community. As a homeowner as a college educated person, and as someone who strived working hard, trying to make ends make, there is a difference. A new arrival their need is much different than me. So the challenges that we each may face are different depending on when you came; because, being here longer, you begin believing in capitalism. There are times where I would say, "Why are you not independent. Why are you not pursuing these goals?" Forgetting all the obstacles and the barriers that are put in place by the system that this person is trying to maneuver. I consider myself part of the established community here, we tend to forget how it was for us back then too.

There is also a tendency of the established community, now educated and well

settled, to use educational achievement as a tool for hierarchy. Haweeyo reflects:

I don't like the idea of Somalis being separated by education. Like you have the educated Somali community and the newly arrived Somalis. I don't want to see myself far removed from newly arrived Somalis and I don't want to see myself as better or as greater than. That's the thing in Somali community, religion wise, that's a no-no, you can't do things like that.

The effect of this hierarchy and the personal need for individuals to differentiate themselves between new arrivals and established Somalis, according to some participants, adds to the already existing disunity among Portland's Somali community. Aamina reflected on this:

As people, live here, people change - even our own community. Like I remember when we first came, the first five years, when you see a Somali, even when you are on the bus, you get so excited. Oh, I see a Somali! Like you will get off the bus and greet them, you don't know them. But now because the community is so large and you're like, "Ah, Somali! They're everywhere." So as a community, we're not very, there isn't much unity.

Lastly, participants shared that problems of clanism, which create clan-related barriers continue to play a pivotal role in their arrival experiences. There are narratives of how individuals from one clan would not offer assistance to those from another, keeping the deeply entrenched clan segregation of Somalia and the refugee camps alive. There are 
also accounts of how informal support agencies are usually formed along clan lines, specifically providing services only to new arrivals belonging to the clan. Participants share that their clan identity precedes them in their names, their place of origin and other identifiers and that it is almost impossible to remove their clan identity in interactions within the community. Clan identity, in this context, acts as both a resource, for insiders, and barrier, for outsiders. Hibaaq shared her own family's experience as Somali Bantus:

When we came here, other Somalis have organizations, but the Somali Bantu didn't have anything like that. You could go to them [other Somali organizations] to ask for help, but they wouldn't help you as a Somali.

Clan identity is also be juxtaposed against other mentions of social capital that aid in the arrival experience. Some participants shared that the benefits of having a prominent and well-respected family name followed into the diaspora. These recognizable names made it easier for new arrivals to secure resources and support within the local preliminary networks. Beydan shares her own family's experience with this:

In the community, we still have a name... The Somali community all know each other. Even now, like when you go to the community and you say, like, "This is my parent or this is the family that I come from," they understand who are you and they respect you. So um, when you kind of have a name and people kind of know you, it helps, yeah.

\section{iii. Adjustment}

In examining most participant narratives on post-arrival adjustment in the United States, the exploration and negotiation of the various components of one's identity and the formation of a new, hybrid identity emerge as an important focus point. Previous researchers such as Asghari-Fard and Hossain (2017) have also discussed this "hyphenated hybridity" in refugee populations upon resettlement. The process and 
formation of this unique, individual identity is influenced by the pushes and pulls of one's roles as one understands the self; an understanding of the self within the context of family roles and expectations as influenced and shaped by life in the United States; and within the context of viewing oneself through the lens of membership within the broader Somali community. The diagram below represents this reconciliation of identities with the social systems influencing them. Previous researchers have explored this as “intersectionality of identities" (Netto 2011).

Figure IV: The Self and Society
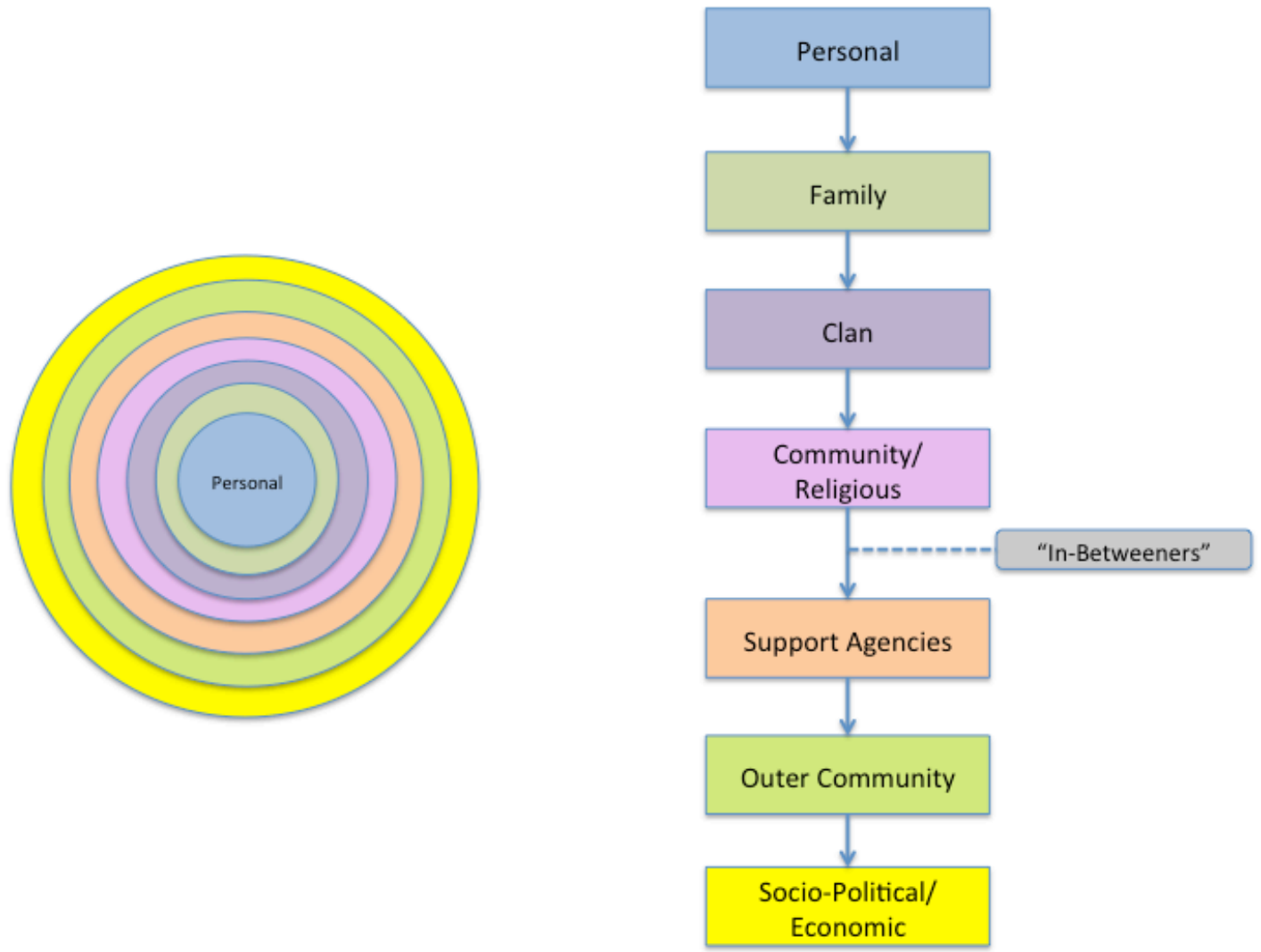

Within the context of identity negotiation, an individual's negotiation and understanding of individualism versus collectivism also emerges as an important subtheme. Somali culture traditionally emphasizes collectivism: an outlook prioritizing 
community cohesion over individual needs or aspirations. Arrival in the individualistic culture of the United States informs an important aspect of self-identity, allowing new arrivals to begin to understand and pursue one's needs and aspirations outside of the collective. Abshir shared:

I think it is in our culture. So when you study something in school, um, your aim is to help the community. But to be honest, I'm a little skeptical about that. First of all, you have to help yourself. And then you can help your people. What I believe is individualism. The thing that I love in America is the individualism. This is good for the collective, to help the people, but I think it's okay to do your own thing too. I think I had that mentality to do for the collective. It's good and it's noble to help the people especially your community - but first you have to help yourself.

Haweeyo summarized her own aspirations: "I think the first thing for me would be taking care of myself." Beydan adds to this with her own reflection of choosing a major in college: faced with the choice of following in her mother's footsteps and pursuing a nursing degree or choosing a major that suited her career goals:

I was actually in school for [pre-nursing] for two years before. Yeah, I was getting ready to apply to nursing school and then I asked myself, "I'm I really making myself happy or my mom happy? Do I see myself doing this all my life?" So I switched [majors].

The understanding and negotiation of religious identity also emerges within the data. There are indications of two aspects of religious identity seen. One in which an individual follows traditional aspects of religion or understands and practices religion as a community experience. Which is how religion is traditionally practiced within the broader Muslim community. The second, in which an individual tailors their religious identity and participation to fit with the individual needs, goals, and history of one's family or self. Researchers such as Valentine et al. (2009) have found that the larger the Somali community within the area of resettlement, the higher the pressure to be a "good 
Muslim" or engage in performative religion for social capital. Smaller Somali

communities, in contrast, result in an increased freedom to practice individualized

religion. Haweeyo shares her own experience of negotiating her religious identity:

I felt like I was taught religion and why we wear hijab and I felt like it was just a Somali thing and not a Muslim thing. It wasn't until I started educating myself that I realized that our religion is not really what I thought I was. I wasn't really practicing until I started thinking about religion and decided that this is what I wanted to practice. Before I was just Somali and that was really important and I didn't like that. Now that my vision is wider and my perspective is much more, I feel I don't like just being [Somali]. I like the idea of being a Muslim a lot more than just being Somali... Where I lived, the only Muslims were Somalis. I like the idea of growing up in a diverse Muslim community. We didn't have that.

Yaasmin shared her own experience of tailoring her religion to her family's

background and personal context:

I have a lot of friends that are Muslim but the way they practice their religion and the way I practice is different. So I just have this culture because my culture and my religion goes together. So, my family, my mum, my grandmum, my uncle, my aunt, the way they used to practice my religion, is they way I'm doing it right now. I didn't follow what the outside world is doing. My religion is to be practiced privately, no one needs to see what I am doing to be a good Muslim.

The experiences of elders within the community are another sub-theme that emerges when looking at identity negotiation in the context of adjustment. Narratives of disconnect from the broader community, an overall resignation from daily or community life, worry about family members left in Somalia, and the general mourning of their past lives and lifestyle of their younger years in their home country characterize the reflections shared. Leylo shared her viewpoint on the challenges elders face:

Older people, especially, need mental health programs as they have experienced longer periods of trauma, violence, and longer lives in the camps prior to arrival here [United States]. They come from a war-torn country and worry about all and everything they have left behind. Our 
culture, though, doesn't believe in mental health assistance and will dismiss it as, "I'm not crazy, you are!" Like my mum, so many of them stop exercising, stay at home, especially during the winter months. Many of them develop illness that also limits their getting around and isolates them. Back home they would go around and visit everyone they knew, do housework, but here it is different, it is sad. They are always talking about going back and my mum always asks me about news from back home.

Abdaale shared his own concerns for the elders within the community:

There is a huge generational gap in-between where children are psychologically and socially and where parents are. A lot of parents are, they have a reverse kind of, well not reverse. There is a word in Somali: buufis. Buufis is basically a kind of thirst or hunger for people to come out of Somalia. To leave Somalia. To migrate out of Somalia. It is almost kind of a psychological or mental health condition. A person suffering from that, according to official Somali diagnosis, is almost losing his or her mind doing everything they can do or always constantly talking about it or going overseas. It happens in a reverse way after people pass the ten-year mark here. A lot of parents I think are suffering from that. The reason is they almost always thinking temporarily, life here is temporarily. Especially those who didn't get integrated better. Those who are not professionals and those who are working mostly in jobs that have less kind of upward mobility. Those were unable to integrate very well but have spent here significant time, they feel sometimes that, if I just go back home, I will just fit right in. I think it's like the grass was green on the other side mentality.

The experiences of the youth, in contrast with that of the elders, highlights an important detail: that of the overall loss of childhood. The trials and trauma of displacement along with familial and community expectations of older children result in experiences that indicate the contraction of the carefree nature and experiences of what we generally understand childhood to be. Some narratives highlight a caretaking role that children had to adopt earlier in life, while others indicate the formation of a parental role taken on by the children for their younger siblings. Amiir reflected on this:

It's a lot of responsibility when you're the oldest in the family. It's... you can't do some of the things that you wanna do it. Um, when the younger ones are attending school, you can't go full time school. You need to work, make some money for the family. You have to do this, do that. Umm, cover 
some of the relatives that you left there... It's a big responsibility. Plus, you are thinking about making your own family, thinking about going ahead, finishing school, get a better job, it's a lot of responsibility.

Narratives focused on the adjustment experiences of youth also leaned heavily towards a broader need to "keep them busy" and "out of trouble." Participants who were parents or older siblings indicated an overarching awareness of the tendency of Somali youth to be pulled towards subcultures that would be detrimental to their lives, such as gang affiliations or radicalization of the Muslim identity. Previous studies have also found this "intergenerational stress" between the youth and elders wherein the latter are worried about the possibility that the latter will lose their culture and be influenced negatively outside the home (Hardwick and Meacham 2008; Portes and Rumbaut 2006). Beydan shared her perspective on this:

When the kids come to the U.S. and they're at a young age, you know what happens is that they're pulled by two different cultures and they get lost in between and sometimes they lose their ways, where they either don't stay in school or they just are doing things that are not good for them, you know? So instilling the value of education and just giving kids a place to be where they can be themselves and can be productive and away from doing the wrong things, that would be something. That's one of the biggest things. It will also help the parents because it will take pressures off of them because parents always worry about their kids and once that sense of worry is alleviated then the parents can also go on to do bigger and better things.

Participants also shared concerns over the realities of culture-loss within the Somali community as younger generations grew up and formed their own, oftenindividualistic hybrid identities. Hibaaq shared her concerns as a parent

I am worried, every day, that the children will grow up and forget their culture. Yeah, definitely. Like, I wish I had the money or the thing I can do to take my kids back to stay a little bit there [in Somalia] to teach them the culture, the everything. So they can understand. That they know. I worry about that, definitely, every day... People keep telling me, "Why did you give that [traditional Somali] name to your kid? It's so hard." I don't care if it is 
hard. My name is hard and people say it wrong. They will learn. It doesn't mean just because the system or the people, I am not going to change my culture or who I am or what I want to do for myself.

Fadumo also shared on her efforts to shape her children's identity, keeping them well rounded and grounded in Somali culture:

My boys go to Islamic School of Portland. I also took them to private school because they were going out of hand, they're boys, you know. If you don't have a specific place for them to know who they are, it's really hard. So I put them there and they're learning Arabic, which is good. I don't know how to write Arabic but they will learn Arabic. They are learning the Quran.

They are also teaching every other subject that public school teaches, which is really nice. So they are learning my religion, my way of life at Islamic school, and they are learning the way of life of the US through the school system, and also the way of our family life through home. So they're having three schools.

Experiences similar to Fadumo's children are also common in the existing literature. For instance, Asher (2008) found that refugee and immigrant youth are able to express their identities in school freely (more specifically, their Americanized identities), but at home they are expected to conform to parental expectations of being immersed in the traditional culture.

Parenting and family roles, and their modification, are another important subtheme that emerged when looking at the adjustment experience. Many participants shared narratives of parents who arrived in the United States and facing the limitations imposed by their new American society or from within the Somali community saw their quest to seek opportunities and success stunted. Hibaaq shared her experience of feeling stunted by the Somali community:

When you are new [to Portland] everyone welcomes you. But when they see you [regularly] within the community, this is the problem. If I know English or I know a little knowledge and I am like getting ahead of them, they don't like it. They will feel like you are bossy or that you are trying to be better 
than them. They will feel bad because they are not doing as well. I feel that every day. I feel it now. I got this new job and it is much better than any I have had... People call me names; call me bossy, I don't care. Even if you help them, they don't understand that part. They just understand that you are somewhere above them and they don't like that. They don't see the part where you are fighting for them [as advocates] or helping them. But they are like that. You can't change them... You have to explain to them, you have to make them understand...

Gender roles and their revision among parents and children were also highlighted. For instance, the creation of a role and identity for the mother as the head of the household. Women and girls were often portrayed as carriers of culture: in charge of the continuity of the identity of the family and community. Girls were encouraged to seek an education and not confine themselves to barriers imposed by traditional gender expectations. There is rich attention paid to the revision and negotiation of gender roles as a result of the resettlement experience in the literature (Donato et al. 2006; Kibria 1993; Lee 2005). Young women as carriers of culture, and as experiencing more restrictions at home in comparison to male siblings (on their mobility, expression of sexuality, or even pursuit of academic or career goals) are themes previously uncovered in prior studies (Lee 2005). Haweeyo shared a different experience within her family:

Yeah, my parents thought education was really important. My dad never said, "Oh, you're a girl, you need to act this way or you need to do this because you are a girl." He always said that you can't rely on people and you have to work for yourself, work hard and get an education. That is what he has instilled in me. To be educated. He never told us, "What's education going to do for you? You are just a woman." Our parents expected us to work and go out there and make a living for ourselves and in the future for our own families... There is nothing that a man can do that a woman can't do.

Gender roles as an important aspect of identity negotiation also emerged within narratives referring to the male youth. Somali males, in contrast to Somali females, were 
often portrayed as fragile. They were worried over both by older female siblings and male parents. Their risk for possible gang involvement or radicalization, as mentioned above, as well as general anxiety for their education and advancement within American society formed a bulk of these narratives. Prior researchers have found that male youth are more likely to encounter negative influences outside the home, thus warranting the worry by their parents and female siblings (Qin-Hillard 2003; Zhou and Bankston 2001). Haweeyo shares her experience with her own brother:

My brother, he wanted to take a year off from college and I filled out his college applications for him because I told my mom who was like, "You know, he's a boy, maybe we shouldn't push him." But I told her, "No, no, we have to push him!" My mom didn't want to, she felt like if she talked to him, he won't listen to her, he would just rebel. So she didn't talk to him, so I had to do all the talking. Maybe it was just letting him take a year off, letting him work. But if he takes a year off, he will take two years and then three and then never go back. I had to push him and tell him to go to school and study. I was always in his face about it and yeah he hated me sometimes. I felt like I made sure he went to school because he is the oldest boy and I just wanted him to be a good role model to the two other boys younger than him... My mom is very happy of the result of him staying in school and she knows it was partly because of me that he is even going to school.

There is an underlying understanding indicated within these narratives of the systemic forces working against the overall success of African-American males within the United States and how these impact Somali boys and men. Their experiences with law enforcement, for instance, emerged several times in the narratives and has been mentioned in prior research as well (Darboe 2003). Haweeyo shares her concerns for her male siblings:

I know for a fact men, in this case Somali men, are very, very lost. They don't have an identity. It's already hard as an African American man in America to make it... Their parents feel like they can't get through to their kid because their kid is between these two worlds where at home he is 
expected to, you know, be all this and then he goes out into the other world. It is just very hard for him as a young male to even take care of his family and at the same time try to figure out on the outside... My cousins grew up in America and they are Somali men and they have gone down the wrong path. I talk to them and I try to get them to [pursue academic success], but every time it's just like, I try to get him in school but he is just like, "No, I don't feel like, I don't feel welcomed. I don't want to change the way I talk." They just feel like they have to change their identity and they are always being judged and it's not the right place for them. It's very difficult. And this is for a lot of communities. When you are an immigrant, it's just very, very hard, you know.

An understanding of available support resources, both for oneself and for future generations of Somalis arriving as refugees within the United States also emerged in the participants narratives. Some viewed resources such as monetary support to aid in resettlement as a vital need while others shunned it as a crutch creating dependency and slowing down independent pursuit of success. Within these narratives, a vital indication of identity as informed by values such as independence and self-help form alongside the overall driving forces of perseverance. Haweeyo shares her own perspective on dependency and independence:

I get really upset when I see Somalis who have come here the same time I have come here but are on food stamps. And like, you're 25-year-old Somali who grew up in America, why are you not in school? Do you not want to break free?... Because we came here for a better life and our parents didn't have this opportunity so why should we not use the opportunity provided to us?... We need to build our own foundations and be self-sufficient for ourselves and our families. I try to not create a gap between Somalis depending on education and all that stuff, but I do find that as an outsider looking in that there are the ones who are educated, and the ones who are, you know, using government assistance and not wanting to budge from that. It's as if they are so comfortable that they don't want to leave.

Post-arrival networks form another theme impacting identity during adjustment.

Just like networks formed by needs within the refugee camps prior to arrival in the United States, or those formed immediately upon arrival, these post-arrival networks also 
find their genesis in the immediate needs of the individual and the community. Narratives show that the overall identity negotiation of the individual or community as a whole greatly shapes the deliberate selection of these networks. As individual and collective values, beliefs, and goals are revised or reaffirmed, there is an intentional inclusion or exclusion of other individuals or groups from one's networks. Adbaale reflected on his own network selection:

When I moved here I was mainly looking for Somalis that are professional. Not that I didn't want to do anything with the other ones but I wanted to leverage their expertise. So I was able to hook up with Somalis who are engineers, who are doctors. These are the people I want to capitalize on their capacity, these are the people I want to work with. I didn't necessarily want to meet a Somali truck driver, right?

Within these post-arrival networks, there are many mentions of the continuing effects of clanism within the community and how this hinders collective unity and individual success. The data shows that the influence of clanism varies on who you ask within the community. Prior studies have shown that the Somali Bantu, for instance, still experience exclusion within the local Somali community (Eno 2008). Some participants within this study acknowledged current divisions and hierarchies along clan lines. Leylo shared:

Well, there are so many Somali communities here, I wish we had one. They are all divided [by] ethnicity; Somali Baraok, Somali Bantu, Somali Bajuni. There are other Somali communities too.

Others, like Ayaan, share a more egalitarian view on dealing with any such barriers:

Ifeel like we're focusing more on the Islamic things, like here in Portland. People are more, we still have, it's still there [clan divisions], but it's not so much focused on... People are focusing more on the religion. It's like, hey, God wouldn't allow that. Let's not be that way. 
There is an acknowledgement of efforts within the community to put aside clan differences and unite under a common group or organization. Participants shared, however, that the formation of this united group is also riddled with community politics and the need to choose an identity as either a support agency or a representative organization that takes on a more political and social role in advocating for the community. Leylo shares her experience with this:

The only one [common Somali organization] I know is SACOO [the Somali American Council of Oregon]. The new one, it's the only one I know they are not separated. They're are like a group of all Somalis from different clans came together. That's working, yeah, I've seen that. But they're new. This is at least their second year. People are coming together, at least. They are more focusing on teaching the mainstream about the Somalis and when there is a big problem in the community, there is something, they are more involved. That is the thing about Somalis, if there is a problem, a major problem, then all people will come together, differences won't matter.

An understanding and exploration of poverty within the context of the broader individual, community, and systemic barriers that limit the Somali community also emerged. This shows an understanding, at the identity level, of the class divide within the United States. This has been studied and shown in previous studies (Colic-Peisker 2005). Within participants' understanding of poverty and other limitations and barriers that they face, emerges a critical understanding of the individual and collective resources seen as antidotes. Be it the pursuit of higher education, homeownership, or even the simple act of having a savings account.

Beydan, who went to college and now works as an educator, reflected on the importance of education for upward mobility:

I've just seen so many people that have not had the chances that I have had. And then, I just see how hard my parents have worked to get us to where we are right now and like, I just see people that are not at the status that I'm at. 
So it makes me thankful first, and second it makes me want to give other people a chance to maybe move up in life, so they can get educated and have more opportunities.

\section{iv. Vision for Future Generations}

The Somali community's collective present identity, as well as its hopes and aspirations for future generations, also emerge as a vital theme within the narrative of identity formation and negotiation during the resettlement journey. Key within this vision for future generations is a call for cultural retention and continuation. Witnessing changes in individual and collective identity, both elders and youth within the community share concerns over the loss of Somali cultural identity through complete assimilation into American culture. Yasmiin shared her concerns about this:

I have boys that are growing up here, hey don't want to go back to Africa because the bad things they see on TV that oh, all the kids in Africa they are hungry, they die of hunger. I'm like, here do you get that? They will forget their identity and they will forget who they are. I don't know what Somalia look like, I would love to know more about it cause I was raised in Kenya and I came to US so I have nothing, you know, to tell people about Somalia. So, people who are younger than me are even worse, they don't know anything so it's really hard.

Some participants' narratives, including those of parents, acknowledge and even celebrate the inevitable nature of some form of identity-related adjustment: openly exploring and incorporating different cultures and ways they encounter within their new home country. While for others, the new intersections of identity are a source of lament: mourning the loss of the prideful cultural identity of their ancestors. Previous studies have shown that loss of culture and identity are determined, within a community, by family cohesion, ties in the community, ethnic pride, retention of ancestral language, and a drive to engage with one's community of origin (Asghari-Fard and Hossain 2017). One 
of the key indicators within the data of the willingness to embrace change and an inevitable evolution of identity (understood as a retention of ancestral identity, but acceptance of new elements) is the practice of marrying a non-Somali individual. Abdaale highlighted his own experience of marrying a white non-Muslim who then converted to Islam:

In my view race shouldn't have any value when evaluating a potential partner. So that is my personal view. I know in my community, going out of your race is, I have asked many people, is viewed as wrong or violating the norm. It's particularly worse for women to do that. In most cases, I would say that is the thing and the gender dynamics that I don't agree with. There are certain thing that they will tolerate for males to do, even though they think it is wrong, but tolerate it more than they would for women. So that is something that I know. If what I did was done by my sister, I was scrutinized but she would be scrutinized far greater and would probably deal with far more bigotry than I did.

Within narratives that represent the current Somali community of Portland,

participants highlighted aspects of identity that are most salient to them. Amiir shared:

We were Somalians first, now we are Somali Americans. So we fit to this country, to this culture, we fit to each other. We help each other, we are neighbors, we are proud to be Americans. We feel like this is home now, but again, there is always something that you are missing when you are here, from back home, and something that you are missing from here, when you are visiting back home.

A need for community unity, cohesion and stepping away from the clanism that has, thus far, informed and shaped the community reemerges when considering the vision for future generations. Some participants indicate that Somalis within Portland live a disconnected existence, not as cohesive and united as other Somali communities in Minneapolis, Minnesota or Portland, Maine, for instance. They speak of a need to move beyond divisions within the community in the formation of a more defined and singular 
community identity. Beydan shared on the lack of cohesion within the current

community:

Well, to be honest, I don't really think that there's a community even though there is a group of Somalis. But for me, for what I consider a community, is like people that are in contact. And they know everything that's going on with each other. And there's events and there's things going on, but there's hardly any of that here. Also, some people are, in my opinion, not included.

Haweeyo also reflected on these exclusions and divisions:

The thing is, when people are talking about clans, I don't understand that language. I don't understand different types of clans. I know for a fact that there is a hierarchy or people think they are more superior than others, but I don't, I am not very open to that.

Participants in the study mention a need to address the invisibility currently limiting the community on a social, cultural and political level that results in individuals within Portland knowing little of the Somali community: what their needs are or even their experiences. This is in part because the Somali community itself, a minority population, has also tried to maintain a low profile. While across the country, in other Somali enclaves such as Minneapolis, political participation in the name of social and political engagement is beginning to become a norm. Participants shared a growing need to have political representatives working on behalf of the community, representing it as its leaders, and putting forward a collective face. Political engagement, for the community, is equated with "being heard" and "being accommodated" as far as their specific needs and challenges go. Abshir shared why political engagement is vital:

Having a political presence is important and having a formal representative and spokesperson. So when you get that, you can influence the local politics... And then have people from the community representing us and fighting for our needs. 
Within the participants narratives also emerge concerns for future waves of Somali immigrants and refugees to the United States and Portland. Participants shared advice they would give to new arrivals, including what challenges to expect. Within this information lie indicators of what cultural values the participants hold dear and their hopes for future generations who will continue to shape the community's identity. Ayaan shared on what future arrivals can expect:

People are going to give you a lot of shit! They're just going to give you so much shit for being an African American, an African, a refugee, a Muslim, if you're a woman, if you're covered, for not speaking English, for speaking it funny, for not having the proper grammar. Like you're just going to get a lot of shit, and in all honesty, not everyone's going to be like that. They are going to be people that see you and see some kind of potential in you and then there will be a lot of people that will put you down or not see anything in you and just push you away and make you feel not valuable but you're still a human being and have a lot to give. You're a valuable person and just don't give up because I know for a fact that there's someone else looking at you. You know? There are people who treated me badly but there are so many people who supported me and just, looked up to me and my confidence for not giving up. I was their inspiration. So I want all us Somalis to continue to inspire others.

The role of an international Somali network also presents as an important theme within the narratives discussing future waves of Somali immigrants and refugees. This international Somali network is viewed as an informal global network that connects various pockets of Somali communities, large and small to each other. Participants indicated that this network is a crucial component of the community, nomadic at its roots, still on the move globally in pursuit of a better life. There were many indications of pride within this supportive network, one that would guide and uplift any refugee or immigrant arriving at any Somali community’s doorstep: be it in Portland, Amsterdam, or Cape Town. At an identity level, the existence of this network explains a critical survival 
support resource, which finds it genesis within a collective identity of "Somali" as a unified and singular identity. The diagram below summarizes the three distinct networks observed within the data.

Figure V: Networks

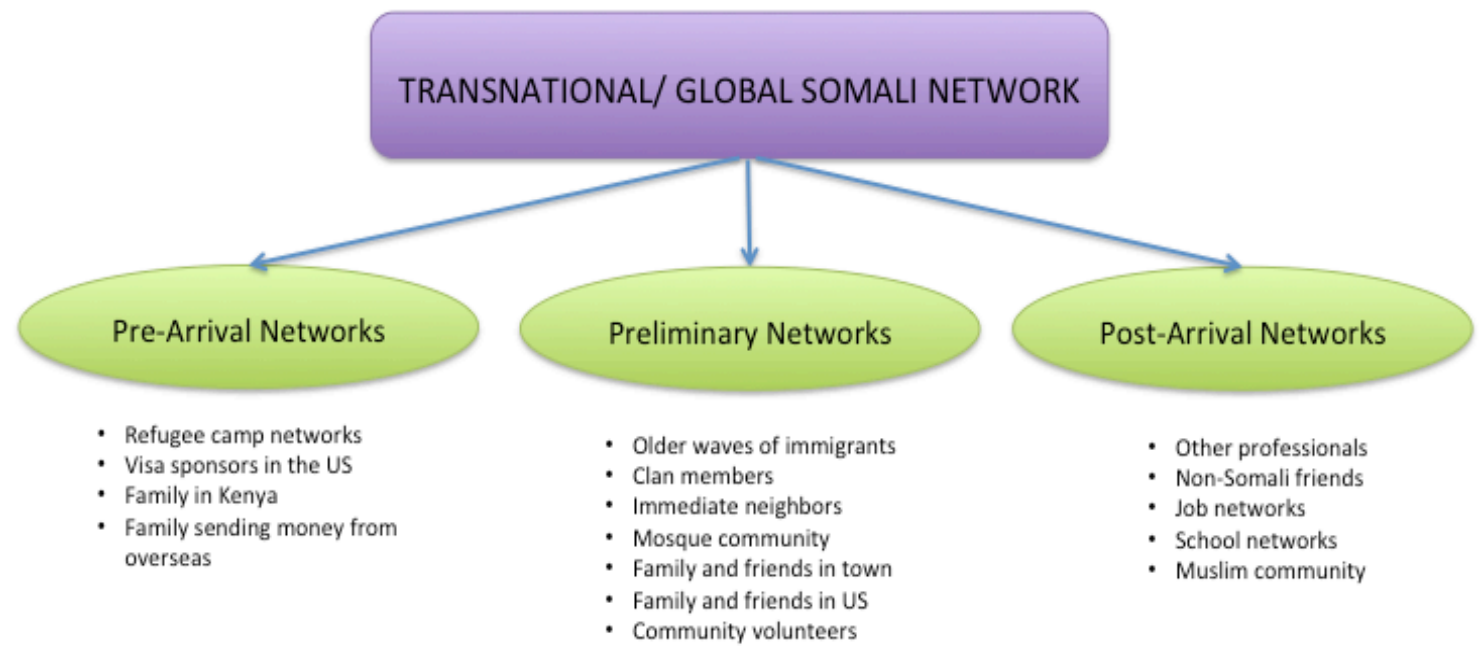

Discussed in the previous section on adjustment, the negotiation and formation of an individual and collective hybrid identity, re-emerges in understanding participants’ narratives in relation to the community's vision for the future. The inclusion and exclusion of different aspects of identity are consciously negotiated to form a tailored, hybrid identity that finds its roots within intersectionality. Somali elders and youth in Portland today negotiate labels informing their identity that are quite unique to the culture they are currently a part of: labels such as “queer" or "person with a disability" or "Somali-American" or "Muslim American" or even the highly debated identity as “African American.” Participants shared anecdotes of which identities or intersection of 
identities, were most important to them and which they feel currently define an overall community identity.

Abdaale shared his perspective on being a "third culture kid:"

I identify myself as a third culture kid. Which means my identity shifts with where I am or where or what I am doing at the time. So if you ask what my identity is while we are in a mosque, I am sure that Islam or Muslim is going to come first. But if I am at some sort of July 1st or Somali Independence Day, I will be Somali. If it is July 4th and I am celebrating American Independence Day, I could be American. Honestly, this is how I see all my identities. Different intersected identities. I look at them as if I am simultaneously all of these. I think that I am not one person. I am not just one dimension. I actually fight against people who try to choose between, "You have to be that or something else." People have endless numbers of identities. They could identify as male, as female, as whatever, as you know, as any kind of identification that is there, people I think could choose simultaneously. Once people view those different identities as mutually exclusive, that's the problem. That's impractical and wrong.

Hibaaq shared her experience with adopting the label "African American:"

Even the black people [here in the US], sometimes they will go far, like if we say we are African, don't say African-American. You are not AfricanAmerican. They are African-American, they think their role is AfricanAmerican and we are just African. So we can't claim that. Some, not everybody, but some people.

Within the narratives of identity, participants shared the individual experiences of shaping and following a personal-religion, tailored to their daily lives and needs while also creating a space for the more conventional, accepted traditional form of community religion. This distinction is highlighted as it shows an ongoing negotiation of religious identity within the current generation of Somalis, which is sure to impact how religion is viewed, understood, and practiced within future generations.

Lastly, examining the experiences of youth and elders within the community, participant narratives show a reflection of the community's past—represented by the 
experiences of the elders - and a look towards the community's future - represented by the youth. Within these narratives, aspects most salient to individual and collective community identity surface. Parents, for instance, shared their hopes for what they want their children's futures to look like. Children shared the current needs and challenges of their own parents and how this impacts how they are shaping their own identities, and the messages and values they intend to pass on to their own children someday.

\section{Social Roles as Informed by Identity}

Identity formation and negotiation informs another critical aspect of adjustment to life in the United States, viz., the social roles adopted by individuals within the Somali community. Social roles were discussed and portrayed by participants as being closely aligned with the values and beliefs held most close within one's identity. The diagram on the next page shows how an individual's identity, a negotiated hybrid identity that includes all the various intersections and experiences unique to the person, informs the various roles she/he/they adopt. These roles are negotiated and tailored within the context of the various responsibilities, associations and aspirations of the self: as a community member, for instance, or as a parent, child of an elderly parent, spouse, sibling, or an individual choosing to live independently from the extended family and community. 


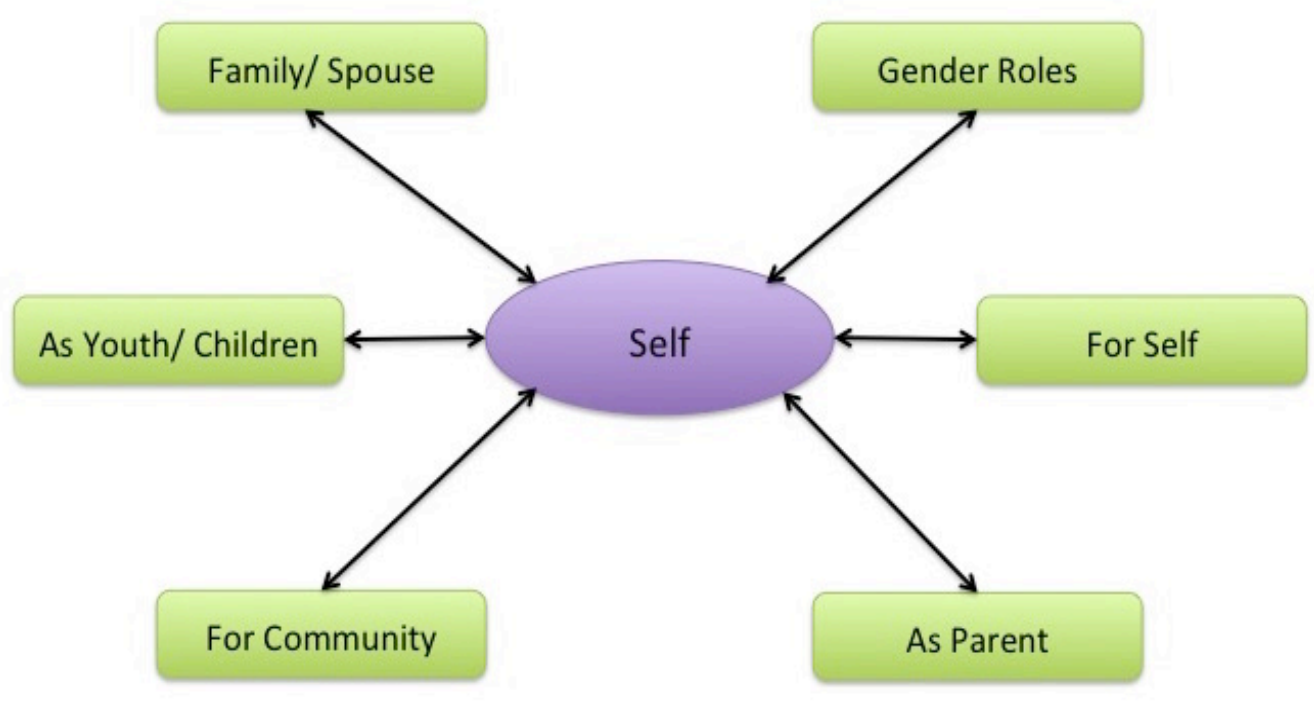

\section{i. For the Community}

One of the most vital roles practiced within current networks and in service of newly arriving community members, is that of establishing and running support groups. Women, for example, operate informal support groups for other mothers and newly married women. Helping them with everything from marital counseling to acquisition of vital arrival resources such as home furnishings or food basics. Previous studies have found, similarly, that women in the diaspora tend to be very resourceful and take on roles in seeking assistance, acquiring resources, pursuing higher education or aspiring for career advancement (Warriner 2004). Fadumo shared about a support group that she helped form for the community:

We have a women's group, we meet Saturday and Sundays for study and we have, like, every Friday we go [to the Mosque] for the Friday prayer. We do social outreach, if women need counseling, if they need like any other support, if you need just someone to talk to, yeah. By the time they [new Somali arrivals] come, we show them the Masjid, we show them where they 
can shop the halal meat, and also we show them where their next-door neighbor is where they can go in case of emergency.

There are narratives of individuals from the earlier waves of immigration, having paid their dues, taking on an intentional role to make the arrival and resettlement experiences of the newer arrivals a much smoother experience. Many work informally from their homes as translators and review important forms and documents to help their relatives and friends in their resettlement journey. Some individuals, within the broader immigrant community, take on roles to meet very specific cultural and religious needs other immigrants may have. Yasmiin shared about her interaction with one such person:

I had my son, was like five years old, and traditionally we circumcise boys. I couldn't have the chance to circumcise him back home because of some medical issue. I moved here and I scheduled an appointment and by the time I went to the doctor, they told me that to circumcise your son, you have to pay like \$2000. I said, "No, I don't have that money," and they said, okay, "Since he is not born here, or he's not like young child that was born, we only circumcise only boys that are born in the hospital..." So it was really a challenge for me because I not take him back to do this and traditionally it is something we do, so it really confused me. So, I got some contact information, I made some friends, they do some referrals and finally I found a doctor from, she's from U.S., but originally, she's from Pakistan, so does free circumcision in Oregon, California and Idaho and she's the one who said, "I can take it and do it for you." So successfully she did it. Everything went ok.

The intentional role as cultural brokers between the Somali community and support agencies or other sectors of the Portland community surfaced as a vital role among participants. An individual's intentional seeking, placement and performance as language interpreters, peer counselors, and employees are aligned with an important individual value to assist the community in some way. There was an awareness of the community's needs and challenges within those working in this capacity, as well as a 
reference point that within their own arrival experiences, the lack of these cultural brokers had resulted in many barriers.

For instance, even the participants in this study, in their role and capacity as representatives of the community, played at role closely aligned to their identities as ambassadors for their culture and experiences: they chose to play an active role in meeting with a community outsider to share their narratives. These participants were largely educated, motivated, well-spoken and well-versed in the varying experiences of their families, community members, and Somali diaspora overall, effectively assuming the role of cultural brokers. Participants also indicated a deliberate calling to occupations and careers that were seen as respectable and directly benefiting the overall community; through services provided or increased representation within these fields. Examples of these career paths included becoming doctors, lawyers, law enforcement officials and social workers. Haweeyo reflects on the Portland Somali community's needs in this area: A lot of Somalis immigrated almost 20 years ago and we are just not where we are. You don't see a lot of Somali doctors or lawyers. Maybe in Minnesota, where there are a lot of Somalis and they are very well educated. Or in Toronto, there are really well educated Somalis there. But in Portland, small cities like this, there are not a lot. There is probably one Somali doctor here. That seems absurd.

Ayaan mirrors this sentiment with her own:

I want to work with the Somali community because I'm Somali and there's just a need for it. Within the Somali community, there is no-um, I don't know anyone who's in the medical or educational field at that high position in the community. So I really want to give back to my community at some point.

Abdaale added his own perspective:

Just because I moved out of Somalia didn't mean the [collectivistic] thinking moved out of me. So there are certain things that I thought, that I 
retained. Like, thinking communally when it's warranted. In this particular instance, choosing my major was a combination of what I personally went through knowing and having a hard time understanding the education system and trying to simplify it for others. Helping others who I thought may be going through the same thing. So partly, I would say 50/50, partly was kind of a selfish thing because I wanted to understand for me, immediately, for my family and my children but for the community at large or the communities at large that would be going through this same thing.

Within the selection of college majors, graduate degrees, and eventual vocations lay narratives of advocacy and representation of the community as an underlying value and goal. For instance, for participants who have attended or are attending college, their chosen majors reflect this underlying need to get an education in a field that would benefit both oneself and one's community. This, very likely, finds its genesis within the barriers individuals, themselves, experienced in receiving support and services during their resettlement, as well as within the community, to meet their needs.

Within roles assumed by individuals towards the betterment of the community, there were also reflections on barriers. Leylo shared her experience of navigating barriers while advocating for women's rights in the community:

In the community today, everybody sort of knows everybody, new and old. They know me. They know I am educated and successful, but people are not proud of this. They think I am brainwashed and dismiss me as having learned too much of American culture and forgotten my own. I attempted to do training once for women in the community telling them about domestic abuse and what they could do. One woman came up to me later and asked me if I was ashamed of myself for losing my identity and culture and thinking "like them." I was shocked. They'd rather experience abuse in the name of tradition than give what I was saying a chance and seek help that was available to them here. It is so sad. She told me I was breaking people apart by what I was saying and was advocating for another culture. I still think that the level of education on this and other issues needs to be focused upon for the community. 
Previous researchers have found that women tend to experience pressures to conform to traditional culture both outside and especially within the home. While they experience more emancipation in the workplace, they are especially pressured at home to follow traditional gender mandates (Espiritu 2001; Kibria 1993; Pessar 1999). It is likely that Leylo's experience are embedded, at their very root, in expectations for her as woman to be more aware of "her place" socially and culturally. Venturing beyond these expectations or challenging any traditional scripts is seen as disrespectful and dividing the community.

Within narrative of roles taken on to influence the community, there were also reflections of other barriers intentionally created by community members in the name of clanism. For instance, some individuals would dissuade others from attending certain community events depending on their dislike for the individual or clan organizing it). Or even discourage individuals from supporting grassroots efforts or membership in cultural organizations as a result of these prejudices or dislikes. Beydan shares on the generational nature of this problem:

They want unity, but people, especially my parent's generation, like the generations that are older than my parents that are here, they are very stuck on clanism and they're stuck on separation and this and that and, "Oh, this person organized this event so we're not going to show up," you know?

The establishment of cultural organizations to represent one's clan or overall Somali community is another critical social role that emerges from the data. The need for unity or separation in accordance with one's values, guides this broader community engagement to pool resources, bring people together, and work for collective benefit. Beydaan shared: 
There is absolutely a need for a common community organization and space. As community, we are expanding. But I don't know if a lot of people will agree the same way because, um, there is a lot of Somali organizations that exist, non-profit ones, that some would say are functionally working but I cannot tell you about one of them that this is the work that they do. Like, there is a lot of them and some of them are even just a tribe. Some of them are sub-tribes and I think it just became, again, having a community organization became a trend. It's really bizarre to me to see almost 20 organizations, like this guy has one, this guy has one, and this one. Combining them might be a bit of a challenge. Because I don't know-even though the people, a lot of the Somalis that are all here, not a lot of them act like tribes-but at the same time, what really drives us is the tribes. We're here, we are labeled as black, African American, sometimes other, but when I'm with a lot of Somalis, I identify with my tribe. That is something that's just how it is.

Leylo, in her narrative, reflected on a time when differences were set aside and

the community came together as one, setting the stage for establishing a common

representative organization, the Somali American Council of Oregon (SACOO):

So there was a time when there was unity in the community, where I saw that a lot of Somalis were coming together. That was when the tree-bombing incident took place [2010] that really brought it out, brought Somalis together and really shocked everyone. Did this really happen? Did we let that happen? A lot of people felt a sense of responsibility because he was our kid. They realized that our actions, even as elders, has an effect on our youth. There were some that were saying that did we really let this kid slide like that, to a point where he felt like he has to do a mass suicide? So that felt like really something. But I think the aftermath that's when it started coming, it was beautiful. Like a lot of clan organizations, hey felt like the only way we can respond to it is now to come together and form one organization that speaks on behalf of the Somali in Portland or Oregon.

Within the roles taken on for the collective benefit of the Somali community is the central role of families in supporting extended family members overseas; back in Somalia, Kenya or those still living in the refugee camps. This role is one of the most important findings because it shares a central intersection within identity-based narratives 
of collectivism, Somali culture, family roles, poverty and socio-economic status and more. Yasmiin reflected on the crucial nature of this role:

When we came [to the U.S.], we left some of our family members in the refugee camp, and we know that they have nothing except what the UN gives them, so we have to work to give them money to support them.

Ayaan shared her experience with this cultural norm of supporting the extended

family financially:

I remember in high school, like I mentioned that, I was like, "Hey, my family sends a couple of hundred dollars every month," and everyone was just looking at me like, "What?! You guys do that?" The teacher was praising me like, "That is so sweet of you, "but that is so normal for us. It's so normal for us and a lot of my Hispanic friends were saying, "Why are they freaking out? We do that all the time." For us it's just so normal. My Asian friends do that. We do that all the time, but I guess, in the American culture they're very individualistic, and sometimes I can be that way too, and so everyone looks out for themselves. Yeah, every month we set aside a certain amount of money and then on holidays, or whenever they call to ask, we send extra money, you know?

Some participants shared taking on deliberate roles that are for the community's benefit, but closely aligned to one intersection of identity most salient to them. Abdaale, for instance, shared about his role in setting up an outreach and information network to educate the larger Portland community about Islam and the Muslim community:

Muslims have a bad rap in the U.S. Anything from media to interaction with local law enforcement or anything. Muslims are scrutinized under a microscope so we like to also put our footprint in a positive way. So we put together events that are open to everybody. For example, our Eid, the celebration of our holiday, we do it in our public parks. It is very visible, open for anyone to come, eat, play, whatever. So they can just see Muslims in everyday boring life. Yeah, so things like that we do. We also invite media. We featured in local TV or newspapers or things like that. Other things we do are like camping, we go as a group. We go rafting, things like that. So really, both help the non-Muslim community understand that these are just their neighbors who just want to go about their business. I go around, for example, and do talks in churches, community organizations, senior citizen groups, things of that nature. My wife does similar things like 
that. We, um, we do a lot of outreach activities. With the community of course, but sometimes we just do it ourselves.

Lastly, social roles are intentionally taken on to serve a segment of the Somali community seen to be at risk or needing added attention or services. There are narratives of young men taking on the role of soccer coaches, after-school tutors, or volunteers at the Islamic school in the community, to provide extra guidance for youth, keeping them out of trouble and focused on their studies and socioeconomic advancement. These roles were also found in previous studies such as that of Spaaij (2015). There are also narratives of young women who take on the role of driving elder members of the community home on errands, or to visit one another. Aamina shared how this stems from cultural expectations:

Like, when you see an elder person or someone carrying a child at the bus stop, in our culture, you stop and offer a ride. It's very, very disrespectful not to. Rude. They are waiting for the bus and it can be raining.

\section{ii. As Parent}

Roles participants shared of their own experiences as parents, or within reflection of their parent's identities show a deep awareness of values and beliefs important to the family and community. Parents, for instance, take on the role of cultural instructors to instill a need and respect for cultural and religious identity with their children. They do so while discouraging group participation among the younger children that would lead to bad associations, overt visibility, or radicalization. As Haweeyo shares:

When I was in high school, I was very active. I always went to meetings that have to do with Somali community or Muslim community. I was part of a lot of student organizations that did work like that. But my mom always told me, "You need to stop doing that." She was afraid that, she was you know, this whole Christmas tree thing and basically a child was kind of, who had "friends" and then he eventually went in the wrong direction with that. My 
mom knew and she was afraid, she doesn't know, but she thinks things like that might happen. She was always telling me to stop going to meetings and talking to these people because she was afraid that this might be something. She would say, "You are a child, you are a teenage girl, what is there for you to talk about?" Then I didn't understand, I thought she was just being a mean mom, but now as an adult I see it from her perspective and the danger that her child could be in to go to meetings like this. Who knows? When you have adults always asking you to come to meetings who are much older than you, you are just 14 or 15. You don't see it but your parents do.

Ayaan shares her own experiences, with her parents, of arriving and living in a post 9/11 United States:

So we came to the US in 2000, and in 2001, 9/11 happened. That was like the worst. Like my mum, she didn't let me go to camp, she didn't let me go to sleepovers, like I was very restricted on what I was doing and wasn't even because of them, it was because my mom, she was just so afraid of that they might do to me. Like she was just so, so afraid, like we would go outside to go to the park - and she would want to be there. Like she wouldn't let us do anything. Like staying after school was the worst thing you could do. All I wanted to do was stay after school and do a project or something but she wouldn't allow that because she was so scared.

Parents also work to instill other collective values such as a respect for authority and elders, and in many cases a respect for diversity and differences among the many Somali clans. Children are taught to follow their parent's example of maintaining low visibility, socially and culturally, and working hard to take advantage of the opportunities their parents were not offered or able to access.

Leylo reflects on this as a young parent herself:

Our parents did not have the experience or resources to prepare us for school or life, but our generation needs to make sure that those that come after us have the tools they need to succeed.

Parents also take on the vital role of supporting their children as they pursue the ever-important goal of attaining an education. Previous researchers have found that elders stress, highly, the importance of education in doing well in the US (Darboe 2003). 
Participants shared narratives of their parents working two jobs and carrying out household chores, such as cooking and cleaning, so that the children could focus on their schoolwork. Ayaan shares:

My dad always believed in school. My parents both always believed in school, so it was something they always wanted for us. Mom still cooks us our meals and everything because she just wants us to focus on school.

Participants also discussed the role parents took an as refugees and individuals removed from their homeland and culture of origin for the sake of their children. This intentional role as sacrificing pioneers is taken on in pursuit of a better life for their children in countries like the United States. Aamina reflected on this:

When we came here, it was completely different culture, people, everything. My mom was really depressed. I remember she was very, she was just sleep, wake up, sleep. She was very active in the refugee camps. In here it was almost like... not at all. For my mother, I think everything she did to come here was because of the best interest of her kids, I don't think it was for herself. Because, she's leaving everything she knows behind, she's leaving her friends, here she doesn't speak the language, and the weather, everything. Even to this day... she still has a hope. She never sold her house back in Somalia, over 20 something years, and she's like, "I'll go back to Somalia when you are all settled down." My mom is a visitor. For 20 years [laughs].

\section{iii. Youth and Children}

Within narratives of family values, cultural norms surrounding roles of children in a family unit and the collective expectations of siblings, the roles that youth and children take on surface. One such vital role is that of being a caregiver or source of financial support for younger siblings, parents or other family members. Elder children, for instance, are expected to work to support the needs of the family as well as their younger sibling's schooling. Some are also expected to step in as breadwinners for the whole family, compensating for parents who are retired or disabled. There is, therefore, a very 
visible experience of parentified children or the loss of childhoods at an early age, especially for participants who accompanied their parents in the resettlement journey—or arrived in the United States before their parents and families. As Haweeyo shares:

He [her father] is very proud of us, actually. He is very proud that, he wants me to go out and work and take care of the family as the older sibling. He wants me to be responsible. He tells me to take care of the siblings. So I know what my role is, he doesn't expect me to but he encourages me to.

Abshir shared his experience on arriving in the country:

I came as a minor, which was 17 years old. I wanted to go to high school but I didn't go to high school because I had to provide to my family back home. I had to work so that's why I didn't go school... I started working, yes, and I was sending money. When my family came to the US, that time I was 21 years old. That time I was older than most high school kids. The maximum age is 19 or 21? Then my parents came, my father was disabled, and my mother was also ready to retire... So I had to keep working.

Older siblings also take on an active role as mentors and guardians for their younger siblings: encouraging them to stay out of trouble, focus on their schooling, or simply offering lessons from their own experiences of discrimination and barriers they faced. Haweeyo, for instance, reflects on how she mentors her siblings by explaining things to them, comparing her own mentoring style to the traditional, more authoritarian style of her parents:

I try to talk to them... That is what I do, because I know that this what my parents could have done differently with me. Sit down and talk to me, instead of yelling all the time. That is unfortunately what a lot of parents do, they just yell and they think that it will work. That makes you hate your mom. I sit down with them and tell them, "This is why things are this way." Even today, Somali parents who are older don't do that. They don't sit down with their child and they don't say, you know, "This is who you are, and this is why sometimes it can get in the way."

Youth also take on an active role seeking and acquiring arrival and other support resources. They, on their own, learn how to network within the community, using their 
English language skills to find support services and support groups such as local mosques or community centers that can aid their families. They actively engage in youth-specific networks, such as identity groups on college campuses to seek peer support and share challenges with others like them who are living unique existences as third-culture kids. Fadumo shared her family's experience:

My brother went out [to look for help]. He took his bike and he went to college, he see some people from Pakistan and Iran and all those stuff, so he talked to them and he learned there were also other Somalis but they were not connected to them. Most have never been there to the mosque, so they didn't know. Those who were there for a month or two before us, they were also lost, so my brother found out a connection. And when he told the people that a Muslim family from Kenya is here, a lot of Pakistani people came with food, clothes, and all those stuff and jackets. And that help us a lot.

In the narratives, the participants also shared another role the youth take on that is integral to their individual and collective identities: that of being more active and vocal participants in community engagement. This presents itself as an important generational divide from their parent's tendency to avoid the public eye and courting outside attention. It also indicates an evolving community identity that influences networking styles, resources and community engagement. Previous studies have shown this tendency of refugee and immigrant youth to venture out (Bal and Arzubiaga 2014).

As Haweeyo puts it:

Visibility was always a concern [for our parents]. So I kind of just buried myself in my books academically. These were always just thoughts that I thought about or spoke about in the confinements of my friends. Now that it is during my last year of school that I kind of started, kind of, be more aware and just wanting to. Itching to read about social issues and kind of speaking up about it. People have always told me that I am very articulate and should speak up about these issues publicly. Now, I kind of want to go back into that... But first, before I go back into it, I have to educate myself [on the issues]... So, I think to be a community leader and all that is great but first I want to be genuine in the stuff that I do. 
Ayaan adds to this narrative with her own reflection:

I just feel like we definitely need more visibility here in Portland, in the Somali community. I think we need to be known not only as people who need help but as those that can help others as well. I think that is really big. We should be able to advocate for ourselves and say, hey we can help too. But at the same time, I feel that a lot of organizations can do that for us as well: try to motivate us to try and start something for ourselves. Instead of always receiving the help, for us to get together and help others.

\section{iv. Family and Spouse}

As mentioned above, an important role instilled very early into the children and youth within the family unit is that of being a model student. Education is viewed and respected as a core value for success for oneself, as well as for attaining the capacity to help one's family and community. Haweeyo shares:

I mean my dad said that the reason we came here was to get an education... I remember when we asked my dad why we came here. He didn't say we fled war, he said we came here to get an education.

Individuals who arrive in the United States prior to their family members or other

loved ones also take on a self-prescribed role of cultural guides: introducing family

members to the new American culture, sharing tips for dealing with barriers, and

negotiating a collective identity within the family that outlines its new values and goals.

Khaalid shared how he put together a presentation for his newly arrived family:

You know, when my wife and children came, what I did is I prepared a presentation for them before they came. And I put the perceptions and all the realities on it because I was doing presentations for all the public schools and all the areas for work. So I prepared one of my own, for my children, and asked them, first even before I showed them, I asked them what their perception was about America. I asked them, "You're here now, what's your expectation?" And we talked about it and we laughed about it. And we do that, so we talked about those perceptions and see how it is. So, and I told my wife, you know, whatever you are thinking, just make sure, just 
don't misunderstand. First try to find out how these things work here because you have realize it takes time.

Most participants also shared narratives that leaned heavily towards the barriers faced due to inadequate housing in Portland, be it due to cost or due to racial and ethnic segregation. Home ownership, thus, emerges as an important role within the family unit, representing both success and security by and for the family. Housing is studied as a critical indicator of successful resettlement: experienced as the post-resettlement struggle to find a stable place to call home, and within the deeply embedded identity-oriented importance of land-ownership within the Somali culture (Netto 2011) Ayaan shares:

We bought our house, like, not a lot of Somalis own a house. In Portland and in many places. My dad, he's thinking about the future. Like, he's like, "I wanna buy a house for my children, I don't wanna live in a rental where someone else owns my land or home, ” you know?

Spouses that arrive in the United States prior to their partners also take on the role of sponsors, filling out necessary paperwork, maneuvering all the red tape, and seeking the resources they need to facilitate their partners' arrival and transition into the United States. Yaasmin shared her own long journey of bringing her husband into the country: My husband, he just came recently from Kenya. Because he was a different nationality and I was a Somali refugee and he couldn't come with me. So I when I came I have to file a visa and it took me three years for him to come. I have to, when I file everything and it didn't work, then I went back to Kenya, then after three month, they approve and he came. So it was a long way...

Upon their spouse's arrival or even if spouses arrive in the United States together, there is almost always an intentional negotiation of parenting and gender roles within the family unit. This negotiation outlines the expected roles of each partner as going to work, co-parenting at home, and meeting social expectations such as volunteering within the 
Muslim community or attending Masjid events and so on. This is done within the framework of a new culture, while staying within the context of traditional roles and values. Ayaan also reflects upon divorce as a practice that has become more common upon arrival and resettlement in a Western culture:

Ifeel that divorce is very common here, it's VERY common. I know that Islamically, divorce is there but it is a last resort. But I feel that people are more likely to do that. I know a lot of women... marriage is very important to us, but I know that divorce is very common now than it was before.

Lastly, families and parents take on the active role of seeking and moving to cities and communities that more closely meet the immediate needs of their family. Depending on the values they hold most salient to their identities, families seek cities, for instance, with a low crime rate, good education and transit system, and good job opportunities. Yasmiin shared about how families in the community sometimes leave Portland, pushed out by challenges they face or pulled by resources they find elsewhere:

Some of them are moving, large families especially are moving into Minnesota. I have three family members close my tribe [clan] that moved to Minnesota because they couldn't find an affordable house with what they got, so they moved there.

\section{v. For Self}

Within the juxtaposition of individual identity versus collective family or community identity, social roles taken on by participants at the individual level emerge. These roles are important to highlight as they show independence in identity formation and negotiation, as well as the acquisition of values, beliefs and goals that are unique to the person. There is a yearning and need for living one's life outside the watchful eye of the community, or away from its societal and cultural pressures. Beydan shared her own experiences with this: 
I wouldn't want to live amongst that many Somalis. Yeah. Like, I don't mean to, it sounds terrible [laughs]. I love my people, I respect them, but I'm okay just being on my own and when I miss them, I'll go to them, get a dose of them, and then when I've had enough, I'll just back away... You know Somalis tend to live around each other, because they form a safety net around each other, we [my family] never lived in that, we have always kind of been on our own. When we miss them we go visit, we chitchat with them for a bit, then go home.

Abdaale shared a similar sentiment about living in a city with a large, overtly connected Somali community versus living in Portland, where the community is dispersed and not living together in large enclaves:

The communities are siloed in large communities like the one in Maine. You could not deviate. But here, the lines are blurred. You could pretty much do anything and people don't know where you are from. You could be under the radar. If you don't want to constantly identify yourself as someone from somewhere, you don't have to. You could just blend with everyone else.

Learning is also taken on as an active role critical to successful adjustment to the new country and culture. Learning takes on several forms: be it going to school, learning English, learning where to get support resources or learning one's rights.

Participants also indicated a need for the pursuit of individual goals aligned with their own identities and associated values. Some exhibited a very individualistic outlook on what success meant to them: prioritizing their own needs and success before turning to help the community or give back. This is important to highlight as it shows a break from the collectivistic tradition of the community and increasing self-advocacy within younger generations.

Another key role that emerged within the context of self-identity is that of aspirations for community leadership and mentorship of other youth. Some participants indicated already having tried such roles within the community while others present this 
as something they would like to work towards: as long as the old guard of older Somalis currently running the community groups, mosques and other organizations are willing to retire and show confidence in the youth's abilities to lead and represent the community. Cabdi shared:

The Masjid [mosque] community now is only led by elders. If I ever say, like me and my friends we tried to help you guys out and we wanna control the Masjid and go retire, they will all go like mad at us. They will just say no this cannot be possible. The new generation from where I am coming from I would love to see some of this younger generation taking over. Problem is an elder right now to me to them I am still the kid. No matter how many years will pass, I will still be the kid to them. And they won't ever acknowledge that I will ever like say like, "I could take over." They will not acknowledge, they cannot in fact they hate this.

Aligned with this aspirational goal of community advocacy, is that of selfadvocacy. Participants showed that they engaged in an active role fighting barriers and discrimination, linked to their identities as minorities for instance, and pushing for the best opportunities for themselves and their children. Active individual perseverance is the core driving force for this role. Ayaan shared her own experiences in school:

When I was in middle school I was really good at Math. Like I was so good, but like for some reason, my really good friend, who was white, was really pushed... like me and her would get the same grades, literally, we would do everything together but for some reason she ended up going to, like the state's and doing her Math competition... She was supported but I was not. In high school, the honor society, I had to go to them and ask, "Hey why didn't I receive an invitation from you guys? I've been pulling a 4.0 this whole time," and they're just like, "Oh, we didn't know, I'm sorry, maybe you just didn't get your paper." And I'm just like, "I didn't get nothing." Like, to a point where I didn't want to do it anymore, you know? It just got to a point where when I was in high school, I didn't want to try. I literally gave up. There were days when I literally dropped out for like a week or two where I stopped going to school... I went back because that's what my parents wanted me to do. The school wanted me to give up and drop out... Even today, I always have to remember me as a little girl. When I was a little girl, I would always say that I want to graduate high school, go to college, get my degree, take care of my parents, take care of myself. That 
was my dream. So whenever I go through something like that, I remind myself of that. That hey, you came all this way, why are you giving up now?

Others indicate that self-advocacy does not always come easy and at times, they

have to look away when they encounter discrimination. Fadumo shared:

How can I deal with it? I just kind of walk away. What is there for me to do? I'm like a short girl and you say something to me, what is there for me to do? Its hurtful but I just kind of walk away coz I know that if I try to fight it, they're just going to try to make me seem irrational, and like, call the cops or something and then it ends up being my fault, you know?

Some participants also indicated that as members of a minority clan, they had to take on the role for advocating for their rights within the community, as well as the rights of their families and loved ones in order to succeed alongside the rest of the community. Barriers, due to minority status, influenced and limited people long before they left Somalia, as Ayaan shared:

The thing for my mom is that she comes from a minority group so when you're from there in Somalia you don't have those advantages. You don't just go to school or get into school, you pay to go to school and after high school, to go to college? College is a LOT. That's not even on your mind. For you after high school, it's about getting married. Yeah. It's different for Somalilanders, like a friend of mine L, her mom's from Somalia, and she went to school. Yeah, and she like married in her late thirties, because that's so normal for them The Somalilanders they have that opportunity to go out of states to go for that opportunity. My mom did not, she was a minority. So it was different from other girls, you know.

Other participants indicated that they, or their parents, take on an active role repaying any favors or assistance they received in their arrival and resettlement journey. Citing core values of pride and honesty, they indicate that they work together with other family members to return favors, reimburse loans taken, and donate time and money to aid the arrival experiences of future waves of Somali immigrants and refugees. Ayaan 
shared about her own father's drive to pay back any favors they received as a family as soon as he could:

My mum and dad know the struggle. Like, they paid thousands of dollars. Like we were sponsored here, we had to pay for our tickets when we got here. That wasn't paid for. My dad paid that off to the church that brought us here. I think a church brought us here... When we came here, I don't think my dad really "accepted" help from these organizations, I think he was more like, "I'm taking it now but I'll pay you back later." My dad was very, he was just such a hard worker. He had like two jobs, and he was like, "I need to pay this off and need to get my kids going." He never stopped.

Some participants also indicated that they take on the role of motivating their parents, siblings, and children to engage in community service as a means of giving back. As Ayaan shared:

I always try to push my mom, tell her about certain fundraising events and she always cooks for them. She's always really happy to cook for it because I told her about it. So if you go out and tell these Somalis that, hey this person needs help or we need help with this, I'm sure they will be willing to help. They may not have much money to give but if you have them actually do something, like come and help set up whatever, I'm pretty sure they'll be willing to do that.

Lastly, some participants indicated that they take on, or plan to take on, a more active role in the rebuilding of Somalia. This is expressed as a personal, family, and community value and is shown to drive their career paths and other decisions. Within narratives shared, there are indications of wanting to return to the homeland or even support the current diaspora around the world. Previous researchers have found that it is youth who were old enough to remember Somalia and their roots when they were displaced that tend to show such fondness for return or understand "Somali" as a national identity over a cultural one. Youths who were too young to remember are typically 
ambivalent about Somalia as they have learned about it indirectly through their families

(Habecker 2017). Leylo shared her own inclinations to go back to help rebuild Somalia:

I consider this my home through and through and would not want to move back, but I do want to help with the rebuilding of Somalia if I can. I was recently offered a very good job with an international aid agency, which would have involved living six months here and six months in Mogadishu. But then the political situation got very tense there and it would have been very difficult for me there, especially with me being a woman and working there. So I decided not to do it, for now.

Abshir shared his own yearning to return to Somalia to help with the rebuilding:

To be honest, I always wanted to give back to people. The reason why I chose [my major in college] is when we talk about development, it's a broad subject. So in Africa war and destruction is there, so it makes me think that an alternative is development. So, to build instead of to break. So now I have started a business, and want to support rebuilding efforts back home.

\section{vi. Gender Roles}

Gender roles and expectations also influenced the active roles participants take on within the family unit or community. A central role taken on often by older female siblings or mothers is that of being the "protector" of younger male siblings or boys within the community. The data shows that this is an important role designed to protect the male youth within the community as they are experiencing very unique barriers, social forces and discrimination (as African-American males) within the country. Ayaan shared her concerns about Somali male youths, which stem from a lack of adequate adult supervision within the family:

It's really sad because a lot of Somali boys are going into juvenile centers and things like that - and it's just really sad because as a community we see it but we don't know what to do. Coz, its different here in the U.S. You know? Like, usually we, usually the older people get together and like try to help the family out, try to look out for their kid and stuff, but the kid doesn't really have anyone to look out for him. So he's just on his own. Both parents are probably working a lot... Like a lot of my students, their parents aren't 
home, so they come to the tutoring place, and I help them out and then they usually go home to the older siblings or something because both parents are working.

Strong women and girls, within the family unit and community, take on the roles and responsibilities of being resource-seekers and securers, network builders, and even breadwinners who support their male spouses or work on their own to support the family. Previous studies have shown overwhelming support for this tendency for women to excel more than men in the diaspora (be it academically, within career settings, or even in the ability to form and sustain support networks) and also have a higher inclination to give back to their communities and work for the betterment of their families (Lopez 2002; Portes and Rumbaut 1996; Rodriguez 2003). Some inevitably take on the role of single parents who work hard to keep the family unit intact and the children in school. Ayaan shared her own hands-on approach to oversee and support her younger siblings' education:

I mean, like, with me being an older sister and me looking after my younger siblings, I wanna trust the teachers and stuff and I look into them and I go to all the conferences, all the teacher's meetings, I do everything with my siblings because I want the teachers to know that I am here and I am supervising everything, and I know how to speak English so there is nothing that can be hidden here. Coz I feel like that was the problem with my parents, they didn't English so they didn't understand a lot of the things. The language barrier, you know? So they just let a lot of the things pass. So with my siblings, if their teachers say something to them, I go to them, I'm like hey what was this about? Like why was this said? You know, I don't want my siblings to come home and feel like they don't want to go to school the next day, you know? They have me. When I was their age, I didn't have anything, I had to deal with it myself.

Somali men, on the other hand, show a more resigned role within the arrival and resettlement experiences. This does not apply uniformly to all men within the community, but is simply highlighted here as a trend observed within the narratives of 
some of the participants. Men view seeking help from the support agencies as demeaning or emasculating. Their own arrival experiences, characterized by loss of status, educational credentials, or social standing, add to the challenges of viewing oneself as a “good provider" or "man of the house." Previous studies have also discovered this understanding of post-resettlement males as "emasculated" or "weakened" while women become breadwinners and run the households (Mohamed-Abdi 2014). Leylo shared about her experience with this:

This is the kind of dismissive discrimination we face not only when looking for jobs but every day in the smallest of interactions. Even though you give them a resume outlining all your qualifications, they take one look at you and decide you're not good enough. This happened to this one guy I know, he had so much difficulty finding a job. He struggled because his qualifications did not transfer over to the U.S., his language skills were not so sharp, they saw he was a black man, and he had a very hard time finding a job. This is why so many men in our community feel that they had it better back home. Some even say life was better in the refugee camps compared to the struggle they face here to find a job, then work menial jobs and barely afford to live!... It is especially difficult for the men and they feel like failures. Imagine how hard it is for them: they have no job, no electricity, a family to support, and know no proper English to find and keep a job. And their funding is about to run out.

Some women take on the role of actively advocating for women's rights and work towards meeting women-specific needs within the community. Some, for instance, form informal groups that support other women experiencing domestic violence, while others do presentations within the community, informing others of their rights. Female participants indicate that, many times, women have to organize in spaces other than the mosque, as that tends to be a male-dominated space. Ayaan shared:

The mosque is an organizing place for the men. Yeah, for the men [laughs]. For the women, I don't think a lot of women go to the Masjid. Like, we are very, um, I don't know, it's like that's a place we've left for the men. Yeah... I feel like we create our own groups outside [women do]. Lke my mum has 
her friends, and so they do things. And sometimes her friends and other people's friends get together and do something, things like that.

Lastly, within service roles taken on by female participants within their families and friends, there is an awareness of the need for same-gender care and support providers. This is aligned with a cultural norm as well as the needs and comfort of the elders within the community. Some examples of these include as interpreters, peercounselors, or even brokers working within the support agencies. For instance, some participants indicated that women may fair or feel better when talking to another woman who more intuitively understand her needs and can advocate for her rights. Fadumo shared her experiences working as an advocate for fellow women, both as an employee within a support organization, and a member of the community:

I work with domestic violence, that you know, most of women when they come here they still feel like they have to be beaten up or abused, you know? So I am advocate for them and told them you not feel safe, if you're not happy with the relationship, if you have any other problem, there are community members that can solve some problems, but when it goes out of hand, when it comes into violence, the community members cannot do anything. So you have to call the domestic violence or the 911 so that way, these people can help you and your kids. Put you in a shelter and until things are resolved. So a lot of women were in abuse and they get out and move on with their life. And I always encouraged them: don't rely on a man. Back home we rely on them because there was no any other way. Here you can work, find a childcare, and you will be able to make income and make something out of yourself. But when you sit at home and rely, the man will think that you're made of nothing and you can't do anything. And if you CAN show that you can contribute to the family too, he might change, you know? He will not be like bossy, he will not be "I'm the man, I'm in charge of everything." You have to show them, you know, change them in some way... Also, one income in USA is hard to support, it's hard to survive with one income. And the man will might get stressed and all that stuff because the income is not enough and there will be some negative issue in the family, but if you are bringing in a second income and he will see that you are also supporting, things will change. If the man is abusive, you can't change him, if someone is abused as a child and grow up to be abusive, you can't change that, but if they're stressed out or burnt out and are acting abusive, they 
need support. You should support them and find a job, find a childcare, or let the husband work daytime, you work nighttime, you work on your schedule and that might help to keep the family stable and, have a better life.

\section{Summary}

The central aim of this study was to explore and understand the arrival and adjustment experiences of the Somali community of Portland. This chapter presents the core findings from the data that highlight the journey of refugee resettlement, including its barriers and triumphs as it applies uniquely to the Somalis of Portland. The chapter presents this overview of findings using a timeline that includes the pre-arrival experiences of refugees - from their displacement to their stay in temporary host countries - to their navigation of the resettlement process that brought them to the United States. It also explores their immediate arrival experiences, highlighting the barriers faced within these experiences, and how these were maneuvered with internal and external resources. The narratives shared show that Somalis, as with all immigrants and refugees that arrive in the United States seeking a new start or a better life, experience their own identity formation and negotiation. Within the experiences of negotiating individual and collective identities, the values, beliefs and goals held close to the community and its members stand out vividly. Identities further inform the social roles taken on by individuals and the community as discussed in the chapter. 


\section{Chapter V}

\section{DISCUSSION}

This research study was designed to understand the reception and resettlement experiences of the Somali community of Portland, as explored by four research questions. The first question asked what the factors were that influenced the arrival and adjustment experiences of the community; the second question asked what the process and experience of adjustment of experience looked like for the community; the third question asked how these factors and the overall experience of adjustment influence the negotiation and construction of individual and collective identity within the community; and the fourth asked how well are the needs of the community met when it comes to support services and other resources for adaptation. The last chapter presented an overview of the findings, and this chapter will discuss the significance of these findings and how they add to the holistic understanding of the journey of displacement and resettlement of the local Somalis. Also presented are areas for future research as well as limitations of the current study.

\section{A. Significance of Findings}

At the beginning of this research, the experience of resettlement was expected to be understood from an endpoint of "successful refugee resettlement": a discernible moment in time when the arriving refugee is now fully adapted to life in the United States. Arrival and adjustment were anticipated to be the two ends of the resettlement journey spectrum. Almost all participants, however, corrected me by indicating that the process of adjustment never really ends. Whether one has been in the country for a week 
or a decade, they continue to face new challenges, learn, and adapt to these challenges. The findings also showed that the adjustment experience is as multi-faceted, diverse and different as the Somali community itself. Individuals within the community experience the resettlement journey in a very individualized, unique way. They do, however, share some important common experiences alongside other community members. Adjustment, therefore, must be understood as on on-going experience that is maneuvered, by the individual and the community one day, and one challenge at a time.

Additionally, it became abundantly clear during the interview phase of this study that in order to fully understand and appreciate the trials and triumphs of the arrival and resettlement portion of the journey, it was critical to explore the narratives of initial displacement as well as applying for resettlement. The findings show that the some of the most acute stages of loss, shock, and adjustment were experienced immediately upon arrival in the country. As one participant pointed out, it was the first time they felt like a refugee: far removed from the comforting proximity to their beloved Somalia. This contrast is significant: even while living in tents and makeshift shelters, or waiting in line for food rations daily, they felt less like refugees than they did upon arrival in the US. Despite living the experience of buufis in the camps, a yearning to make it to the US, the contrasting realities of arrival shattered many dreams.

This is a strong testament to the resettlement system of the country: one that has been reviewed critically within previous chapters. Displaced individuals are selected for placement in the country within a system that relegates them to a passive status, onlookers whose fates are decided for them. After all, it is dismissively assumed, they have been let into the country, what more could they need? The result is placement into 
alien environments which they have no choice in deciding over, and admittance into a scheme of integration that resembles a production line, which prioritizes economic selfsufficiency above anything else: including the long term prosperity and happiness of those chosen as the select few to make it here. The barriers to "successful adaptation" within this scheme are many, the supports few and far in between.

\section{Experiences of Arrival}

The culture of individualism hit home as soon as individuals and families arrived in the US. The message that welcomed them was clear: life here in the US is what you will make of it, and you are on your own to determine where it goes. This is critical to highlight as Somalis come from a predominantly collectivistic culture: one in which individuals and families can lean back and relax in times of need, and rely on the community to look out for them and provide them the help they need. Somalis in Portland learned, very quickly, that not many collective supports existed as part of the resettlement system. The emphasis was on promoting independence and self-sufficiency: familiar yet distant concepts for the collectivistic Somalis. The US, they learned, was not a welfare state but a capitalist one where everyone carried their own weight.

A crucial central message came through clearly within the narratives of this study: that of endurance and perseverance as a centrally Somali trait. The community has long been familiar with the challenges and disappointments that are innate to life as displaced people. They, however, manage to push forward, look at the bright side of things, and make the most of what is at hand. This was seen to be especially true of the participants within this study; all having arrived as first generation migrants who had fought to get here and made many sacrifices along the way. Optimism as well as gratefulness to having 
made it here were seen as core characteristics within the population studied. There were mentions of the younger generations, born here, not understanding the trials, sacrifices, and disappointments it took to be where their families were. This is a concept that has been shown in previous studies as well.

Discrimination and exclusion was also experienced very early in the stages of arrival to the country. Somalis arrived not having important reference points about how social stratification works in the US: a dominant deciding factor of placement being racial or ethnic background. As a community, they were more familiar with the social classifiers of income, clan affiliation or nationality. The result of this, for many participants, was an experience of exclusion and subjugation in settings such as school (for those who arrived young) or work. Many did not understand, but learned quickly, that outward appearances precede the person within to determine experiences in the country. How one looks, one's skin color, the clothes they were, their ability to speak English, and their accent determines their immediate placement. In a post 9/11 country where Muslim citizens and new immigrants were dealing with Islamophobia, Somalis quickly learned that they were "others" on many levels: Be it being black, being Muslim, or being immigrants. In a culture where, for example, children are taught not to challenge authority figures and show them respect, this intersection of discrimination and cultural norms added to the already-difficult initial transitions to the country. Youth in schools, for instance, did not speak up when they were discriminated against by teachers or other administrators or fellow students. The result was an initial silencing that is important to underline here. 
Somalis arriving in Portland, or in other cities before eventually moving here, realized quickly that the resources they landed with would determine their initial placements in American society: be it their fluency in English, any work experience they had before they arrived, if they came with the rare academic credentials that were recognized here, or even having an incessant personal drive to succeed. Other resources met them upon arrival, such as resettlement support agencies, cultural brokers within these agencies (already in place for those arriving in later waves of immigration), or preexisting networks. Social networks, and narratives of their impact on arrival experiences as well as later adjustment were prominent within this study. Networks, as mentioned before, were formed and experienced as pre-arrival, preliminary or postarrival depending on the stage of resettlement. Somalis, furthermore, developed and took advantage of other specific niches or sub-groups within these networks: be it the dominant Muslim community, or the existing Somali community, or the larger panAfrican community, or even the broader immigrant community.

Narratives highlighted the resourcefulness of Somalis as a people who survive and thrive. Information, for instance, travels fast within the global Somali network: be it telling others back home in the camps what life in Portland is like, or letting each other know locally where to go for what services, or even sending and receiving monetary help when urgently needed. The latter is a well-known feature of Somali networks in the existing literature: global remittances sent to and received from loved ones in all corners of the world through an elaborate money transfer system operated by the Somalis themselves. Locally, communities come together in the Mosque to do emergency 
fundraising if one of their own is in need. As one participant, Beydan, put it: "Tragedy unites us."

While community networks are largely experienced as resources, arriving Somalis learned that there are some elements of the networks that act as barriers. Clanism, for instance, retains the social hierarchy of the motherland, sustaining a divide in a community that otherwise would benefit from unity. Many participants shared that who they were, their family name, or simply middle and last names (indicative of patrilineal heritage) were subtle classifiers. The Somali Bantu, as minorities, especially feel the brunt of clan affiliation locally. Narratives showed that they are excluded from broader social events, are not offered the same support and services within community efforts, and also repeatedly reminded: "You are not Somalilanders". This exclusion, eventually, was to encourage the local Somali Bantus to organize independently to establish community-specific support resources. When, during the course of the data collection phase, I would ask participants about their clan identity, it would immediately be greeted with an awkward silence or nervous laughter. I recognized, quickly, that those participants that were Somali Bantu shared their clan identity freely (for they wanted to share more with me later on the barriers they faced due to their minority status). Many participants, now college educated and having seen the divisions clanism creates, made it very clear that they did not want to share their clan identity because they did not believe in a clan hierarchy. I am sure that had I interviewed their parents or grandparents, there would possibly be a freer sharing of clan identity, and the advantages and disadvantages it brought. 
The community as a network, participants shared, also acts as a barrier in some important unexpected ways: there were mentions of jealousy and sabotage within the community. In the case of one participant, for instance, her father was persuaded to resign from his otherwise stable and well-paying job because (it was told to him) that it was time for his children to work and support him. The participant shared that the economic impact of this decision of her father to leave the job impacted the family significantly: adding to their financial burdens. This inter-community "meddling" is familiar to me, as I am also from a collectivistic culture where everyone knows each others business, and very rarely do people experience or express happiness at the success of someone else.

Participants also shared another significant piece of information about the local community: that there is another hierarchy formed and sustained within it that is independent of clan affiliation - that of the wave of arrival. It was noted that the experiences of local Somalis differed significantly depending on which wave they arrived within. These waves were informally understood as the "old Somalis" and the "new Somalis". The old Somalis arrived in and maneuvered a completely alien landscape: one in which they were the first of their backgrounds to arrive, where there were no established Mosques or community networks, and there were few (if any) resettlement resources or support agencies. The new Somalis arrived in a landscape where the early pioneers had already done the groundwork to make their transition easier. Today, however, there is an indication of some bitterness regarding the "ease" of arrival of the newer Somalis. Old Somalis believe that the newer ones do not have to work as hard, have not had to suffer as much for mundane things, and are therefore spoiled and 
unaware of how easy they have it. Old Somalis, now viewing themselves as "more Americanized" or "better educated", have a tendency to look the other way when the new Somalis are struggling. A surprising rhetoric, shared within this study, was that of community members saying, "Let them suffer. There was no one here to help us when we arrived." One participant shared this as an indicator of the Americanization of the old Somalis: they were taking on the individualistic aspects of American culture (each to their own, I can only worry about myself) versus the traditional cultural norm of looking out for each other, even total strangers. As one participant put it, "We change when we come here."

Participants also indicated another vital barrier they experienced upon arrival in Portland: not knowing what resources are available to them. Many did not know the vast array of support services that existed beyond the domain of the receiving resettlement agencies, and relied upon word of mouth to learn about them. Participants showed surprise when I would discuss some lesser known services and resources in the city, saying that they had they known back then, it would have made things a little easier. This is the reason why I have outlined a section, below, on unmet community needs as well as recommendations for service agencies.

When it came to receiving services or monetary aid from the resettlement agencies, participants shared mixed feelings. Monetary aid was seen both as a resource and a barrier, although different participants within this study tended to pick one outlook over the other. Those that supported refugees getting a monetary allowance during their period of initial arrival saw a necessity in helping people who arrived penniless. Those that spoke against it felt that giving any money, even at the beginning, planted the seeds 
for long term dependence on the system (another indication of individualistic thinking, likely as a result of their longer stay in the US). The latter group felt that the necessity of making money at arrival, for survival, would launch people into a solid foundation of self-sufficiency. Both groups shared some rich narratives, from within the community, of people they knew that would have either not have made it so far without monetary assistance, or are still dependent on some form of support or another, despite their (presumed) ability to be otherwise. It is interesting to learn of these diverse viewpoints on arrival aid within the community, and it highlights the hierarchy between old Somalis and new Ones. New Somalis are more likely to support better support programs, extended monetary aid, and increased patience in allowing different speeds of adjustment through economic self-sufficiency.

Participants in the study also shared the myriad reasons that made they choose Portland for a second resettlement. All participants had arrived in a different initial city before deliberately moving to Portland. This intentional second resettlement is a testament to Portland as a city with many resources and amenities. While culturally homogenous, it offers an extensive transit network (which many participants indicated was crucial for those that did not drive), well-organized support agencies that work with immigrant groups, and also a thriving (albeit numerically small) African migrant community. Most participants indicated that they were encouraged to look into Portland for resettlement by someone they knew that was already here, or had heard about it. They also indicated that they did their research prior to arrival: learning what the job market looked like, how much housing cost, what the schools were like for the children and so 
on. It is interesting to learn that for many, Portland was an intentional and wellresearched second choice: one which they chose to call their permanent home.

Accounts of persistent poverty formed a crucial portion of the narratives shared.

Be it the loss of socio-economic status (either as a result of arrival or eventual resettlement), an inability to transfer over prior academic credentials, or the overall experience within the US system of class-based division and discrimination (be it in housing, schooling, jobs, healthcare, food access and so on). Participants showed an awareness that the system was somehow designed to keep people "in their place" once they were placed within an economic stratum. There is an indication (from my understanding of the narratives of poverty and struggling to rise above menial jobs, living paycheck to paycheck, and being able to afford basics such as housing) that the very system of resettlement is structured in such a way as to assign people to low-end jobs. Whether this is intentional or not is not as relevant as the long-term effects of the immediate placement (within the secondary labor market) of incoming refugees that is characteristic of the resettlement system. The goal is to get individuals a job, any job to get them independent, and then they are on their own. In a more holistic system, the long term economic success of the refugees would be thought about and incorporated via initial programs offering educational or vocational training, career counseling, or job networking resources (prior to job placement). Somalis arriving locally are struggling to make it, economically, within the first few months of arrival itself. The aid they are given is more often than not insufficient (some mentioned being given $\$ 600$, for example, for rent money when they rent was over \$900) and was cut off within a few months of arrival. There were indications, within the narratives, that the system of initial reception 
is designed to create desperation financially: If people are not given enough money to survive, they will have no choice buy to accept the first job they are offered. Participants also indicated that the resettlement system tends to lump all refugees and immigrants as one (which makes sense from a bureaucratic efficiency and funding sustenance perspective), which results in specific needs not being met. They shared that the needs of the elders are different from the elders, as those of men from women. It must be noted that many local resettlement agencies and support organizations do offer some rich community and population-specific programs.

Lastly within narratives of arrival experiences were mentions of critical mental health awareness and assistance. The experiences of trauma within refugee populations are well-covered in the existing literature and resettlement agencies are well-aware of the difficulties their service recipients endure due to undiagnosed and under-treated disorders and issues. The call for more mental health support (at arrival and throughout the first few years of adjustment) had a quiet yet strong presence within the narratives of this study. I believe that if mental health services are provided (as they are locally though the Lutheran Community Services counseling program for immigrants and refugees), they will be sought and taken advantage of. These programs, however, need to be culturally responsive, and tailored to specific needs (for example, having female peer counselors for female clients). There also needs to be an awareness of the stigma of mental health concerns within the community as well as the broader accessibility issues Somalis face in seeking mental health care: be it affordability, the lack of culture specific services, not having other people of color or Somalis as therapists, or the fact that mental health support is currently low on the list of priorities within the resettlement system. 


\section{Experiences of Adjustment}

Central within narratives of adjustment experiences were the formation and negotiation of identity. All participants indicated, in one way or another, that they were trying to understand and negotiate their place between different currents of culture. The most dominant arena for the clashing of culture was between their ancestral Somali culture and the culture of their new homeland: the US. Identity was witnessed as both rigid and fluid within the narratives. Some participants indicated a deeper need to hold on to parts of their culture (or their culture in its entirety) while shunning "Americanization", while others showed an affinity for acculturation (retaining the old identity while incorporating new elements from the host society). Identity was formed and shaped for all participants through the displacement experience, by the nature of their arrival, by the overall adjustment experience, as well as ultimately informing their vision for future generations of Somalis. Identity retention was a different priority for the elders/ parents versus the children. The children, part of the second-generation diaspora born in the US, identified much more freely as Somali Americans. Their parents and grandparents feared they would lose their culture and would thus actively push them to engage in everything from attending the local Islamic school, to attending after-school cultural trainings at the local Mosques. This fear of loss of culture is an understandable one, and has been prominently featured in a lot of literature on immigrants and refugees. The intergenerational differences on what identity means are also extensively studied.

Youth negotiate identity in very unique ways: be it negotiating their place in US society as African Americans or Somali Americans, or maneuvering the often polar expectations of identity at home and school, negotiating belonging in their own networks 
(such as soccer teams), or adapting to the alien US school system if they have just arrived. The Christmas tree bombing-attempt mentioned in the introduction chapters was a defining moment for the local Somalis. It thrust one of their children into the spotlight, portraying him as an Islamic extremist, which consequently was how the rest of the community was thought to be. The relatively hidden and forgotten Somalis of Portland were suddenly well known - for all the wrong reasons. This is possibly the reason why concerns for children, especially male youths, were very prominent within the narratives. There is awareness among the parents and community that male youth are more susceptible to bad influences outside the home (such as gang affiliation). There is also an awareness that Somali boys and men are exposed to and experience the same social treatment that African American males do within the country: their rights and lives threatened by law enforcement officers for instance. The result is an over-protectiveness towards sons, brothers, fathers and uncles that was very prominent within the narratives.

The experiences of elders in negotiating their identities, in contrast, vary greatly. They are portrayed in the narratives as being caught between worlds. Many were spoken of as being "visitors" in the country: dreaming of returning home to Somalia one day. Many have held on to their ancestral homes in anticipation of this moment, and have extensive family networks back home. There are many regrets among the elders: was it worth coming to the US and making all the sacrifices they did to get here? Life was definitely not as east as they had hoped it would be. They justify the prices they have paid thinking it was all worth it for the benefit and future of their children and grandchildren: who they worry may now lose their Somali culture and become American. Many await their children growing up and becoming independent so that they can return home. There 
were several, deeply saddening, narratives of grandparents isolated at home, never having adjusted to life in the US, deeply longing for the better days of their youth.

Religion and religious identity also emerged as central to the local Somali community. All the way from their life in the camps or cities of initial settlement to the US, religion has played and continues to play a pivotal role. In the camps, religious organizations showed up offering them help in exchange for learning the Quran or wearing hijabs; they were exposed to Arabic Islam early in their history; they turned to religion during times of violence and turmoil to cope. When in the US they turned to faith-based organizations and religious networks within the community for assistance. They maneuvered religious differences with Christian organizations both in the camps and within the resettlement system: making sense of their religious identity while acknowledging their need for help - any help. In the US, they maneuver individual versus collective religion: the formation of an individual religious identity seen as a sign of identity-based emancipation from the broader Muslim community. Collective religion is often practiced as performative, with deep pressures to be a "good Muslim". Also emerging within the narratives were the forgotten experiences of another minority within the Somali community: the Somali Christians who, as one participant shared, were terrified of being identified by others (for reasons unspecified to me). It was especially interesting to learn of the social maneuvering Somali cultural brokers have to do, working within Christian organizations. They are told by some of their Somali community members that they should not be working with Christians, that they were letting their people down. These participants, surprised by such accusations, try to share that the work 
they are doing is for the benefit of the community to begin with: an explanation that usually falls on deaf ears.

At the identity level, additionally, the distinction between Arabic and Somali identity were made clear to me. Many participants indicated that there was a loss of the original Somali culture (of the proud Puntland) that occurred as a result of the infiltration of Arabic culture by traveling merchants to Somalia. There was a sense that the loss of culture was not a new worry within the community (as a result of arriving in the US) but had been experienced and reconciled earlier within their history. Arabic culture came with the introduction of Sunni Islam and also the cultural ways of the Arabic people. These ways, made prominent within the Somali community, changes everything from gender roles, to community structures, to the family unit and the laws and government of the land. Many participants bemoaned the loss of their ancient culture, saying "We are trying too hard to be Arabic, and have forgotten how to be Somali."

The experiences of men and women, on a gender identity level, also formed a prominent theme within the findings of this study. Gender differences in immigrant and refugee communities are well studied in the existing literature. Within the local Somali community, it was noticed that the girls and young women were more likely to go to college for a higher education. Seen as carriers of culture at home, they were often sheltered from too much involvement in activities outside the home that could put them at risk. The girls, as a result, did much better in school (due to increased supervision, stronger networks within schools with other studious Somali girls, and the messages from their parents to excel at their studies). The girls and young women were told that they too, like their brothers, should not hold back when it came to seeking an education and a good 
career path for themselves. The result, as seen within this study, is a confident and driven younger generation of Somali women: going to college to earn degrees with which they can make a difference and give back to their families. They recognize that education is critical for upward mobility in the US, and know that earning a higher education degree will be a source of immense pride for their families.

In the older generations, gender as a component of identity is experienced differently: with the elders following the patriarchal structures and cultural norms much more rigidly. They ascribe the traditional gender norms and expectations to culture: something to be held on to. Women from this generation, within the local community, find it easier to conform to traditional gender expectations and roles. Surprisingly, however, they encourage their daughters to seek more individualized and emancipated expressions of gender for themselves. Women of all generations, as the broader literature shows, tend to be the cultural ambassadors for the community, representatives for their families (especially in settings where they go to seek support services), and driven and successful.

The men, on the other hand, are viewed as "emasculated" within the broader literature. This is understood as a loss of traditional social and family positioning as the head of the household or provider. Upon arrival in the US, many men face difficulties in getting jobs that can help support their families, or find jobs that do not pay enough. Locally, Somali women have had to venture into the workforce and into identified and acquiring the resources their families need. Women, in many ways, have become the heads of their respective households: a fact that displaces the power differential at home and within intimate relationships. This was very evident from the narratives of the female 
participants in this study. The males, for the most part, did not acknowledge any loss of status or concerns about female emancipation. Male participants with daughters emphasized that they saw no difference among their children based on gender.

Also evident within the narratives of the participants as related to identity construction and negotiation were mentions of the intersections of identity. Discussed within the literature as "hyphenated hybridity", local Somalis maneuver different elements of their identity depending on the situation they are in. I learned that the two dominant cultural identities were being Somali (of national origin) or Muslim (of religious origin). Some participants identified as Muslim over Somali, others identified as Somali first, and then Muslim. This was an interesting finding, which upon further exploration, led me to discover that identities were like clothes, a different outfit was chosen for the surrounding one was in. In other words, an individual would be "Muslim first" while at the Mosque, and "Somali first" when among other Somalis organizing to establish a community organization.

Another interesting finding that must be highlighted is that of the parentified child within the Somali family. Many participants mentioned that they had taken on parenting roles towards their younger siblings. I learned that, like many collectivistic cultures, there was an age-based hierarchy among siblings. Older siblings were recognized and respected as parents. As a result, they often take on parenting roles to support their parents who may be working two to three jobs to make ends meet. What I realized within these proud narratives of mentoring and supporting their younger siblings, was a selfless lack of recognition of a loss of their own childhood to some extent. This, however, is a cultural norm and should be understood and respected as such. 
Also prominent within the participant narratives was the call for more unity in the local Somali community: which was divided due to many reasons such as clan divisions, lack of geographical proximity, people living busy lives and so on. The participants of this study indicated that now was the time for increased visibility by the local Somalis. It was time to put aside the concerns of their parents' generation (which saw a survival necessity in lying low within the communities of resettlement) and come out as Somali Americans. Participants indicated a need to organize into a unified Somali cultural organization, to increase political and civic engagement, run for office, and have more trained Somalis in influential positions such as doctors and lawyers (that could give back to the community). An interesting contradiction to this expressed need for unity and visibility was a similarly expressed need for a small Somali community. Several participants recognized that they prefer the numerically small Somali community of Portland in comparison to the large enclave cities such as Minneapolis - St. Paul. A large Somali presence was linked to having community members meddling in each other's affairs, knowing everything about each other, and thereby restricting the freedom of the community members. Several participants indicated that while they would like to be more involved with the rest of the Somalis, they like to "visit briefly and then go home" to their own lives and independence. I understand that this, very likely, emanates from the freedom and independence members of collectivistic cultures get accustomed to living in an individualistic culture like the US. While one yearns for the presence and support of the community, one also loathes the negative aspects of too much community meddling (such as gossiping). 
Lastly, but importantly, within experiences of adjustment are the social roles taken on as a result of identity formation and negotiation. Many of these are already discussed above, but some specific examples are the roles women take on within the community as activists: forming support groups, fighting against domestic violence, helping new arrivals with basics and so on. An important finding in this study was that even the choice of college majors, in the local Somali community, is guided by a broader vision and drive to give back to the Somali community. Many participants sought degrees in community health, education or psychology so as to eventually make an impact within their communities. Even those who do not seek a higher education dedicate a portion of their time to giving back, for instance by coaching local Somali soccer teams. This is a strong testament to the rich history of the Somalis who always have their community and its benefit in the back of their minds.

\section{B. Community Needs and Recommendations for Service Agencies}

This section outlines unmet community needs as well as recommendations for service agencies as highlighted by study participants in their narratives. "Unmet needs" within this context refers to any mentions of services, support or broader changes presently needed by the Somali community of Portland to aid in their adjustment to life in the United States. These needs span both the old and newer waves of Somali immigrants and refugees present in Portland, as well as both the younger and older generations within each wave. They are not comprehensive in any way or form, and are limited to the needs highlighted directly by the participants within this study: as such they are limited to the participants' own experiences, priorities and awareness of broader community barriers. Needs presented in this section, furthermore, are not listed in order of importance. 
Recommendations for service agencies are drawn using both direct suggestions, within the interviews, from the participants or also from within the broader narratives on barriers. These recommendations are linked to the community needs in some ways, and distinct in others. Some of the recommendations listed come directly from the narratives of participants who currently work and volunteer within the service agencies, and are therefore considered vital to underline, as they are "insiders" within the support system. The overall list for recommendations, it must be pointed out, is a result of my own deduction of the data, an awareness of the current refugee resettlement system, and how this ties to the specific experiences of the Somali community as shared with me.

Sharing the community's needs as well as recommendations for service agencies within this chapter, rather than within the Findings chapter, is intentional. The information gleamed from participant interviews, as relating to unmet community needs as well as experiences with support agencies, was loosely scattered throughout the primary narratives (which consisted more heavily of narratives on the particulars of the pre-arrival and arrival experiences, as well as reflections on identity formation and negotiation). This study presents the experience of identity formation and negotiation, as it explains and influences the broader resettlement journey, as its central focus. The peripheral findings of community needs as well as any recommendations for support agencies, therefore, are presented as secondary and distinct from the overall findings. This in no way implies that these "findings" are any less important - but simply presented in the way they are as they are deemed important enough to highlight, but also outside the scope of the theoretical focus of the thesis. 


\section{Unmet Community Needs}

1. The Somali community is currently in need of broader unity and inclusion. Clan divisions separate community members, and work against the cohesion needed for any meaningful collective organizing and planning. As such, efforts made towards forming a unified cultural organization, representing the whole community, or even events organized within the community fall through. The younger generation indicates that it is time to put aside old differences and come together as one, especially as the realities of life in the United States demand this cohesion and collective representation of needs and interests.

2. The community has also been in need for a central representative organization that can be its "face" and also advocate for its needs. These needs are often unheard or ignored within settings where broader public policy decisions, directly impacting the community, are made. The community is also not as well represented within other social and cultural spaces, such as within law enforcement. As such, the community needs a representative organization that brings all clans under one roof. Thus far, the Somali American Council of Oregon (SACOO), a relatively new organization, has been the first to be able to successfully unify the community. It has been well-received within the community, and its efforts are respected and thought of as adequately representing the varied needs and interests. The organization, however, was formed and functions predominantly under the leadership of Somali men, and needs to include more female leadership and engagement. 
3. As a part of arrival support for incoming immigrants and refugees to the Somali community, there is an urgent need for mental health screening and support. Most individuals are experiencing a second displacement as a result of their journey to the United States, and are also dealing with the trauma and difficulties they experienced prior to arrival. This support should be included as part of the arrival programs available to all refugees arriving to Oregon. Some participants indicated that while there is a desperate need for mental health care, there would likely be some culturally intrinsic hesitancy to admit needing such support or utilizing any help provided. As such, it might benefit the community more if these services are mandatory upon arrival: especially a mental health screening to ascertain further needs. Such programs are currently available as part of the resettlement services provided by Lutheran Community Services (LCSNW) and others such as the Oregon Health and Science University (OHSU). They, however, need to be the norm - embedded within the arrival programming - rather than a special and separate effort within the local community that individuals have to seek out as needed. This is touched upon further within the recommendations section.

4. The community also needs gender-specific and culture-specific resources. Women, for instance, need medical care that takes into account different cultural variables that influence healthcare decisions. They need more advocates in service settings who can speak up for their rights, translate forms, and explain procedures for them. One participant indicated that her wishes to not deliver her baby using a C-section were ignored when she went into labor, and the predominantly white medical care staff made decisions on her behalf, and also talked her into signing 
consent forms she did not understand. Women also need access to resources on domestic violence awareness and support, and couples counseling to help navigate changing power differentials and gender dynamics within their intimate relationships as a result of living in the United States.

5. Upon arrival in the country, most immigrants and refugees experience a loss of academic and work and skill credentials. Sometimes this happens because their educational training abroad is not recognized in the United States, sometimes they lack adequate documentation to prove their training, and sometimes they are not made aware that they can pick up where they left off, in terms of selecting a career, getting the additional schooling needed to make up for any deficits and so on. There is a critical need to support a more seamless transfer of abilities and experiences to the new home country for all arriving immigrants and refugees. In the absence of this, many experience the loss of a lifestyle, prestige, and income they were accustomed to. Many lose the results of working towards a degree or vocational goal they had worked so had towards prior to arrival. The loss can be tremendous: both on a personal level (affecting individuals' mental health, pride, self-sufficiency, and ability to support their loved ones) as well as a on a family and community-level. Support agencies should set up programs that aid in the recognition and transfer of credentials, as well as support the gaining of any additional training required for professionals arriving as part of the resettlement program. On a socio-economic level, also, this would help prepare and further empower incoming immigrants to give back to the local economy. 
6. Participants also shared the undue stress they encounter as a result for applying for the citizenship naturalization process, which can be up to hundreds of dollars per person and is particularly burdensome for those working minimum-wage jobs, or barely managing to pay their bills. Participants indicated that any financial support made available to the community to aid with this process would be greatly appreciated.

7. Youth arriving within the community need culture-specific transition assistance and support as they maneuver a completely new schooling system within a completely alien new society, surroundings, language, and culture. Participants indicated that many times, children are enrolled within grades that match their age rather than their learning level or linguistic ability. A more realistic assessment and placement program needs to be in place, within the school system, so that the kids are empowered at the very start to succeed, and not fall behind because they are struggling to keep up. Teachers within the school system also need special training to be aware of and aid in this transition. Participants shared their difficulties in dealing with teachers who did not support them or treated them unfairly due to cultural or racial bias. This needs to be addressed thoroughly within such training programs so as to prevent a re-occurrence with any marginalized student group within the school system.

8. Participants also indicated that there is a need for a space and/or location within the community that is for the Somali community specifically. Something along the lines of a Somali community center. The existence of such a space would help bring the community together for organizing, cultural and social events, and 
would provide a space for events and programs such as weddings, after-school programs for the youth, a space for the elders and so on. In the past, such a space was made available to the community, participants shared, but this fell through due to a variety of reasons. There is still, however, a strong need for such a space and an indication that the city can and should assist in designating it.

9. Elders within the community have a variety of specific needs. One need that came up multiple times within participant narratives was that of a Somali senior center. A lot of elders live isolated lives where they are disconnected from the community, resigned, and unhappy. They miss their families back home, their land, their customs, and are homesick overall. The only thing keeping them going is the hope of going back someday. The availability of a senior center with support programming, social events, and so on would truly help reintroduce the elders to a more productive social life. They would feel included, important, and would find a purpose again, participants indicated.

10. Also linked to the experiences of the elders is a need within the community to record and preserve the narratives of the elders. Saving them for future generations, whether as video records, oral narratives, or in written form would ensure that their legacy would be passed on to their descendants. Several generations down the road, the Somali community of Portland would without doubt cherish and learn from these narratives of the early pioneers.

11. At the other end of the age spectrum, the youth of the community also need special attention and programming. Participants indicated that the youth need programs tailored to them that help them stay out of trouble, stay in school, and 
remain focused on doing well in life overall. Some participants indicated that there is also a need of programs that focus on teaching the youth about their culture and history. Youth-needs were shared to be gender-specific: with the boys and girls (my gender binary reference is intentional as it reflects participants' views) having distinct needs: the boys currently have a need to aid them in avoiding any radicalization or gang activity, while the girls need continued support to pursue their academic goals, for example. All youth need culturallytailored after-school study programs, academic and career assessment and guidance and counseling, as well as support and empowerment in making career choices, higher schooling decisions and so on. This is especially true of youth whose parents both work full-time, and are unable to "keep an eye" on their children, some participants indicated.

12. Participants also indicated there is a need for training within the local law enforcement agencies to bridge divides between them and the community. The current social reality of the discrimination and barriers that the black community of the United States faces with law enforcement impacts the Somali community too, participants indicated. There is, for instance, a direct impact on the male youth who are navigating the currents of self-identity and involvement in gang activities or other youth deviance. As such, there is a need for advocacy efforts that represent the needs of the community vis-à-vis law enforcement. One participant indicated that in the past, a local police chief visited the community to speak on bettering relationships with the Somalis, but did not care to consult community members about what their needs or experiences before hand. The 
representative used data he had acquired from the Minneapolis police department, on their Somali community, and assumed the same applied to Portland's community. Several Somali individuals in the audience walked out when this happened, as it was seen as dismissive and disrespectful. Thus, participants indicate, there is a dire need for culturally responsive policing training within the local law enforcement agencies. There is also a need for law enforcement to reach out to and include the community in crime prevention and crime aftermath efforts when a member of the community is involved. Participants indicated that when a member of the community "goes astray", everyone else takes it very seriously and comes together to learn what went wrong, how they can support those impacted, and more importantly, how they can prevent it from happening again. Local law enforcement should use this community involvement and drive as a resource within its efforts.

13. Participants also indicated that the best way to include the needs and voices of the community within such important institutions such as law enforcement and the higher echelons where public policy decisions are made is to encourage more community members to become more active politically and socially, to gain more visibility for the community, and to advocate for its needs and interests. In 2016, Portland received its very first Somali female police officer, and this was seen and celebrated as a very proud moment for the community. Participants shared that the community needs to come out of its shell, and stop fearing political engagement, and encourage each other to take on more similar roles within social institutions. 
14. Within the broader community, culture-specific needs and barriers of the Somali Bantu minority are often ignored or understood as a part of the collective. There is a need, participants who identity as Somali Bantu indicate, to reach out to and understand their unique experiences and needs as minorities. As a result of this outreach, specific services and programs tailored to the community should be developed within the resettlement system.

15. Within broader outreach efforts towards the community, be it from the media, or academic researchers, or even support organizations, participants indicate that it is important to aim to understand the various intersections of race, culture, religion, history to help bridge divides. There is a need for a more comprehensive lens of understanding that avoids viewing the community as a monolith, and understands the varying needs and interests within. Participants also indicated that, in the past, there has been a tendency to learn, write or speak about the community without approaching it and learning directly from it. They indicated that it is respectful and essential to give the community a voice by asking it what its varied needs are. This is especially true of community-related information used within the creation and amendment of public policies that impact the community directly.

16. Within the resettlement journey and experience, some participants indicated that it is critical to revisit and revise what "successful resettlement" means as it is understood by service agencies and other actors within the resettlement system. At its core, economic independence is relied upon as a singular indicator of "success". Once an arriving refugee/ immigrant has a job (any job), is paying their own bills, and is mostly free of reliance on any financial aid or support, she/he is 
assumed to be successfully resettled. There is an assumption that no further support or interaction is needed by service providers with such individuals. Even the monetary support and other support services they receive, a critical component of the resettlement system, are tapered off with time - with an expectation that economic independence and self-sufficiency must be attained as quickly as possible. While this can be understood within the socio-cultural priorities of a post-welfare capitalist state, the community and its members suffer as a result of such limited support. Participants have indicated that more longitudinal (versus more front-ended upon arrival, as it currently is) and tailored (versus lumping all refugee groups as one) support programming is needed for successful resettlement, and that the concepts of "success" and "speedy resettlement" need to be revised to include other critical milestones such as cultural adjustment, seeking and receiving mental health support, acquiring a higher education, community engagement and so on. This is touched upon further within the recommendations section.

17. Participants also indicated that one of the barriers they faced when working with support programs upon arrival was knowing that the services and support existed in the first place. Many were reliant upon the information their caseworkers provided them, or what they heard through word of mouth within their networks. Some participants expressed surprise that some services were available for all refugees within the community, because they had never heard of them. As such, they could not tell others about them. Lutheran Community Services (LCSNW) put together a directory of support resources and other services available to all 
immigrants and refugees (called the "Portland Refugee and Immigrant Community Directory"). All of the participants interviewed for this study, however, shared that they did not know that such a comprehensive, helpful resource was out there. Perhaps this is due to the fact that they were from earlier waves of immigration, and the resource listing is fairly new. Regardless of this, there is definitely a need within the community to have a central and comprehensive information resource wherein they can learn about all the services and support available to them, and are able to share this with the rest of the community or with those yet to arrive in the country. The need for this resource, preferably translated into Somali, is mentioned again in the recommendations section.

18. Participants also shared a need for support for self-advocacy empowerment within the resettlement system, and in the community as a whole. Refugees, for instance, do not have a say in which city they will get resettled in upon arrival in the country. Some participants indicated that this takes away the voice and agency of the individual or family, who is now a silent bystander as her/his fate and future are decided for her/him. Within the resettlement system, this is understood as a systemic necessity, as a fixed number of individuals are accepted for resettlement within cities and communities that open their doors to them. Despite this, some participants indicate that they would simply like to be asked and included in the decision-making process - especially since many of them have relatives, families and friends within specific resettlement cities. Reunification with them would 
greatly aid their overall journey of resettlement as they would have the networks and support available to them upon arrival.

19. Self-advocacy and its need within the community also appeared within the narratives of participants who shared that a lot of barriers they faced within the schooling system, or as employees within their first jobs, or even as seekers of support services was the cultural norm to not challenge authority or to respect authority figures and elders. As such, Somali youth in school, facing barriers from their educators would not challenge them directly. As employees, they will not stand up for their rights as easily. In support agencies, they will take what they are given, and not ask for more, or what they need. It is critical to understand and incorporate the impact of this cultural tradition and value in assisting the community within the resettlement experience. One participant summarized it well when she said, "Help us help ourselves."

20. Participants also indicated a need for increased conversations and cultural sharing with the African American community. There are currently divides between newly arrived African immigrants and the black community within this country. These divides are real and understandable. Participants, however, indicated a growing awareness that while in the United States, they are seen and treated by everyone else as African American, and no different. As such, there is a growing need to understand and embrace this identity. Participants indicated that every time someone reminds them that "You are not black, you are African!" it has a deep and alienating impact on them, which makes them feel even more so like outsiders that do not belong. 
21. Participants also shared that there is a need for parent support groups, where individuals maneuvering the journey of parenting can come together to share their experiences, challenges, needs and triumphs. This especially applies to parents worried that their children are losing their identity and culture. There is currently a need to create an intentional space and forum where parents can come together and support one another.

22. Housing emerged as a very central need within the community, and can be understood within the context of recently rising rental prices within Portland as a whole. Participants, however, shared another aspect to housing: that of understanding how housing and schooling works within the United States. A participant indicated that she did not know that the area she decided to rent in (or was able to afford to rent it), would also impact the schools her children would be able to attend. This was not information shared with her, and it was something she learned upon consultation with other parents within the network, who encouraged her to rent above her means, and "move up" so that her children would benefit. An understanding of the system of poverty within the country, participants indicate, is also something that is learned while here and while struggling to make ends meet. Many reflected on poverty as a system meant to keep one in their place and prevent upward mobility, as experienced through their own difficulties in doing better. They indicated that this is culturally specific information they could have benefitted knowing ahead of time, as it would give them some context in knowing what they needed to do different or better. Information such as this as part of arrival orientation from the support agencies, as well as more subsidized 
housing, and rent-payment support programs are desperately needed within the community.

23. Lastly, participants shared that the current refugee resettlement system largely misses the mark on one critical aspect: family reunification. Many times, it takes years to bring family members who are waiting in refugee camps overseas to join their loved ones. In today's political climate where family reunification visas, as part of the country's broader immigration system, are sought to be ended completely by conservative legislators, this is becoming even more difficult for the Somalis already here. While new Somali refugees, shut out and unable to enter the country due to the current ban on Muslim refugees from certain countries (including Somalia) have little to no hope to make it here, those who were otherwise able to join their family members already here are also suffering as a result. Families separated for decades cannot reunify, and loved ones continue to live in a flux of uncertainties.

\section{Recommendations for Agencies}

It is vital to begin this section by acknowledging the exceptional work already being done in supporting immigrant and refugee arrival and adjustment in the Portland community. Dedicated caseworkers, staff, volunteers, leaders and visionaries within local organizations go out of their way to understand the needs and challenges of those they serve, and do their best to meet these needs with the resources and support at hand. They, many times, anticipate these needs preemptively, and other times improvise what they have to work with, resource-wise, to fill in the gaps in service provision. In the course of 
researching for and writing this thesis, I have personally encountered some incredibly compassionate, forward-thinking and motivated individuals working within the major support agencies locally. Indeed, some of the participants of this study represented those working tirelessly to give back to the community with this work. This list of recommendations is made respectfully, and in the sincere hope that it brings some useful and constructive ideas to the table - adding to the work they are already doing for the Somali community, and all other refugee and immigrant communities they serve.

1. There is currently a need for a detailed arrival guide for the community containing all the information a newly-arriving refugee or immigrant needs to navigate the resettlement process. This comprehensive guide should be made available in various languages, including Somali, and should use simple language and diagrams along with photographs to be made as accessible as possible. Agencies can take advantage of their Somali caseworkers, staff and volunteers to help put together such a guide tailored to the Somali community: one which includes "tips" and narratives from the community members. Local organizations, such as the Oregon Commission for the Blind, can be approached to put together a braille version of the guide for those with vision loss. Individuals with other disabilities can also be accommodated with versions tailored to their unique needs. Information to be contained within this guide is already available, scattered, in many different places: organizational websites, community brochures, procedural manuals, and so on, and simply needs to be consolidated in one place to be shared and updated as needed. Such a guide would, ideally, contain information on the 
resettlement system (how it works, its ins and outs), expectations of individuals who are service recipients, their rights and responsibilities (understood again as expectations), what support services are available locally (LCSNW's Refugee and Immigrant Community Directory on local resources can be included as a part of this, as the work has already been done exceptionally well), and lastly a guide to the local community (including customs, culture and traditions). Organizations might have to work together to create such a consolidated, succinct resource, but it is one that would aid innumerable clients upon arrival, as they navigate this very confusing and intimidating system for the very first time.

2. It is also vital to continue to make the procedure of connection to other community members a core component of the initial arrival support. Participants in this study shared that a connection made, at times within the first day of arrival itself, was most critical as it helped them feel at home knowing someone who spoke their language, understood what their immediate needs were (for instance, where to buy halal meat), and would help them navigate all the forms and agencies they had to navigate. Such community-liaison volunteers from within the Portland Somali community should be made a part of the resettlement services programs, perhaps as its own volunteer program that comes with some regular perks or formal acknowledgements.

3. Individuals arriving to the country, encountering the currency for the very time, experiencing the system of credit and credit cards, and navigating bills for the first time need all the help they can get to make sense of everything. There is a dire need for budgeting assistance in the community, as well as financial wellness 
assessments and counseling. This can be put together as a separate support program that draws in community volunteers, supporters and donors such as local banks or credit unions. Participants in this study have indicated that the way arrival assistance works in the form of money they are eligible for as well as bills they are required to pay is very confusing, they can use additional support and guidance to ensure they get a strong fiscal foundation upon arrival, which will aid in further successful resettlement.

4. As mentioned in the previous section, mental health care programs are an urgent need within the community. While such programs are available, in one form or another, within the community, they are not an integral part of the resettlement system as, say, job placement or English-language training. Their accessibility is reliant upon individuals recognizing that they need the services, knowing where they are available (affordable and tailored to multicultural contexts), and then navigating the hurdles to get in the door (many low-cost clinics have long waits, for instance, and provide short-term care). Mental health assessment and care is essential when working with a population such as refugees because they are maneuvering multiple external and internal challenges at once: displacement and second displacement, a loss in socioeconomic status if their credentials do not transfer over, loss of their homes and loved ones, culture shock, family issues, identity negotiation and so on. Tailored trauma-informed care is needed to best support and empower individuals who are arriving already weighted-down with challenges and barriers even before they enter the country. We then expect them to have a speedy resettlement experience, and be successful productive citizens 
who get to work and become financially independent. Their internal turmoil, in terms of mental health needs, is most often ignored because it is an invisible struggle - one that shows itself in times of extreme stress and duress where individuals have nervous breakdowns or need hospitalization for more acute psychiatric care. Participants in this study have indicated that stressors such as everything from an inability to pay bills on time, to worrying about loved ones back home, to dealing with the trauma they experienced makes mental health care one of the most essential current needs within the community. Mental health screening as well as follow-up care such as individual or group therapy should be a mandatory part of the resettlement services everyone receives upon arrival. At the very least, a mental health screening should be required of everyone to assess their needs and then be referred out as needed. Organizations such as Lutheran Community Services already have a successful program that provides such screening and culturally-responsive care to clients, but this needs to be the broader norm within the resettlement system.

5. In addition to screening and assessment for mental health needs, there also needs to be similar attention paid to needs based on disabilities. For many individuals arriving as refugees and immigrants, some disabilities are undiagnosed because they are invisible (such as learning disabilities) and others that are visible have not previously received treatment or support. It is vital to include the awareness of disabilities, and provision of support and accommodations as needed, as a critical component of resettlement programming efforts. 
6. Participants also indicated that there is a need for more translation help when it comes to understanding and navigating the forms and instructions needed to learn about, sign up for, and receive the various support efforts available to them. My recommendation is that while translators, be it volunteers or even staff within the agencies, are essential, it would also help to have the forms, brochures, and guides translated into the various languages of the primary clients the agencies work with: in this case, translated into Somali for easy access.

7. Participants in this study have also indicated that there is a continued need for service agencies to recruit, train and include more Somali employees. These cultural brokers help bridge the divide between the service providers and the communities they serve. Most agencies already recognize this, and tailor their staff recruitment efforts as such. This recommendation is made to encourage even further intentional and tailored efforts to include the communities served within the agency setting.

8. Once Somalis are hired it is critical to provide them with special support as they navigate their often-challenging work of being "in-between" the system and the community they come from. Many face some real challenges in the demands they navigate from the community: including at times assumptions and allegations of favoritism, withholding of resources, and not being willing to do their jobs. Often, service recipients file formal complaints against those from within their own communities because they feel that they should go above and beyond in helping them, and catering to their every need. For an employee working within the limits of policies, procedures and limited available resources, this can be very difficult, 
and makes an already-challenging job (of being a caseworker, for instance) even more difficult and thankless. As such, it is vital for service agencies to routinely check in with their in-community employees and provide them all the support and tools they need to do their work. One such tool can be a standardized procedures and policies guide translated in Somali. Such a guide would help create norms for expectations and roles between clients and caseworkers, for instance, and would detail all the procedures policies both would need to follow. It would eliminate or reduce any misunderstandings, and will empower clients with the information they need.

9. Participants in this study have also indicated that much of the support programs offer them is heavily front-ended: they focus almost entirely on the initial arrival difficulties such as linguistic barriers or job placement. There is currently a need for more longitudinal, longer-term support within the community. Keeping in mind the funding limitations support agencies already face, including the everpresent threat of funding cuts, it might be possible to acquire support for such programs through grant applications, or by advocating for such programs within research conducted as part of routine program evaluation.

10. Participants have also indicated that there is a dire need for more structured vocational and career assessment and placement programs that focus upon job and skill training, job placement, in-job support and also including credentials, skills, and experiences acquired prior to arrival in the country. While many agencies provide some form of vocational preparation support, participants indicate that this is a core need and more needs to be done to help clients. 
11. It is also vital for service agencies, especially those working under an overseeing organization that is faith-affiliated to fully explore, understand and explain the role of religion in the work they do. Participants have indicated concerns about seeking or receiving help from organizations that are affiliated with religions that are not their own, and wondering what was wanted from them in return (concerns of proselytizing, for instance). It is vital for caseworkers and other staff members to freely broach the subject of religion in social work, within the context of individual agencies, with their clients. It is critical to go towards such dialogue with an open mind, and assure clients that while there may be a Christian cross on the business cards, for example, this does not mean one needs to be Christian to be helped. Clients would also benefit from learning the rich history of how faithbased organizations work alongside federal and state social welfare agencies, and receive much of their funding from these secular sources to do the social outreach work they do.

12. Participants have also indicated that service providers need to learn the community's specific needs and barriers from the community directly. When it comes to routine program evaluation within agencies, it is important to conduct regular assessments of the service recipients as well: asking them what worked, what did not, and what recommendations they may have. This makes the clients feel included and heard. Participants also indicated that most immigrant and refugee communities within Portland are understood to be monolithic and treated as such by support providers: assuming that needs are identical within different populations. While this approach provides a good beginning position for serving a 
particular community, participants have indicated that more tailored and culturespecific programs are needed that take into account differences and diversity in needs.

13. Some participants within this study asked for a crime and deviance prevention program that focuses upon the youth and includes the community in its efforts, as well as a tutoring program for after-school support for the youth. Elders within the community also need more programs that bring them together and give them a purpose. Participants have further indicated that there is a need for support programs for family members back home. One of the primary stressors for individuals currently here is supporting their loved ones back home, and worrying about their safety and security. Any intentional programming that helps alleviate this responsibility in some way would help the community a lot.

14. This last recommendation is vital for all service agencies locally, albeit an "ideal world" one. Participants have shared that different agencies, scattered all over different locations in town, provide different services. This reduces accessibility to support services in many ways for clients: many have to navigate public transit to go to different offices to ask for different support, and also have learn the differences between the services they are eligible for and provided at the site they are at. Ideally, clients would benefit from a one-stop-shop system where all services are consolidated, explained, and provided to them. While this is difficult given how different agencies are a part of different overseeing organizations and funding sources, I have personally witnessed an already-strong collaboration between agencies in Portland, with referrals made between each other to get the 
clients the help they need. This collaboration needs to be continued and sharpened keeping the clients' ease of access and use in mind.

\section{Future Research}

While this study has aimed to maintain a broad line of inquiry to understand, holistically, the arrival and adjustment experiences of the local Somali community, throughout the data gathering and analysis process, themes and topics emerged that in hindsight would have been good to inquire about and incorporate. Many of these topics came about as mentioned directly by the participants, some spoken about forthright, while others hinted at, and yet others making their presence known within the unsaid. Understanding, for instance, vital identity intersections such as visible and invisible disabilities, gender and sexual identity, mental health needs and being children/ parents within single-parent households or families experiencing abuse or domestic violence would be a helpful line of inquiry. Also critical to understand is the experience of the perceived and experienced "emasculation" of fathers and young men within the community as a result of the displacement experience would be interesting to explore within the local community. The theme that arose within the data, of the overprotectiveness towards boys and young men was seen as prevalent elsewhere within the current literature and would be interesting to study locally. The intersection of African American identity and culture with Somali American culture also makes for an interesting study, while exploring what it means to be "Somali" in the current sociopolitical climate of xenophobia, racism, Islamophobia and discriminatory immigration laws would be vital. It would be important, for instance, to understand the impact of the current climate on the community present here, and on those waiting for entry to the 
country. It would be also interesting to explore what it means to members of the community to be a minority on so many levels (race, gender, religion, gender/ sexual orientation, national origin and so on).

Also important to study, within the local Somali community, are the intergenerational narratives surrounding identity and cultural retention. Children of immigrant parents and grandparents were, for the most part, spoken on behalf of within this study. It would be interesting to compare their perspectives on belonging, on their motivations to ever return to Somalia, and the overall future evolution of Somali identity. It is also critical to carry forward the current studies on the mental health needs and experiences with trauma informed care of the local Somalis. What do their interactions and care look like when dealing with mental health service providers who do not share vital identity intersections or experiences with them? What are the barriers in sharing their needs and challenges with another person of color, or a member of their own community who may be available to work with them in a mental health services setting?

It has become abundantly clear from my experiences within this study that the narratives of elders within the community: their stories of loss, hope, survival, pride and homesickness need to be captured and preserved for future generations. Within this study, their experiences were spoken about by their children and grandchildren: they were primarily these shadow figures that were in the background: longing for their countries of birth, their separated loved ones, and past lives that they considered much happier.

It is also important to further explore gender roles and expression within the community: especially within an Islamic cultural context. It would be interesting to see if and how future generations transcend the gender binary and experience alternative forms 
of gender identity, norms and expressions as a result of their identity negotiation and continued adjustment within the country. Lastly, on an identity level, it would also be interesting to know if there is currently any effort within the community to reclaim a precolonial and pre-Arabic identity, for instance that from the ancestral Puntland. There were mentions within this study about youth as "lost" culturally and about the community taking on an Arabic identity and forgetting its "Somaliness". It would be interesting to focus on this in more depth.

\section{Limitations of Study}

Whenever an attempt is made by a researcher to understand the experiences of a culture or people that are not her/his/ their own, there is an innate risk of missing the mark vastly. Significant limitations arise in a study like this due to the "outsider looking in" status of a researcher like myself. While I did share some common identity-based similarities with the Somalis I wanted to understand: being a person of color, an immigrant, and from East Africa. I also did not share some critical common experiences and identities: I am not a black person, I am not a Muslim, I was not forcefully displaced from my home, and I did not have to endure endless barriers and problems in my journey to come to the United States. I consider this "distance" between myself as a researcher and the community that let me in, and shared their stories a "limitation". I was told, however, that my status as an outsider was seen as welcome by many: that I would look at the community with a fresh pair of eyes, that I would be able to practice the humility and objectivity such a study needed, and that it is within our differences that I would find an ability to draw comparisons and understand their narratives better. 
Another major limitation of this study has been the silent voices within it: the two ends of the age spectrum that remained vastly unrepresented. These were the elderly parents and grandparents of the participants, and their young children. They were spoken about by their children and parents (the participants) and it would have been nice to be able to capture their voices as well - giving this study somewhat of a holistic representation. It was my hope, at the start of this study, to be able to interview individuals across different age groups within the community. I quickly learned that, of course, it would be the younger, educated, English-speaking, community oriented individuals that would come forward to participate in an academic study of their community. Linguistic, cultural and other accessibility barriers kept the elders away from my efforts to get to know them. Even if I did encounter them, what would our conversations have been like? I had assumed that my fluency in Swahili would have been helpful in transcending the barriers of communication: but participants in this study were quick to tell me that their fluency in Swahili had greatly diminished since they arrived in the US (for many, they did not live in Kenya long enough to learn the language, or did not venture outside the linguistic enclaves of the refugee camps where everyone spoke Somali, or even were too young then to remember the language today).

That being said, every effort was made to make the sample within this study as representative as possible of the local Somali community. Any assumptions or generalizations made, being unaware or simply ignorant, were crosschecked with the research participants who were kind enough to quickly educate me. This study also aimed to represent a proportionate number of men and women: so as to capture their diverse 
experiences of displacement and resettlement. It does not, however, represent other nonbinary-conforming individuals within the community.

\section{E. Conclusion}

This study set out to understand the arrival and adjustment experiences of the Somali community of Portland. Their experiences were understood using a broader framework of the US refugee resettlement system as well as the experiences of the immigrant diaspora within the country. The factors influencing the arrival and adjustment experiences of the community were explored using a longitudinal timeline that spanned the displacement experience, exile in refugee camps, applying for resettlement in the US, and finally arriving in the country. The resources and barriers that influenced the journey, at each stage, were understood.

Also understood was the experience of adjustment within the community. One of the core reasons to undertake this study was that the experiences of local Somalis were hidden to the rest of the city: their trials and triumphs within their adjustment experiences were consequently unknown. Within this study, some important details of the nature of the adjustment experience, embedded within narratives of identity formation and negotiation, were learned.

Lastly, and perhaps most importantly, the overall experiences of the local Somalis within the resettlement system, were understood. Details of how well their needs are met were explored using a backdrop of local faith-based and secular support agencies.

Furthermore, the unmet needs of the community, as well as their own recommendations to service providers were learned and highlighted: with the hope that it improves the experience of arrival and adjustment for current and future generations of Somalis. 


\section{An African Prayer}

by Samuel Manguale Apach

(Sudanese refugee)

Let there be peace in Africa.

Peace is based on justice.

Peace depends on the establishment of justice and the respect for the rights of all men and women.

Peace is not simply the absence of war, but is the fruit of justice and love.

Let there be peace in Africa. We have to transform the mentality and dismantle the structures that generate oppression of people.

Let there be peace in Africa.

Our beloved continent.

Our ancestors' land. 


\section{References}

Abdi, C (2006) "Diasporic Lives and Threatened Identities: Gender Struggles of Somalis in America," Ph.D. Dissertation, Department of Sociology, University of Sussex, East Sussex, U.K.

Abdi, C. M. (2014). Threatened Identities and Gendered Opportunities: Somali Migration to America. Signs: Journal of Women in Culture and Society, 39(2), 459-483.

Asghari-Fard, M., and Hossain, S. Z. (2017). Identity construction of second-generation Iranians in Australia: influences and perspectives. Social Identities, 23(2), 126-145.

Asher, N. (2008). Listening to Hyphenated Americans: Hybrid Identities of Youth From Immigrant Families. Theory Into Practice, 47(1), 12-19.

Shome, S. (2011) Assimilation of Somali Refugees and Immigrants in the Kansas City Area. Dissertation submitted to the graduate degree program in Geography and the Graduate Faculty of the University of Kansas in partial fulfillment of the requirements for the degree. (n.d.).

Barbera, M. La. (2015). Identity and Migration in Europe: Multidisciplinary Perspectives, $13,1-14$.

Bashir, A., Muse, A., and Curry-Stevens, A. (2016). Oregon Somali Community Needs Assessment: The Somali Community in Oregon. Retrieved from https://multco.us/file/56387/download

Bayer, P., Stephen L. R., and Giorgio T. (2008). "Place of Work and Place of Residence: Informal Hiring Networks and Labor Market Outcomes.” Journal of Political Economy 116: 6: 1150-1195.

Bek-Pedersen, K., and Montgomery, E. (2006). Narratives of the Past and Present: Young Refugees' Construction of a Family Identity in Exile. Journal of Refugee Studies, $19(1), 94-112$.

Benson, G. O. G. (2017). How refugee community groups support resettlement, (February), 50-52.

Berry, J. W. (2001). A psychology of immigration. Journal of Social Issues, 57(3), 615632.

Berry, J. W. (2005). Acculturation: Living successfully in two cultures. International Journal of Intercultural Relations, 29(6), 697-712.

Berry, J. W., Phinney, J. S., Sam, D. L., and Vedder, P. (2006). Immigrant youth: Acculturation, identity, and adaptation. Applied Psychology, 55(3), 303-332.

Blackledge A (2005) Discourse and Power in a Multilingual World. Amsterdam: John Benjamins.

Bloem, J., and Loveridge, S. (2017). The secondary migration of refugees resettled in the US, (February), 26-28.

Bourhis RY, Moïse LC, Perreault S and Senécal S (1997) Towards an interactive acculturation model: A social psychological approach. International Journal of Psychology 32: 369-386.

Brubaker, R., and Cooper, F. (2000). Beyond identity. Theory and Society, 29, 1-47.

Bucholtz M and Hall K (2005) Identity and interaction: A sociocultural linguistic approach. Discourse Studies 7: 585-614. 
Buyer, M. (2008). Negotiating Identity and Displacement among the Somali Refugees of Cape Town. South African Historical Journal, 60(2), 226-241.

Carling, J. (2002). Migration in the Age of Involuntary Immobility: Theoretical Reflections and Caper Verdean Experiences. Journal of Ethnic and Migration Studies 28 (1): 5-42.

Carling, J. (2014). The Role of Aspirations in Migration. Paper presented at Determinants of International Migration, International Migration Institute, University of Oxford, September 23-25.

Carlson, S. (2005). Contesting and Reinforcing Patriarchy: An Analysis of Domestic Violence in the Dzaleka Refugee Camp (Working Paper 23). Oxford: Refugee Studies Center, University of Oxford.

Castles, S. (2010). "Understanding Migration: A Social Transformation Perspective." Journal of Ethnic and Migration Studies 36 (10): 1565-1586.

Cerulo, K. A. (1997). Identity construction: New issues, new directions. Annual Review of Sociology, 23, 385-409.

City of Portland, Office of Neighborhood Development. (2017). People and Programs. Retrieved July 12, 2017, from https://www.portlandoregon.gov/oni/?c=62226\&a=448753

Colic-Peisker, V. (2003) 'Bosnian refugees in Australia: identity, community and labour market integration', New Issues in Refugee Research. UNHCR Working Paper No. 97, online at www.unhcr.ch

Colic-Peisker, V. (2005). “At Least You”re the Right Colour': Identity and Social Inclusion of Bosnian Refugees in Australia. Journal of Ethnic and Migration Studies, 31(4), 615-638.

Colic-Peisker F., V. . T. (2006). Employment Niches for Recent Refugees: Segmented Labour Market in Twenty-First Century Australia. Journal of Refugee Studies, 19(2), 203-229.

Colic-Piesker, V., and Walker, I. (2003). Human Capital, Acculuration and Social Identity: Bosnian Refugees in Australia. Journal of Community and Applied Social Psychology, 13(July), 337-360.

Connor, P. (2010). Explaining the Refugee Gap: Economic Outcomes of Refugees versus Other Immigrants. Journal of Refugee Studies, 23(3), 377-397.

Connor, P., and Krogstad, J. M. (2016). 5 facts about the global Somali diaspora. Pew Research Center, (April). Retrieved from http://www.pewresearch.org/facttank/2016/06/01/5-facts-about-the-global-somali-diaspora/

Darboe, K. (2003). New immigrants in Minnesota: The Somali immigration and assimilation. Journal of Developing Societies, 19(4), 458-472.

De Beauvoir, S. (1983). Women and the politics of the family. In S. Groage and K. Offen (Eds.), Women, the family, and freedom the debate in documents (pp. 247-412). Stanford: Stanford University Press.

De Fina, A. (2007) Code-switching and construction of ethnic identity in a community of practice. Language in Society 36: 371-392.

De Fina A., Schiffrin, D. and Bamberg, M. (eds) (2006) Discourse and Identity. Cambridge: Cambridge University Press.

De Haas, H. (2011). “The Determinants of International Migration, Conceptualising 
Policy, Origin and Destination Effects.” Paper Demig project 2. Oxford. IMI working paper 32 .

Developments, K. (2017). Latest Horn of Africa Fact Sheet, 2017.

Dolan, J. (1975). The immigrant church: New York's Irish and German Catholics, 18151865. Baltimore: Johns Hopkins University Press.

Donato, K. M., Gabaccia, D., Holdaway, J., Manalansan, M., and Pessar, P. R. (2006). A glass half full? Gender in migration studies. International Migration Review, 40(1), $3-26$.

Eby, J., Iverson, E., Smyers, J., and Kekic, E. (2011). The Faith Community's Role in Refugee Resettlement in the United States. Journal of Refugee Studies, 24(3), 586605.

Ebaugh, H. and Chafetz, J. (2000). Religion and the New Immigrants: Continuities and Adaptations in Immigrant Congregations. Walnut Creek, CA: Altamira Press.

Eno, O (1997). The Untold Apartheid Imposed on the Somali / Jareer People in Somalia. In H.Adam. Mending Rips in the Sky: Options for Somali Communities in the $21 \mathrm{st}$ Century. Laurenceville: Red Sea Press.

Eno, O (2009). African Urban Spaces in Historical Perspective (Rochester Studies in African History and the Diaspora). Rochester: University of Rochester Press.

Eno, O. A., \& Eno, M. A. (2008b). The Making of a Modern Diaspora: The Resettlement Process of the Somali Bantu Refugees in the United States. In T. Falola \& N. Afolabi, (Eds.), African Minorities in the New World. New York, NY: Routledge.

Espiritu, Y. L. (2001). "We don't sleep around like White girls do": Family, culture, and gender in Filipina American lives. Signs: Journal of Women in Culture and Society, 26(2), 415-440.

Fishman, J.A. (1989) Language and Ethnicity in Minority Sociolinguistic Perspective. Clevedon, $\mathrm{OH}$ : Multilingual Matters.

Gal S (2006) Linguistic anthropology. In: Brown K (ed.) Encyclopedia of Language and Linguistics. Oxford: Elsevier, 171-185.

Garcés-Mascareñas, B., Penninx, R. (2014), European University Institute., Robert Schuman Centre., and Migration Policy Centre. (n.d.). Integration Processes and Policies in Europe : Contexts, Levels and Actors.

Giddens A (1991) Modernity and Self-identity: Self and Society in the Late Modern Age. Cambridge: Polity.

Gleason, P. (1968). The conservative reformers: German-American Catholics and the social order. Notre Dame, IN: University of Notre Dame Press.

Gold, S. J. (1996). From the workers' state to the Golden State: Jews from the former Soviet Union in California. Boston: Allyn and Bacon.

Gordon, M. (1964). Assimilation in American Life: The Role of Race, Religion, and National Origins. New York: Oxford University Press.

Grinberg, L., and Grinberg, R. (1989). Psychoanalytic perspectives on migration and exile. New Haven: Yale University Press.

Habecker, S. (2017). Becoming African Americans: African Immigrant Youth in the United States and Hybrid Assimilation. Journal of Pan African Studies, 10(1), 5575.

Handlin, O. 1951. The Uprooted: The Epic Story of the Great Migrations that Made the 
American People. Boston: Little Brown and Co.

Hardwick SW, Meacham JE. (2008) "Placing" the refugee diaspora in Portland, Oregon:

Suburban expansion and densification in a re-emerging gateway. In: Singer A, Hardwick S, Brettell C, editors. Twenty-first century gateways: Immigrant incorporation in suburban America. Washington, DC: Brookings Institution Press pp. 225-256.

Hatoss, A. (2012). Where are you from? Identity construction and experiences of "othering" in the narratives of Sudanese refugee-background Australians. Discourse and Society, 23(1), 47-68.

Harper, M. (2012). International African Institute., Royal African Society., and Social Science Research Council (U.S.). Getting Somalia Wrong? : Faith, War and Hope in a Shattered State. Zed Books.

Herberg, W. 1960. Protestant, Catholic, and Jew: An essay in American religious sociology (2nd ed.). Garden City, NY: Anchor.

Hill, M. 2010. "No Redress: Somalia's Forgotten Minorities.” Minority Rights Group International.http://reliefweb.int/sites/reliefweb.int/files/resources/DCAF9B4C12ED 9AC8C12577E4004A9973-Full_Report.pdf

Hirschman, C. (2004). "The Role of Religion in the Origins and Adaptation of Immigrant Groups in the United States.” International Migration Review. 38:120633.

Ho, D. (1995). Internalized culture, culturocentrism, and transcendence. Counseling Psychologist, 23 (1), 4-24.

Holtzman, J. D. (2000). Nuer journeys, Nuer lives: Sudanese refugees in Minnesota. Boston: Allyn and Bacon.

Horn, R. (2010). Exploring the Impact of Displacement and Encampment on Domestic Violence in Kakuma Refugee Camp. Journal of Refugee Studies, 23(3), 356-376.

Horst, C. 2006. "Connected Lives: Somalis in Minneapolis, Family Responsibilities and the Migration Dreams of Relatives." Research Paper no. 124, New Issues in Refugee Research, UN High Commissioner for Refugees, Geneva. http://www.unhcr.org/44b7b6912.pdf.

Huisman, K. A. Editor; Hough, Mazie Editor; Langellier, Kristin M. Editor; and Nordstrom Toner, Carol Editor, "Somalis in Maine: Crossing Cultural Currents" (2011). Faculty and Staff Monograph Publications. 48.

Hume, S. E. and Hardwick, S. W. (2005), African, Russian, and Ukranian Refugee Resettlement In Portland, Oregon. Geographical Review, 95: 189-209. doi:10.1111/j.1931-0846.2005.tb00362.x

Hussain Y, Bagguley P, 'Citizenship, ethnicity and identity: British Pakistanis after the 2001 'riots', SOCIOLOGY, 39.3 (2005), 407-425

Ioannides, Yannis M. and Linda Datcher Loury. 2004. "Job Information Networks, Neighborhood

Effects, and Inequality.” Journal of Economic Literature 42: 4: 1056-1093.

Iredale, R. (2001) 'The migration of professionals: Theories and typologies,' International Migration 39: 7-24

Itzigsohn, J., and Giorguli-Saucedo, S. (2005). Incorporation, Transnationalism, and Gender: Immigrant Incorporation and Transnational Participation as Gendered 
Processes. International Migration Review, 39(4), 895-920.

Jansen, B. J. (2017). The Royal African Society Between Vulnerability and Assertiveness : Negotiating Resettlement in Kakuma Refugee, 107(429), 569-587. Kaplan, D. 1998. Travels into America's future: Southern California and the Pacific Northwest. The Atlantic Monthly, 282(2): 37-61.

Karnieli-Miller, O., Strier, R., and Pessach, L. (2009). Power Relations in Qualitative Research. Qualitative Health Research, 19(2), 279-289.

Kellner, D. (1992) The Persian Gulf TV War. Boulder, Col: Westview.

Kerwin, D. M. (2011). The Faltering US Refugee Protection System : Legal and Policy Responses to Refugees, Asylum Seekers, and Others in Need of Protection By Donald M . Kerwin The Faltering US Refugee Protection System : Legal and Policy Responses to Refugees, Asylum Seeke, 43. Retrieved from http://www.migrationpolicy.org/pubs/refugeeprotection-2011.pdf

Kibria, N. (1993). Family tightrope: The changing lives of Vietnamese Americans. Princeton, NJ: Princeton University Press.

Koyama, J. (2017). For Refugees, the Road to Employment in the United States Is Paved With Workable Uncertainties and Controversies. Sociological Forum, 32(3), 501521.

Krogstad, J. M., and Radford, J. (2017). Key facts about refugees to the U.S. Pew Research Center. Retrieved from http://www.pewresearch.org/facttank/2017/01/30/key-facts-about-refugees-to-the-u-s/\#

Kroskrity PV (2000) Identity. Journal of Linguistic Anthropology 9: 111-114.

Kunz, E.F. 1973 "The Refugee in Flight: Kinetic Models and Forms of Displacement," International Migration Review, 7. Summer.

Lee, S. J. (2005). Up against whiteness: Race, school, and immigrant youth. New York: Teachers College Press.

Levitt, Peggy. 2001. "The transnational villagers". Berkeley: University of California Press.

Lopez, N. (2002). Rewriting race and gender high school lessons: Second generation Dominicans in New York City. Teachers College Record, 104, 1187-1203.

Lopez, N. (2003). Hopeful girls, troubled boys: Race and gender disparity in urban education. New York: Routledge.

Louie, V. (2004). Compelled to excel: Immigration, education, and opportunity among Chinese Americans. Stanford, CA: Stanford University Press.

Marlowe, J. M. (2010). Beyond the Discourse of Trauma: Shifting the Focus on Sudanese Refugees. Journal of Refugee Studies, 23(2), 183-198.

Matsumoto, D., LeRoux, J. A., Robles, Y., and Campos, G. (2007). The Intercultural Adjustment Potential Scale (ICAPS) predicts adjustment above and beyond personality and general intelligence. International Journal of Intercultural Relations, $31,747-759$.

Meer, N. and Modood, T. (2015) 'Religious pluralism in the United States and Britain: Its implications for Muslims and nationhood', Social Compass, 62(4), pp. 526-540.

Menjívar, C. 1999. "Religious institutions and transnationalism: A case study of Catholic and Evangelical Salvadoran immigrants." International Journal of Politics, Culture and Society, 12, 589-612. 
2001. "Latino immigrants and their perceptions of religious institutions: Cubans, Salvadorans, and Guatemalans in Phoenix, AZ." Migraciones Internacionales, 1, 65 88.

2003. "Religion and immigration in comparative perspective: Salvadorans in Catholic and Evangelical communities in San Francisco, Phoenix, and Washington D.C." Sociology of Religion, 64,21-45.

McKeary, M., and Newbold, B. (2010). Barriers to Care: The Challenges for Canadian Refugees and their Health Care Providers. Journal of Refugee Studies, 23(4), 523545.

Migration Policy Institute. (2017). Refugees and Asylees in the United States. Retrieved July 12, 2017, from https://www.migrationpolicy.org/article/refugees-and-asyleesunited-states

Min, Pyong. 1992. "The Structure and Social Functions of Korean Immigrant Churches in the United States. International Migration Review, 26, 1370-1394

Mooney, M. 2006. "The Catholic Bishops Conferences of the United States and France: Engaging Immigration as a Public Issue.” American Behavioral Scientist 49(11): $1455-1470$

Morales, M. C. 2016. "From Social Capital to Inequality: Migrant Networks in Different Stages of Labor Incorporation." Sociological Forum 31: 3: 509-530.

Muse, A. (2016). OREGON SOMALI COMMUNITY.

Nawyn, S. J. (2006). Faith, Ethnicity, and Culture in Refugee Resettlement. American Behavioral Scientist, 49(11), 1509-1527.

Netto, G. (2011). Identity negotiation, pathways to housing and "place": The experience of refugees in glasgow. Housing, Theory and Society, 28(2), 123-143.

Ondeko, R. and Purdin, S. 2004. Understanding the Causes of Gender-Based Violence. Forced Migration Review. 19:30.

Ong, A. (2003). Buddha is hiding: Refugees, citizenship, the new America. Berkeley: University of California Press.

Oregon Department of Human Services. (2017). Refugees in Oregon Data. Retrieved July 12, 2017, from http://www.oregon.gov/DHS/ASSISTANCE/REFUGEE/Pages/data.aspx

Payne, L. 1998. Food Shortages and Gender Relations in Ikafe Settlement, Uganda. Gender and Development 6:30-36

Pessar, P. R. (1999). Engendering migration studies: The case of new immigrants in the United States. American Behavioral Scientist, 42(4), 577-600.

Pew Research Center. (2017). Key facts about refugees to the U.S. Retrieved July 12, 2017, from http://www.pewresearch.org/fact-tank/2017/01/30/key-facts-aboutrefugees-to-the-u-s/

Phinney, J. S. (1990). Ethnic identity in adolescents and adults: review of research. Psychological Bulletin, 108(3), 499-514.

Phinney, J. S. (1991). Ethnic Identity and Self-Esteem: A Review and Integration. Hispanic Journal of Behavioral Sciences, 13(2), 193-208.

Phinney, J. S., Horenczyk, G., Liebkind, K., and Vedder, P. (2001). Ethnic identity, immigration, and well-being: An interactional perspective. Journal of Social Issues, 57, 493-509. 
Porter, G., Hampshire, K., Kyei, P., Adjaloo, M., Rapoo, G., and Kilpatrick, K. (2008). Linkages between Livelihood Opportunities and Refugee-Host Relations: Learning from the Experiences of Liberian Camp-based Refugees in Ghana. Journal of Refugee Studies, 21(2), 230-252.

Portes, A. (1995) 'Economic sociology and the sociology of immigration: A conceptual overview,' in The Economic Sociology of Immigration, A. Portes (Ed.), New York: Russell Sage Foundation, pp. 1-41

Portes, A., Escobar, C., and Arana, R. (2008). Bridging the gap: Transnational and ethnic organizations in the political incorporation of immigrants in the United States. Ethnic and Racial Studies, 31, 1056-1090.

Portes, A. and Min Z. 1993. "The New Second Generation: Segmented Assimilation and Its Variants." Annals of the American Academy of Political and Social Science 530: 74-96.

Portes, A., and Rumbaut, R. (1996). Immigrant America: A portrait (2nd ed.). Berkeley: University of California Press.

Portes, A. and Rumbaut, R.G., 2006. Immigrant America: a portrait. 3rd ed. Berkeley, CA: University of California Press.

Qin-Hillard, D. B. (2003). Gender expectations and gender experiences: Immigrant students' adaptation in schools. New Directions for Youth Development, 100(Winter), 91-109.

Charles Ragin (1994): Constructing Social Research, Thousand Oaks: Pine Forge Press, 31-53.

Robeyns, I. 2007. "The Capabilities Approach: A Theoretical Survey." Journal of Human Development, 6 (1): 93-117.

Rodriguez, T. (2003). School social context effects on gender differences in academic achievement among second-generation Latinos. Journal of Hispanic Education, 2(1), 30-45.

Rong XL and Brown F (2002) Socialisation, culture, and identities of black immigrant children: What educators need to know and do. Education and Urban Society 34: 247-273.

Ryan, D., Dooley, B., and Benson, C. (2008). Theoretical Perspectives on Post-Migration Adaptation and Psychological Well-Being among Refugees: Towards a ResourceBased Model. Journal of Refugee Studies, 21(1), 1-18. https://doi.org/10.1093/jrs/fem047

Sarroub, L. K. (2005). All American Yemeni girls: Being Muslim in a public school. Philadelphia: University of Pennsylvania Press.

Schrijvers, J. 1997. Internal Refugees in Sri Lanka: The Interplay of Ethnicity and Gender. European Journal of Development Research. 9:62-82

Song, M. (2003) Choosing Ethnic Identity (Cambridge: Polity Press and Blackwell Publishing)

Song, M. (2004). Introduction: Who's at the bottom? Examining claims about racial hierarchy. Ethnic and Racial Studies, 27(6), 859-877.

Spaaij, R. (2015). Refugee youth, belonging and community sport. Leisure Studies, 34(3), $303-318$. 
Stepick, A. and Stepick, C. D. (2010). "The Complexities and Confusions of Segmented Assimilation." Ethnic and Racial Studies 33(7), 1149-67.

Stritikus, T., and Nguyen, D. (2007). Strategic Transformation: Cultural and Gender Identity Negotiation in First-Generation Vietnamese Youth. American Educational Research Journal, 44(4), 853-895.

Tajfel, H. (1981). Human groups and social categories. Cambridge: Cambridge University Press.

Tajfel, H., and Turner, J. C. (1986). The social identity theory of intergroup relations. InW. G. Austin, and S. Worchel (Eds.). The psychology of intergroup relations (2nd ed., pp. 7-24). Chicago, IL: Nelson-Hall.

Tomasi, S. (1970). "The ethnic church and the integration of Italian Americans in the United States.” In S. M. Tomasi and M. H. Engel (Eds.), "The Italian experience in the United States." (pp. 163-93). New York: Center for Migration Studies.

Tyson, C. (2017). Towards a new framework for integration in the US, (February), 4849.

UNHCR (2017). Global Focus: Operation Somalia (2016, December 02). Retrieved July 12, 2017, from http://reporting.unhcr.org/sites/default/files/pdfsummaries/GA2017Somalia-eng.pdf

Valentine, G., Sporton, D., and Nielsen, K. B. (2009). Identities and belonging: A study of Somali refugee and asylum seekers living in the UK and Denmark. Environment and Planning D: Society and Space, 27(2), 234-250.

van Heelsum, A. (2017). Aspirations and frustrations: experiences of recent refugees in the Netherlands. Ethnic and Racial Studies, 9870(August), 1-14.

Van Lehman, D., and Omar E. (2003). The Somali Bantu: Their History and Culture. Washington: Center for Applied Linguistics.

Wallerstein I (2005) World-Systems Analysis: An Introduction. Durham, NC: Duke University Press.

Walls, M. (2014). A Somali Nation-State: history, culture and Somaliland's political transition. Pisa: Ponte Invisibile

Walls, M., and Kibble, S. (2011). Discourse and Intervention in Somaliland: Tensions and successes in the transition from deliberation to representation. Somaliland: the way forward. Pisa, Italy: Ponte Invisibile

Waters, M. C. (1996). The intersection of gender, race, and ethnicity in identity development of Caribbean American teens. In B. J. R. Leadbeater and N. Way (Eds.), Urban girls: Resisting stereotypes, creating identities (pp. 65-84). New York: New York University Press.

Weiss, R. S. (1994). Learning from strangers: The art and method of qualitative interview studies. New York: Free Press.

Zetter, R. (1991). Labelling refugees: Forming and transforming a bureaucratic identity. Journal of Refugee Studies, 4(1), 39-62.

Zetter R, Griffiths D, Sigona N, Hauser M (2002) Survey on Policy and Practice Related to Refugee Integration, Department of Planning, Oxford Brookes University. 
Zhou, M., and Bankston, C. L., III. (2001). Family pressure and the educational experience of the daughters of Vietnamese refugees. International Migration Review, 39(4), 133-151.

Zong, J., and Batalova, J. (2015). Refugees and Asylees in the United States, (January), $1-11$. 


\title{
Appendices
}

\section{Appendix A: Research Announcement/ Participant Recruitment Poster}

\author{
Our Story in Our Voices: \\ A Study of the Somali Community of Oregon
}

Are you interested in sharing your story of arrival in the United States? I am conducting a research study on the arrival and adjustment experiences of Somali immigrants in and around Portland. This study aims to highlight the narratives of the Somali community in the voices of its members. As a participant in the study, you will be asked about your journey to the United States, your arrival in/ around Portland and the adjustment experiences you encountered.

About Me: My name is Neil Panchmatia and I am from Kisumu, Kenya. I am currently a Master's student at Portland State University, studying Sociology. I am an immigrants' rights activist and am an adamant supporter of social justice and equality. I am active with various multicultural diversity councils on campus at PSU and in the Portland community - and currently volunteer with several immigrant rights/ advocacy groups. This research study is being done to meet the thesis requirements for my Master's program. With it, I hope to share the stories of the Somali community with the rest of Oregon (and beyond). I believe that the Somali community is one of the most vibrant, resourceful and persevering immigrant groups in the country. Its rich stories of arriving in a foreign land and adjusting to a new social and cultural environment must be shared widely and with pride. I am also a fellow immigrant from Africa and I intend to share the stories of the Somali community with respect and all due consideration.

How you can help: Please sign up to become a participant in this study. You will be interviewed and asked about your experiences of arrival/ adjustment. The interview will last about 1 hour and can be conducted in a place and time of your choosing. Your identity and any information you share will be strictly confidential, as is required by the research protocol at Portland State University. I will never record or share any identifying information. Anything you share will be reported within my thesis with the utmost care taken to protect your privacy. Participants can be male or female and should be over 18 years of age.

Contact information: To participate or learn more, you can contact me via text or call at 612-807-7361 or via e-mail at neil5@pdx.edu --- You can also view and share details of the study on Facebook at www.facebook.com/somalicommunityofportland --- Please share the details of this study with your friends and relatives and encourage them to participate as well! 


\title{
Appendix B: Informed Consent Form (English Version)
}

\author{
Portland State University \\ Consent to Participate in Research \\ Research Title: The Church, the State and the Refugee: \\ Reception and Resettlement Experiences of Somalis in Portland, OR \\ $\underline{08 / 01 / 2014}$
}

Neil A. Panchmatia

Student Researcher

Department of Sociology, Portland State University

Tel: 612-807-7361

E-mail: neil5@pdx.edu

Hello, My name is Neil Panchmatia. I am from Kisumu, Kenya and am currently a student at Portland State University.

You are being asked to participate in a research study that aims to capture and understand the arrival and adjustment experiences of Somalis in the Portland urban area. You have been selected for the study as a member of the Somali community in order to share your individual experiences. This form will explain the research study, and will also explain the possible risks as well as the possible benefits to you.

As a participant, you will be asked to participate in one interview that will last about an hour. In the interview, you will be asked questions about your coming to America, the experiences you have had adjusting to the local community as well as your experiences with local social service organizations that are you are currently receiving (or have previously received) services from. These services can be anything from housing assistance, to language training, to legal advice to job placement. Information you provide me will be added to information received from other Somalis that will be interviewed in Portland to help me write about the services and support available to the Somali community and may help the organizations understand how they may serve the community better.

Please know that your participation in this research study is completely voluntary. You are not required to participate in it and if you choose to, now or at any point during the interview, not participate anymore, there will not be any negative consequences whatsoever. You are not required to participate in this research study in order to qualify for any services and choosing not to participate will not lead to you being disqualified from receiving any services. By participating in this research you will not be entitled to any financial or other benefits apart from being able to share your experiences. The risks 
to you are minimal and are limited to you possibly recounting any difficult experiences of your transition to America. If you find the recollection of any such events to be difficult, please feel free to choose not to share them with me. I also have a list of community organizations that I can provide to you that can assist you with any support services you need. You are not obligated to answer every question I ask you and can ask to pause the interview at any time. There will be no negative consequences whatsoever for skipping a question. I shall aim to make this interview as comfortable for you as possible. Please know that I do not represent any social service organization, government agency or community group nor am I obligated to share any of my findings with them. I am only affiliated with Portland State University and the Human Subject Research guidelines that I am bound by require me to fully protect your identity, your legal rights and welfare, as well as any information you share with me.

Any and all information you provide me will be kept strictly confidential. With your permission, our interview will be audio recorded for record and research purposes only. The audio recording will not be shared with anyone but will be stored securely and accessible only by me. Information contained in your study records is used by myself and my supervising professor, Dr. Alex Stepick. The Portland State University Institutional Review Board (IRB) that oversees human subject research and/or other entities may be permitted to access your records, and there may be times when we are required by law to share your information. It is the my legal obligation to report child abuse, child neglect, elder abuse, harm to self or others or any lifethreatening situation to the appropriate authorities, and; therefore, your confidentiality will not be maintained.

During the interview, you may choose an alias using which I will refer to you and save the information you provide under. This way, there will be no identifying information that will link this interview or any information you share to you. I do not require any additional identifying information or documentation from you. Please rest assured that I will protect your identity fully and completely. Local social service organizations will not be able to link any information or you to this interview. They shall not have access to this interview or to your real name. Your name and identity will never be revealed publicly in my research report or any future publications.

If you need any additional information about me or this research study, you may contact my supervising professor, Dr. Alex Stepick at 503-725-9843 or E-mail: stepick@pdx.edu You may also contact Portland State University's Office for Research Integrity at (503) $725-2227$ or 1(877) 480-4400 to learn more about the research project as well as your rights as a participant.

You are not required to sign this document to indicate your consent to participate in this research study or to show that I have provided the information above to you. You may, however, provide me with a verbal consent indicating this and that I have provided the information above to you regarding the project and your rights and welfare and have answered any questions you may have. 
You may also mark an " $\mathrm{X}$ " in the line provided below indicating your consent. By indicating your consent, verbally or by marking an " $\mathrm{X}$ ", you are not waiving any of your legal rights as a research participant.

Thank you.

(Please sign or mark with an " $\mathrm{X}$ " to indicate your consent)

Today's Date 


\title{
Appendix C: Informed Consent Form (Swahili Version)
}

\author{
Portland State University \\ Ridhaa ya Kushiriki katika Utafiti \\ Utafiti Wa: Kanisa, Jimbo, na Wakimbizi: \\ Mapokezi na Uzoefu wa Makazi Mapya ya Wasomali katika Portland, OR \\ $\underline{08 / 07 / 2014}$
}

Neil Panchmatia

Mwanafunzi Mtafiti

Idara ya Sociology,

Portland State University

Tel: $612-807-7361$

E-mail: neil5@pdx.edu

Habari, jina langu ni Neil Panchmatia, kutoka Kisumu, Kenya na wakati huu, mimi ni mwanafunzi katika Chuo Kikuu cha Jimbo la Portland.

Ningependa kuuliza ushariki wako katika utafiti kwamba ni kujaribu kuelewa uzoefu ya kuwasili, na marekebisho ya Wasomali katika eneo la mijini ya Portland. Ningependa mahojiano karibu saa moja. Katika mahojiano, nitakuuliza maswali kuhusu ujio wako Marekani, uzoefu wako kurekebisha na jamii ya mtaa, pamoja na uzoefu wako na uduma za mitaa ya kijamii, mashirika ya kwamba unapata, au ulipata huduma kutoka.

Habari utanipatia itaongezwa na habari kutoka Wasomali wengine ambao nitahoji katika Portland kunisaidia na maandiko ya Thesis yangu kutoka Chuo Kikuu cha Portland.. Maandiko yangu yanahusu huduma na msaada inayopatikana kwa jamii ya Wasomali, na inaweza kusaidia mashirika kuelewa jinsi wanaweza kutumika kujenga jamii bora.

Ushiriki wako katika utafiti huu ni hiari kabisa na kila kitu, unaweza kuniambia itakuwa siri. Nitajaribu kufanya mahojiano fariji kwenu kama iwezekanavyo. Hautakiwi kufanya mahojiano hii na katika hatua yoyote wakati wa mahojiano ukichagua kuruka swali bila kujibu au kukataa kushiriki tena, hakutakuwa na madhara yoyote. Hautakiwi kushiriki katika utafiti huu ili ustahili kupata huduma yoyote, na kuchagua kukataa kushiriki haita kusababisha kuwa hastahili kupokea huduma yoyote. Kwa kushiriki katika utafiti huu hakutakuwa na haki ya faida yoyote ya kifedha au nyingine, mbali na kuwa na uwezo wa kushiriki uzoefu wako. Nina orodha ya mashirika ya jamii ambao husaidia na huduma za msaada kama una nia. Tafadhali jua kwamba mimi si mwakilishi wa shirika lolote za uduma za jamii, shirika la serikali, au kundi la jumuiya. Wala sina wajibu wa kushiriki yoyote ya matokeo ya utafiti wangu pamoja nao. Nina uhusiano pekee na Chuo Kikuu cha Jimbo la Portland na Maendeleo ya miongozo Utafiti wa Chuo Kikuu cha somo kwamba nimefungwa nayo yanahitaji nilinde kikamilifu utambulisho wako, haki yako ya kisheria, na ustawi wa jamii, na taarifa yoyote utashiriki na mimi. 
Taarifa yoyote utayonipatia yatayekwa madhubuti za siri. Na ruhusa yako, nitarekodi sauti yako kwa mahojiano yetu. Rekodi hii haitasikilizwa na mtu yeyote, na ithafadhiwa kwa usalama na kupatikana tu kwa sababu yangu. Habari zilizomo katika kumbukumbu za utafiti wako hutumiwa na mwenyewe na profesa wangu anayesnisimamia, Dr. Alex Stepick. Portland Chuo Kikuu cha Jimbo ya Taasisi Review Board (IRB) ambayo inasimamia binadamu wa somo ya utafiti na/au vyombo vingine inaweza kuwa na ruhusa ya kupata kumbukumbu yako, na kunaweza kuwa mara wakati sisi ni kwa mujibu wa sheria, kushiriki habari yako. Ni wajibu yangu ya kisheria kuripoti unyanyasaji wa watoto, utojali ya watoto, unyanyasaji wa wazee, madhara binafsi au watu wengine au hali yoyote ya kuhatarisha maisha kwa mamlaka husika, na; kwa hiyo, usiri wako haitatunzwa.

Wakati wa mahojiano, unaweza kuchagua jina lisilo kweli kutumia ambayo nitakuita kwa. Kwa njia hii, unaweza kushiriki habari na mimi kwa siri. Tafadhali hakika kujua kwamba nitalinda utambulisho wako kikamilifu na kabisa. Kama una matatizo yoyote au una maswali kuhusu mimi au utafiti huu, unaweza kuwasiliana na profesa anayenisimamia, Dr. Alex Stepick katika 503-725-9843 au E-mail: stepick@pdx.edu. Unaweza pia kuwasiliana na Ofisi ya Portland Chuo Kikuu cha Jimbo la Utafiti wa Uadilifu katika (503) 725-2227 au 1 (877) 480-4400 kujifunza zaidi kuhusu mradi wa utafiti, pamoja na haki yako kama mshiriki. Nitakupa nakala ya fomu hii.

Hautakiwi kutia saini hati hii kuonyesha idhini yako ya kushiriki katika utafiti huu au kuonyesha kwamba nilikupatia taarifa iliyo juu. Unaweza, hata hivyo, kunipa ridhaa kwa maneno kuonyesha kukubaliana na mahojiano, na kwamba nilikupatia taarifa iliyo juu kuhusu mradi na haki yako na ustawi wa jamii na nimejibu maswali yoyote unaweza kuwa nayo. Je, una maswali yoyote?

Unaweza pia weka alama ya "X" katika laini zinazotolewa chini, kuonyesha idhini yako. Kwa kuonyesha idhini yako, kwa maneno au kwa kuashiria "X", hauachi kudai haki yoyote yako ya kisheria kama mshiriki wa utafiti.

Asante.

(Tafadhali alama na "X" kuonyesha idhini yako)

(Tarehe ya Leo) 


\section{Appendix D: Interview Protocol \\ Introduction Components}

- Thank you; My name; Purpose of Study.

- Share Informed Consent Form and review it with participant.

- Ask if participant has any questions/ concerns.

- Signature/ Verbal consent/ Mark X on Informed Consent Form.

\section{Demographic Characteristics}

- When did you arrive in the US?

- How long have you lived in Portland? Other cities of arrival/ residence?

- Are you currently married/ single? Do you have any children?

○ Note without asking sex/gender

- What is your religious background?

- Are you currently active with local religious organizations/ communities? What is your Somali tribal affiliation?

- What part of Portland do you live in? Do you own/rent your home? How many people reside in it with you?

\section{Experience of Moving to the US/ Portland}

- Can you please describe your experience of coming to the US from Somalia?

- How is life in the US different from life in Somalia?

[Probes: Culture; Gender roles; Community; Family structure] 
- What are some of the main challenges or barriers you faced/ currently face in your adjustment to life in the US/ Portland [Probes: Family/children]

- Have you and/ or How did you overcome the challenges or barriers?

\section{Local Community/Somali Community}

- Did you/ do you find the local community to be welcoming/ supportive?

[Probes: Support organizations; Somali inter-community support;

Neighborhoods]

- Please tell me a little bit about the Somali community here in Portland.

[Probes: Supportive; Difference from Somalia; Services for community members;

Role of religion; Hierarchy; Tribes; Family structure; Remittances to relatives in Somalia $]$

\section{Local Organizations/Support Services}

- From what local organizations have you in the past received any adjustment/ support services from? (You may need a probe of for example....and then you should have a list in mind of what is available.

[Probes: Currently receiving services; What kinds of services]

- Are there any additional services/ programs that you wish local organizations would be providing to you? Please elaborate.

- Can you describe a typical visit to Organization X? Repeat for each organization mentioned in the previous two questions. 
- Do you currently receive a monthly support check from the government via Organization Y?

[Probes: Who collects the check/ In whose name; Meets needs; Experiences of receiving financial assistance]

- In your family/ household, is it you or another family member who goes to the support organizations for services? Why?

[Probes: Language barrier; Gender roles; Children, How would you say you are treated there?]

- Are you currently employed? Seeking employment?

[Probes: Role of organizations in job training/ placement; Opinion on time to selfsufficiency; Educational credential transfer; Cultural barriers]

- In your encounters with the support organizations, have you ever felt/ experienced any difficulties? How did you deal with these?

- Overall, would you say your (your family's/ community's) needs are met by the resettlement agencies here in Portland? Please be specific, which needs are being met, which ones are not?

[Probes: Access (Geographic; Cultural); Cultural competency; Challenges]

\section{Recommendations}

- Do you have any recommendations for local refugee support organizations to help them better serve/ represent the Somali community in the future?

- Knowing what you know now, if you were to choose to move anywhere in the country to begin your life in the US, would you choose Portland again? Why? 
[Probes: Do anything differently?]

- Do you have any advice that you would like to give to Somalis who have not yet arrived in Portland?

[Probes: Services; Community; Challenges]

\section{Closing Components}

- Is there anything more you would like to add?

- Would you like to have a copy of the List of Community Organizations providing services to Somalis in Portland?

- Do you have any other questions for me?

- Thank you for your time. 
Appendix E: List of Community Organizations

\section{Somali Community Support Organizations}

- Somali American Council of Oregon (SACOO)

SACOO's mission is to empower the Somali community by enhancing relationships between members of the community and between the community and state wide and/or federal agencies while also promoting cultural expression and diversity.

Location: 11918 SE Division Street \#377, Portland, Oregon 97266 Phone: (971) 266-0919

E-mail: info@sacoo.org

- Somali-Bajuni Community Services

Coalition of Oregon 9123 SW Barbur Blvd, Portland, OR 97219

(503) 595-0368

- Muslim Community

Center of Portland

Website: www.mccpdx.org

Location: 3801 NE Martin Luther King Jr Blvd, Portland, OR 97212 Phone: (503) 281-7691

- Islamic Social Services of Oregon

State (ISOS) Website: www.i-

sos.org/

- Somali Bantu Community Organization of

Oregon Location: 2788 SE 82nd ave, Suite

203B, Portland, OR, 97266. Office Phone: (503)

389-4126

Email: oabdirahman13@yahoo.com or information@somalibantuoregon.net

- African Women's Association

Provides support, guidance and educational opportunities for African Women.

Location: 1125 SE Madison, Suite 210.

Portland, OR 97214 Person of contact: 
Oluyinka Akinjiola: AWC Coordinator Email:

oakinjiola@awcportland.org

Phone: (503) 972-4930

- Africa House - IRCO

Location: 631 NE 102nd Ave, Portland, OR Phone: (503)

802-0082

\section{Local Social Service Organizations (Refugee Services)}

- S.O.A.R (Sponsors Organized to Assist Refugees) Refugee Services and S.O.A.R Legal Immigration Services

Services Provided: Comprehensive and compassionate resettlement services, case management, advocacy, immigration and asylum counseling, legal services and volunteer recruitment to help refugees build new lives in community.

Website: www.emoregon.org/soar.php or

www.ethniccommunities.org Location: 7931 NE Halsey

St., Suite 314 Portland, OR 97213

Phone: 503-284-3002

E-mail: soar@emoregon.org

\section{- Catholic Charities of Oregon}

Services Provided: Supportive services to expecting mothers, such as baby and maternity supplies, and resource assistance in planning. Counseling, including relationship counseling and parenting education. Adoption services provided at no cost. Immigration Legal Services provided as well as their Project UNICA Program, a domestic violence support program. There is also a Housing Transitions Program and the Refugee Resettlement Program.

Website: www.catholiccharitiesoregon.org Location: 2740 SE Powell Blvd., Portland, OR 97232 Phone: 503-2314866

\section{- Lutheran Community Services Northwest}

Services Provided: Offers a wide range of multicultural counseling services. Outpatient mental health and alcohol and drug program providing 
individual, couple, and family counseling. Medicaid (OHP), Medicare, private insurance, and sliding fee scale accepted. Addresses the mental health needs of low-income, and/or English-limited individuals and families for whom existing services are inaccessible due to cost, language, and/or cultural barriers.

Website: www.lcsnw.org/mcs

Location: 605 SE Cesar E Chavez Blvd., Portland, OR 97214 Phone: 503-231-7480

- IRCO (Immigrant and Refugee Community Organization)

Services Provided: Assists refugees, immigrants and multi-ethnic communities to develop self-sufficiency and cultural awareness while affirming and preserving each culture within an ever-changing global environment. Services include the Asian Family Center, the International Language Bank, youth and family services, employment programs, community education, health and environmental outreach services and arts for new immigrants program. Main programs for refugees: New Arrival Employment Services (NAES), Pre-Employment Training (PET), and Coordinated Assistance to Support Employment (CASE).

Website: www.irco.org

Location: 10301 NE Glisan, Portland, OR 97220 Phone: 503-

234-1541

- Citizenship classes are offered by the following: S.O.A.R Legal Immigration Services (contact information above), the Multnomah County Library (Midland, Woodstock, Rockwood and Troutdale locations) 503988-5392, at IRCO (contact information above) as well as the Hurtado Center Jesuit High School 503-291-5482.

- ESL (English Language) classes are offered by the Multnomah County Library (Rockwood) 503-988-5396, at E Gresham Elementary and Hall Elementary (sponsored by Catholic Charities/ People-Places-Things) 503492-6726 ext. 248, Wilkes Elementary 503-320-5510, and Mt. Hood Community College (Main Campus) 503-491-7333

FOR MORE INFORMATION: An excellent resource for community social service organizations and support programs (job placement, housing, legal 
services and so on) available to the Somali community (including culturally specific mental healthcare services), please consult the Portland Refugee and Immigrant Community Directory online. If you do not have access to the internet or to a printer, please let me know and I shall provide you with a printed copy of the directory.

Website: www.lcsnw.org/portland/pathways/ResourceDirectory.pdf 